\title{
Adjustable gastric banding, sleeve gastrectomy and Roux-en-Y gastric bypass by laparoscopy : long term outcomes and laparoscopic solutions in case of failure
}

Citation for published version (APA):

Himpens, J. (2013). Adjustable gastric banding, sleeve gastrectomy and Roux-en-Y gastric bypass by laparoscopy : long term outcomes and laparoscopic solutions in case of failure. [Doctoral Thesis, Maastricht University]. Datawyse / Universitaire Pers Maastricht. https://doi.org/10.26481/dis.20130222jh

Document status and date:

Published: 01/01/2013

DOI:

10.26481/dis.20130222jh

Document Version:

Publisher's PDF, also known as Version of record

Please check the document version of this publication:

- A submitted manuscript is the version of the article upon submission and before peer-review. There can be important differences between the submitted version and the official published version of record. People interested in the research are advised to contact the author for the final version of the publication, or visit the DOI to the publisher's website.

- The final author version and the galley proof are versions of the publication after peer review.

- The final published version features the final layout of the paper including the volume, issue and page numbers.

Link to publication

\footnotetext{
General rights rights.

- You may freely distribute the URL identifying the publication in the public portal. please follow below link for the End User Agreement:

www.umlib.nl/taverne-license

Take down policy

If you believe that this document breaches copyright please contact us at:

repository@maastrichtuniversity.nl

providing details and we will investigate your claim.
}

Copyright and moral rights for the publications made accessible in the public portal are retained by the authors and/or other copyright owners and it is a condition of accessing publications that users recognise and abide by the legal requirements associated with these

- Users may download and print one copy of any publication from the public portal for the purpose of private study or research.

- You may not further distribute the material or use it for any profit-making activity or commercial gain

If the publication is distributed under the terms of Article 25fa of the Dutch Copyright Act, indicated by the "Taverne" license above, 


\section{Adjustable gastric banding, sleeve gastrectomy and Roux-en-Y gastric bypass by laparoscopy:}

long term outcomes and laparoscopic solutions in case of failure 
(C) Copyright Jacques Himpens, Maastricht 2013.

All rights reserved. No part of this thesis may be reproduced or transmitted in any form or by any means, electronic or mechanical, including photocopying, recording, or any information storage or retrieval system without permission from the author, or when appropriate, from the publishers of the publications.

Cover artwork: Massimiliano CRESPI

Production: Datawyse | Universitaire Pers Maastricht

ISBN 9789461592026 


\title{
Adjustable gastric banding, sleeve gastrectomy and Roux-en-Y gastric bypass by laparoscopy:
}

\section{long term outcomes and laparoscopic solutions in case of failure}

\author{
DISSERTATION \\ to obtain the degree of Doctor at Maastricht University, \\ on the authority of the Rector Magnificus, Prof. dr. L.L.G. Soete \\ in accordance with the decision of the Board of Deans, \\ to be defended in public \\ on Friday February $22^{\text {nd }} 2013$, at 12.00 hours
}

by

Jacques Himpens

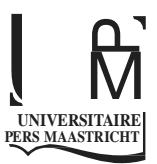




\section{Promotor}

Prof. dr. J.W. Greve, Atrium Medical Center, Heerlen, the Netherlands

\section{Co-Promotor}

Prof. dr. G-B Cadière, Centre Universitaire Saint Pierre, Brussels, Belgium

\section{Assessment Committee}

Prof. dr. L. Stassen (chairman)

Prof. dr. J-M Chevallier, Hopital Européen Georges Pompidou, Paris, France Prof. dr. L. van Heurn

Dr. B. Van Ramhorst, EM Nieuwegein, the Netherlands 


\section{Contents}

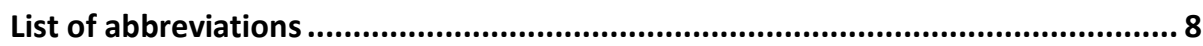

Chapter 1.

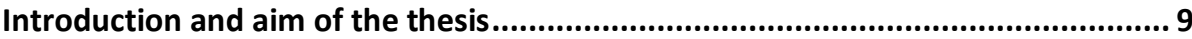

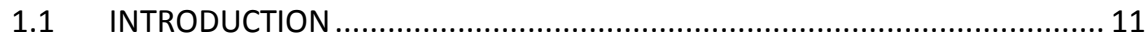

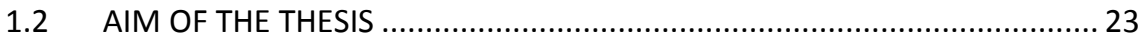

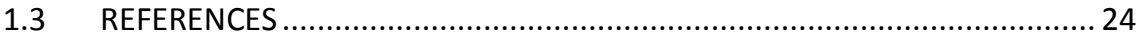

Chapter 2.

Adjustable gastric banding, sleeve gastrectomy and Roux-en-Y gastric bypass by laparoscopy: technique and mechanism of action .................................... 27

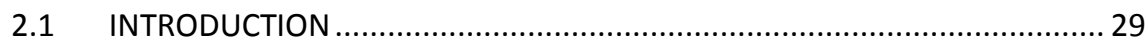

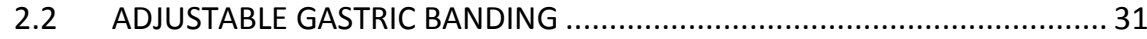

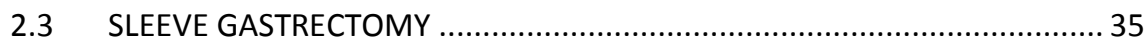

2.4 ROUX-EN-Y GASTRIC BYPASS (ANTECOLIC, ANTEGASTRIC) ...................... 39

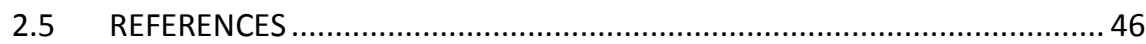

Chapter 3.

A Prospective Randomized Study Between Laparoscopic Gastric Banding and Laparoscopic Isolated Sleeve Gastrectomy: Results after 1 and 3 Years .............. 49

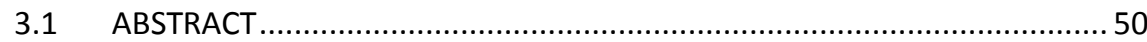

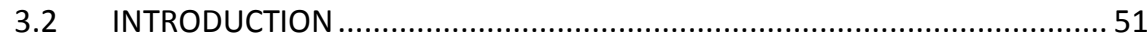

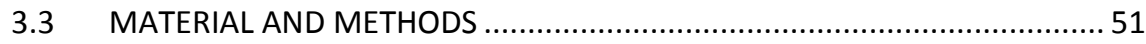

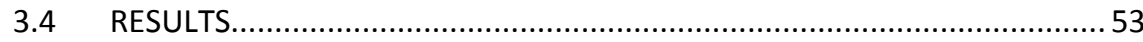

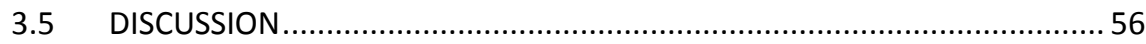

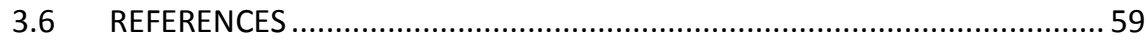

Chapter 4.

Long-term Outcomes of Laparoscopic Adjustable Gastric Banding ..................... 63

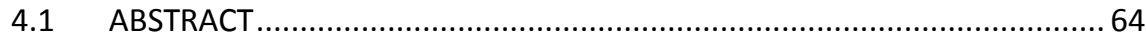

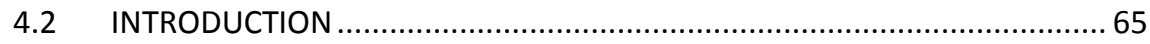

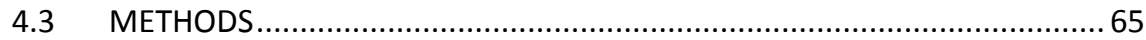

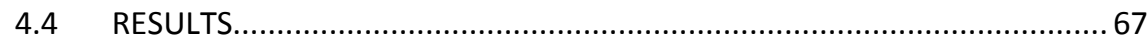

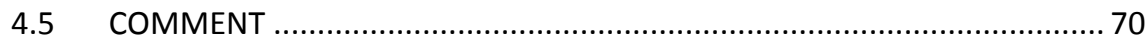

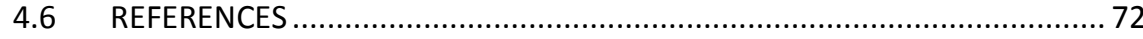




\section{Phapterof.}

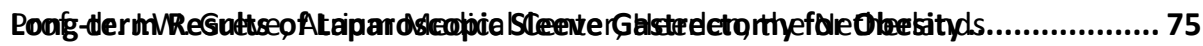

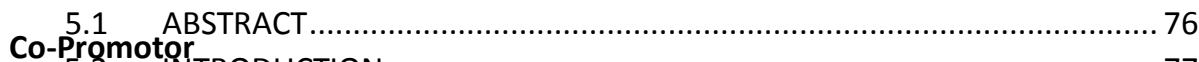

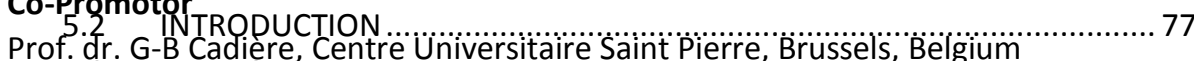

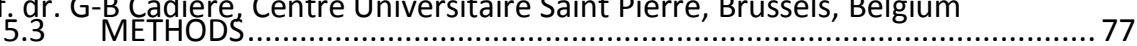

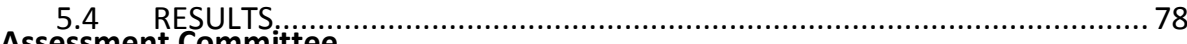

Assessment Committe

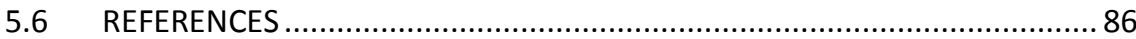

Chapter 6.

Long Term Results of Laparoscopic Roux-en-Y Gastric Bypass: Evaluation after 9 Years

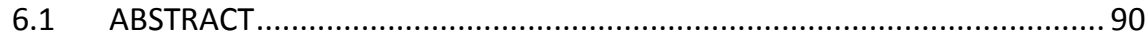

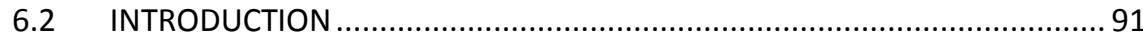

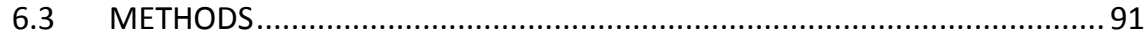

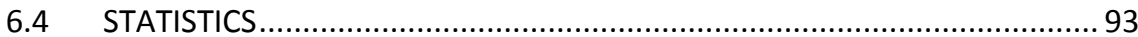

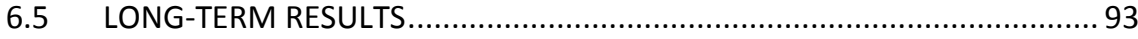

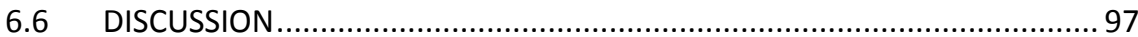

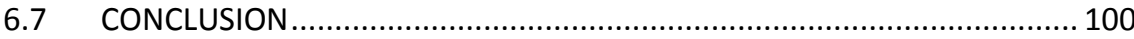

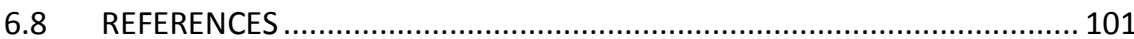

Chapter 7.

Outcomes of Revisional Procedures for Insufficient Weight Loss or Weight Regain after Roux-en-Y Gastric Bypass........................................................... 105

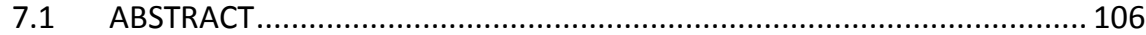

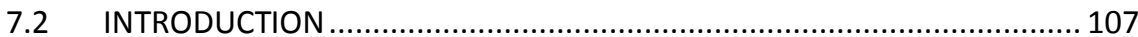

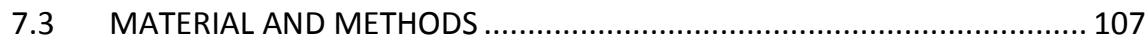

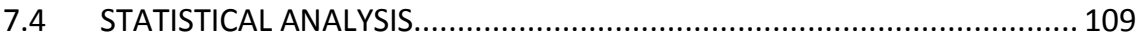

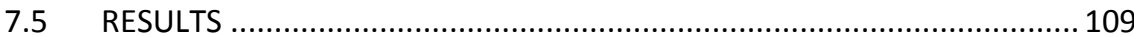

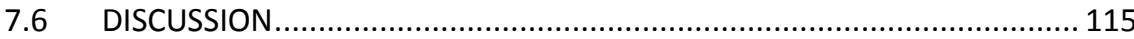

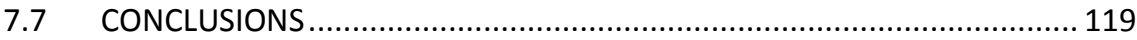

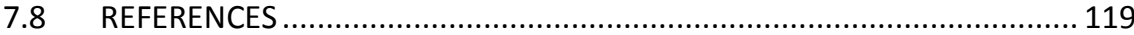

Chapter 8.

Summary \& final conclusions........................................................................ 123

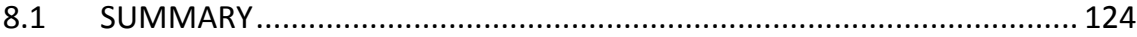

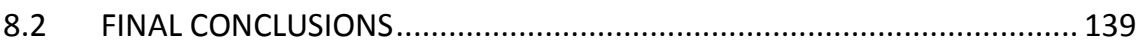

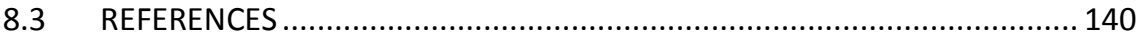

Chapter 9. 


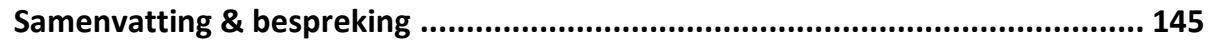

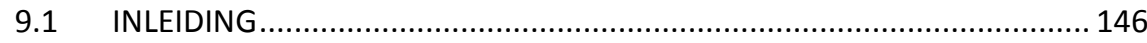

9.2 TECHNIEK EN WERKWIJZE VAN LAGB, LSG EN LRYGB ......................... 148

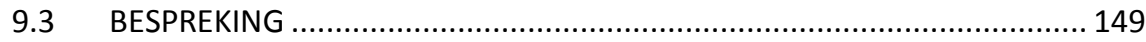

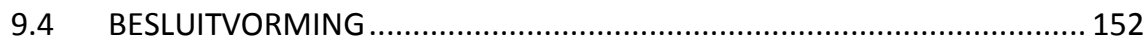

Chapter 10.

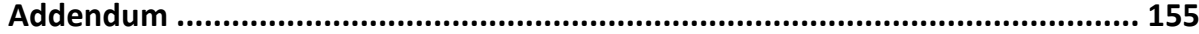

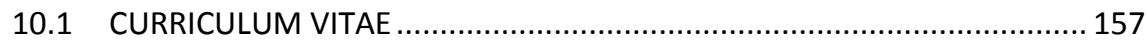

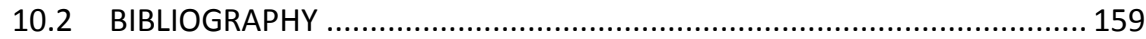

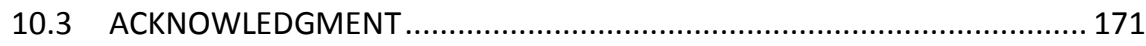




\section{List of abbreviations}

\begin{tabular}{|c|c|}
\hline ASA & American society of anesthesiologists \\
\hline$A G B$ & adjustable gastric band \\
\hline ASBS & American society for bariatric surgery \\
\hline ASMBS & American society for metabolic and bariatric surgery \\
\hline BAROS & bariatric analysis and reporting outcome system \\
\hline$B M I$ & $\begin{array}{l}\text { body mass index: calculated as weight in kilograms divided by height in } \\
\text { meters squared }\end{array}$ \\
\hline$\% E B M I L$ & \%excess BMI lost \\
\hline$C T$ & computerized tomographic \\
\hline$D S$ & duodenal switch \\
\hline$\% E W L$ & \%excess weight loss \\
\hline$G B$ & gastric banding \\
\hline$G E$ & gastro-enterostomy \\
\hline GER & gastroesophageal reflux \\
\hline GERD & gastroesophageal reflux disease \\
\hline Gl & gastrointestinal \\
\hline GLP1 & glucagon-like peptide 1 \\
\hline$D M \|$ & diabetes mellitus type II \\
\hline IFSO & $\begin{array}{l}\text { International Federation for the Surgery of Obesity and Metabolic } \\
\text { Disorders }\end{array}$ \\
\hline$J / B$ & jejunoileal bypass \\
\hline$L A G B$ & laparoscopic adjustable band gastroplasty \\
\hline LSG & laparoscopic sleeve gastrectomy \\
\hline$L R Y G B$ & laparoscopic Roux-en-Y gastric bypass \\
\hline$H H$ & hiatal hernia \\
\hline $\mathrm{NIH}$ & national Institute of Health \\
\hline$P P I$ & proton pomp inhibitor \\
\hline PYY & Peptide $Y-Y$ \\
\hline RIZIV & $\begin{array}{l}\text { Rijksinstituut Voor Ziekte- en Invaliditeitsverzekering Belgian } \\
\text { Government for Health Insurance }\end{array}$ \\
\hline$R Y G B$ & Roux-en-Y gastric bypass \\
\hline$S D$ & standard deviation \\
\hline SG & sleeve gastrectomy \\
\hline SRVG & silastic ring vertical gastroplasty \\
\hline$Q O L$ & quality of life \\
\hline VBG & vertical banded gastroplasty \\
\hline
\end{tabular}


Chapter 1.

\section{Introduction and aim of the thesis}




\subsection{INTRODUCTION}

\subsubsection{How was weight loss surgery developed?}

Obesity has been an epidemic problem in most developed countries for several years and is gaining significance in emerging economies such as Asia, especially east Asia. ${ }^{1}$ Obesity is associated with co-morbidities that are responsible for a shorter life expectancy $^{2}$ and for more than 2.5 million deaths per year worldwide. ${ }^{3}$ There is substantial evidence that surgery is the only treatment that is effective in the long term for morbid obesity. ${ }^{4}$ Interesting parallels exist between the evolution of overall surgical techniques and the evolution of surgical treatment for obesity.

The obese patient creates a challenge for the surgeon. The adipose mass is located both subcutaneously and intraperitoneally and constitutes a considerable obstacle to surgical access to the target organs. Furthermore, the fatty infiltration of tissues makes them fragile and thereby hampers their manipulation. Surgical techniques must account for these conditions.

Considering the limited technological assets at the time, the first surgical weight loss procedures were designed to be relatively easy from a technical standpoint in order to reduce complications while still reducing caloric intake. Surgeons focused on accessible areas in the abdomen, avoiding the high epigastrium, which is relatively inaccessible, especially in obese patients. Therefore, the first weight loss operations ignored the stomach and took advantage of the fact that caloric intake is directly related to the absorptive bowel surface exposed to food. This phenomenon was noted after incidental subtotal small bowel resections in humans were observed to cause a substantial reduction in fat and (to a lesser extent) protein absorption. $^{5}$

The first bariatric procedures consisted of bypassing or even resecting large parts of the small bowel. The first bariatric surgery ever recorded was performed by AJ Kremen ${ }^{6}$ in 1954 and consisted of an intestinal bypass. The surgery was based on his experiments in dogs showing that resection of the distal $50 \%$ of the small bowel resulted in malabsorption and weight loss. ${ }^{7}$ In the face of rather poor long-term weight loss of the intestinal bypass, Payne ${ }^{8}$ in 1963 tried to radicalize the procedure by performing intestinal bypasses that joined the proximal jejunum to the colon. This latter technique was short-lived because it caused intractable diarrhea and electrolyte imbalances. In 1969, Payne therefore turned again toward jejuno-ileal bypass with an end-to-side jejuno-ileostomy performed only $15 \mathrm{~cm}$ proximal to the ileocecal valve. ${ }^{9}$ 


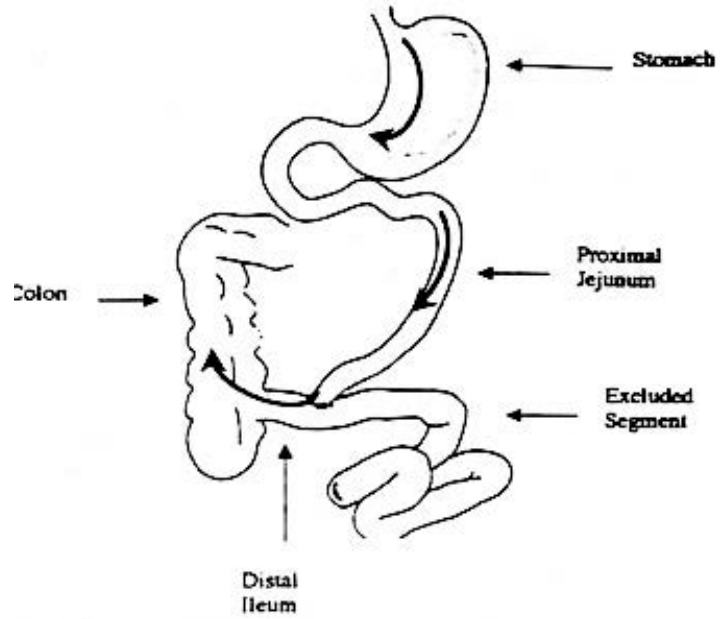
The Jejuno-Ileal Bypass with end-to-side
anastomosis (1969)

It was quickly apparent that the end-to-side technique would not produce the expected results. ${ }^{10}$ The reason was that bowel fluids refluxed in a cephalad direction into the absorption-eager ileum, minimizing weight loss. To prevent this reflux, Scott ${ }^{11}$ in 1971 performed an end-to-end anastomosis between the jejunum $(30 \mathrm{~cm}$ distal to the ligament of Treitz) and the ileum $(20 \mathrm{~cm}$ proximal to the ileocecal valve). The distal end of the jejunum was oversewn, and the proximal end of the ileum was anastomosed to the colon.

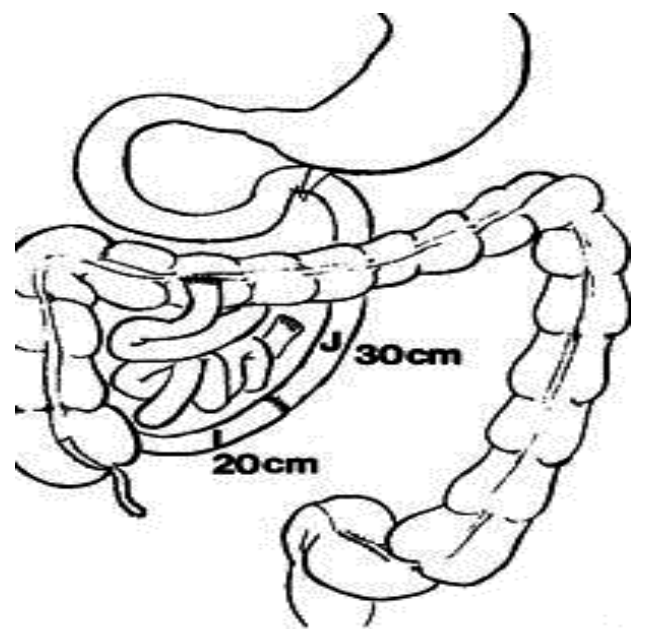

The Jejuno-lleal Bypass with end-to-end anastomosis (1971)

Although vitamin B12 absorption was found to be severely impaired with the endto-side technique, this result was not observed with the termino-terminal anasto- 
motic technique ${ }^{12}$.Long-term weight loss however still was not satisfactory, mostly because the small bowel adapts after the procedure with spontaneous macroscopic lengthening and microscopic villus hypertrophy. ${ }^{13}$ In addition, the long-term metabolic effects of this type of bypass surgery were often disastrous, mainly because of a marked loss of minerals and fat-soluble vitamins via stool. Moreover, the loss of bile salts combined with low plasma albumin levels can exhaust hepatic cholesterol synthesis, possibly resulting in cirrhosis, liver failure and death. ${ }^{14,15,16}$

In an effort to improve clinical outcomes from jejuno-ileal bypass, Scopinaro ${ }^{17}$ developed a revised weight loss procedure he first performed in man in 1976. In this operation, the intestinal bypass is less radical, but weight loss is still ensured by an "ad hoc" gastric resection that consists of an antrectomy. Scopinaro established the minimal (ad hoc) bowel length that, in conjunction with this stomach resection, provides significant weight loss without endangering plasma protein levels. ${ }^{18} \mathrm{He}$ called this procedure the biliopancreatic diversion (BPD).

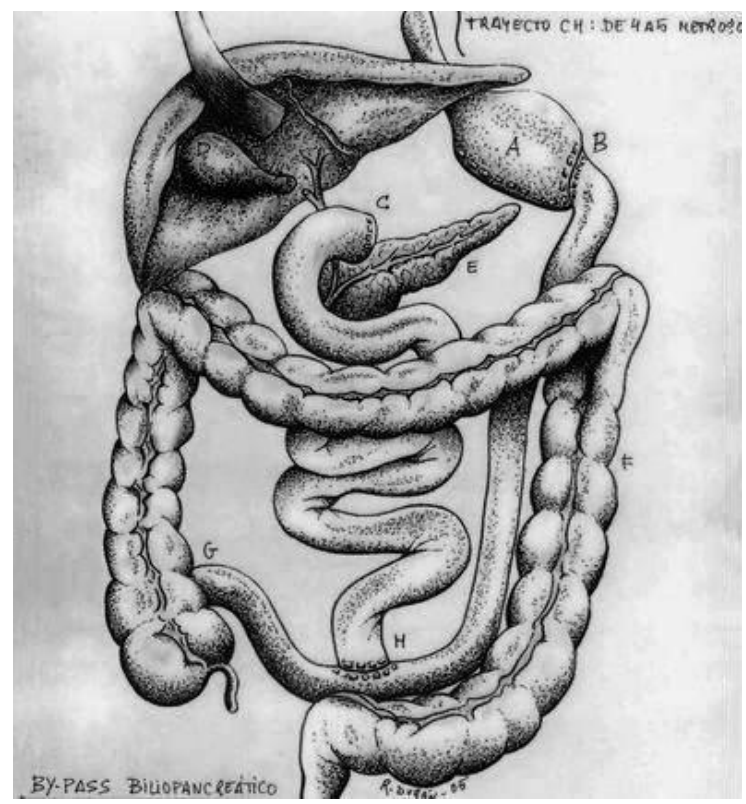

The Scopinaro Biliopancreatic Diversion (1976)

This combination constituted a milestone in obesity surgery. The concept of addressing the stomach, rather than just the small bowel to achieve weight loss was however not new, having been introduced in 1966 by Mason. ${ }^{19}$ Mason's initial procedure was called gastric bypass (GB) and was based on experiences with partial gastrectomy for ulcer disease, a procedure that usually resulted in substantial weight loss. At the time, the rather rudimentary operation consisted of a horizontal transection of the proximal stomach and a loop gastro-enterostomy. 


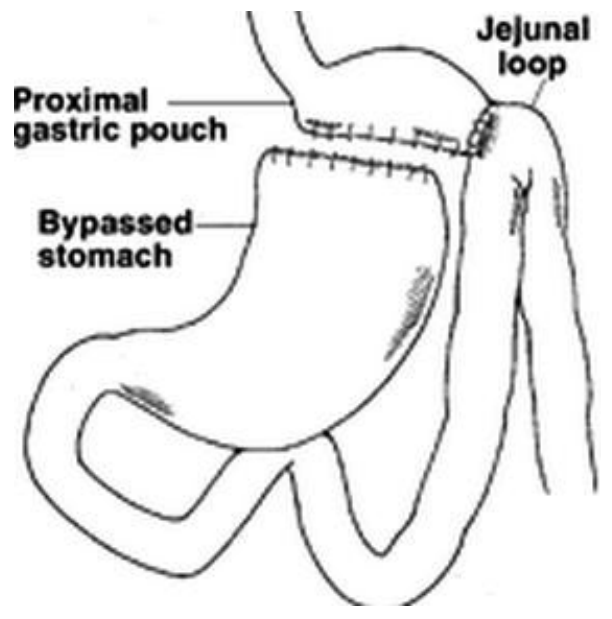

The Mason “loop" Gastric Bypass

(1966)

However, by 1979, Mason had all but abandoned the GB procedure because of its disastrous results at that time, with $100 \%$ postoperative mortality being reported before $1975 .^{20,21}$

Consequently, proximal stomach dissection was for a long time considered technically challenging and hazardous in obese individuals.

\subsubsection{Advent of mechanical stapling}

At the same time as newer attempts at weight loss surgery were undertaken, a significant evolution had taken place in the surgical world with the introduction of mechanical stapling devices. Invented in the Soviet Union, these tools were introduced to the western world by Ravitch. ${ }^{22,23,24}$ These devices allowed surgeons to operate on parts of the body that formerly had proven inaccessible for safe resection and suturing, including the cardia in obese individuals.

Aided by the new stapling devices, Mason was able to fine-tune his procedures. With the linear stapler, he performed a gastric partitioning.The philosophy behind gastric partitioning had been described by Gomez: ${ }^{30}$ food is retained for some time in the upper part of the stomach, creating a sensation of fullness that ultimately leads to the ingestion of fewer calories. Gomez' horizontal stomach partitioning was however shortlived because of the tendency for the greater curvature to dilate. ${ }^{25}$ 


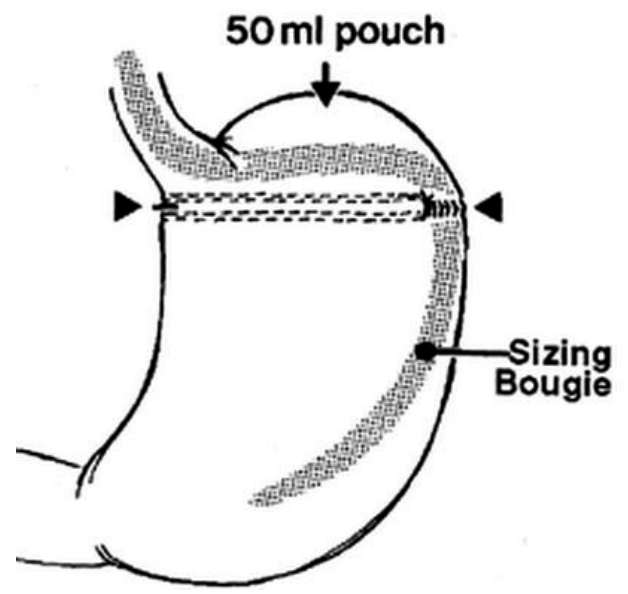

The Gomez Horizontal Gastric Partitioning (1979)

Conversely, Mason created a vertical, small (14 cc) pouch located at the uppermost part of the lesser curvature of the stomach. This pouch was connected to the distal stomach, rather than to a bowel loop, by a small "stoma". The lesser curvature clearly had less of a tendency to dilate, unlike the stoma. Stoma dilation caused weight regain ${ }^{26}$ and required reinforcement of the stoma with foreign materials, such as polypropylene mesh. ${ }^{27}$ Reinforcement of the stoma completed the procedure and gave it its popular name: the vertical banded gastroplasty (VBG). ${ }^{28}$

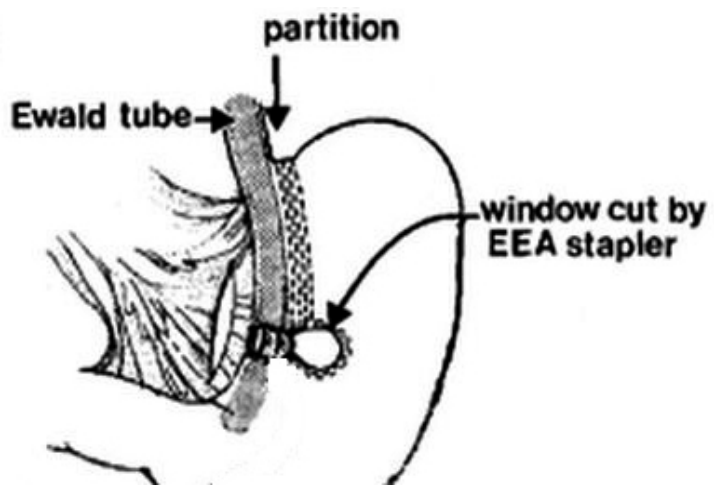

The Undivided Vertical Banded Gastroplasty with reinforced "stoma" (EEA = circular) (1981)

Alternatively, when a silastic ring was used for stoma reinforcement, the procedure was called the silastic ring vertical gastroplasty (SRVG). ${ }^{29}$ This method constituted a true volume-reducing procedure that usually did not create vitamin, mineral or other dietary deficiencies. ${ }^{31}$ 
Along with further advancements in surgical technique, alternatives and improvements to the original technique of gastric partitioning were pursued and implemented. Rather than partitioning the stomach by simple stapling, as proposed by Gomez and Mason, a technique that was prone to recanalization, MacLean ${ }^{40}$ performed stapled transection of the stomach.

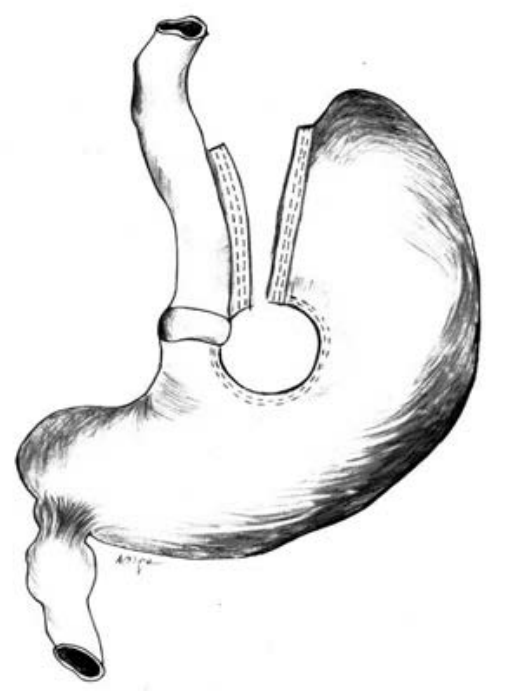

The Divided Vertical Banded

Gastroplasty (MacLean) (1981)

Despite the advantages of gastric partitioning in terms of unwanted side-effects, proponents of the gastric bypass stood by their belief that patients could evade gastric restriction by simply eating more frequently or by ingesting high-calorie food and drinks. More drastic measures were needed, such as re-routing the normal food pathway. The new surgical staplers had proven to significantly reduce the morbidity of the stomach surgery and to allow for reconstructions similar to Mason's gastric partitioning combined with a Roux-en-Y anastomosis, merely to avoid biliary reflux. ${ }^{32}$ Quite logically, this procedure was named the Roux-en-Y Gastric Bypass (RYGB). The anastomosis was approximately $0.9 \mathrm{~cm}$ wide to prevent weight regain. $^{33}$ 


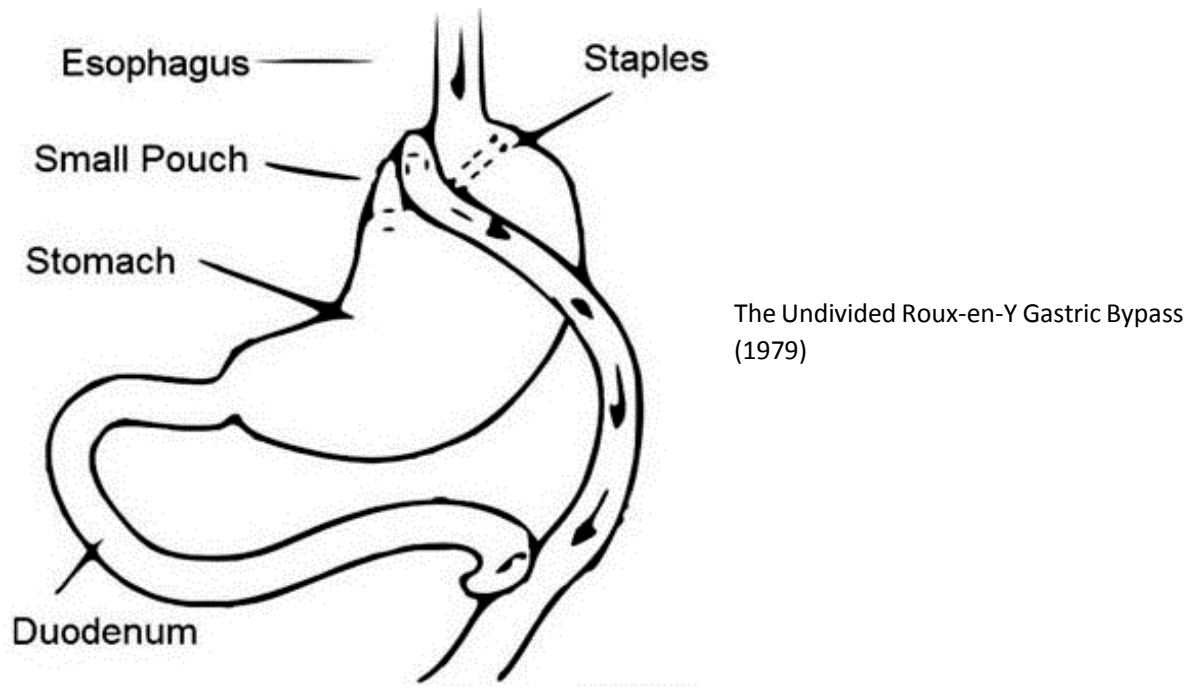

This new gastric bypass procedure with complete transection of the stomach was the ultimate refinement of the initial gastric partitioning and proved to be more efficient. $^{34,35}$ By the early 1980's, the RYGB had become the standard operation for surgical treatment of morbid obesity. ${ }^{36}$

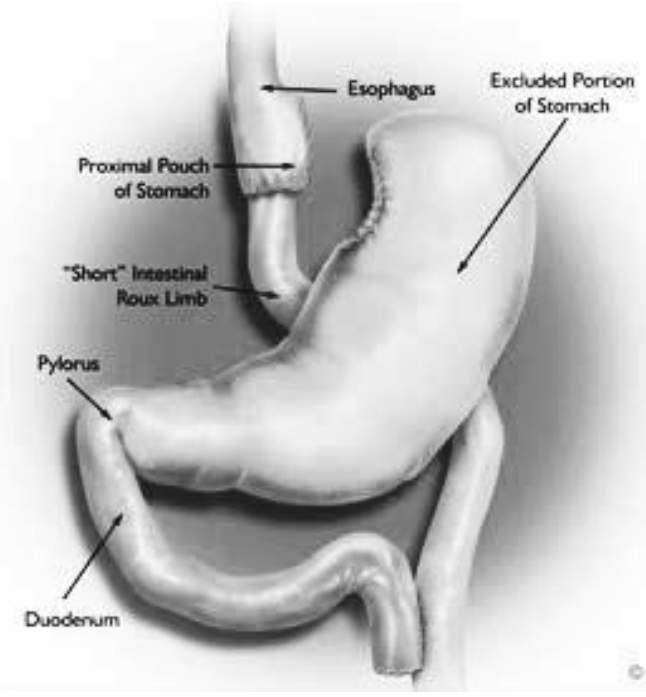

The Divided Roux-en Y Gastric Bypass (1980)

The RYGB proved to be safer than the JIB that connects the proximal jejunum with the distal ileum. ${ }^{37}$ Consequently, some patients benefited from conversion of a JIB 
into an RYGB, but this operation was associated with substantial morbidity. ${ }^{38}$ Subsequently, failed gastroplasties were revised to RYGB as well. At the time, however, the procedure, although effective, was still judged to be notably difficult. ${ }^{39}$ Nevertheless a trend was set to convert one construction to another in case of lack of success or in case of severe side-effects

At the same time, in an effort to make weight loss surgery better accessible and less permanent, attempts were made to use foreign material to engirdle the stomach ${ }^{40}$ without altering its anatomy. Based on the research of Angelchick ${ }^{41}$ who had designed a circular prosthesis that, wrapped around the upper pole of the stomach, aimed at treating gastro-esophageal reflux disease (GERD), several investigators extrapolated that concept to caloric restriction and performed what was called the "band gastroplasty". ${ }^{42}$

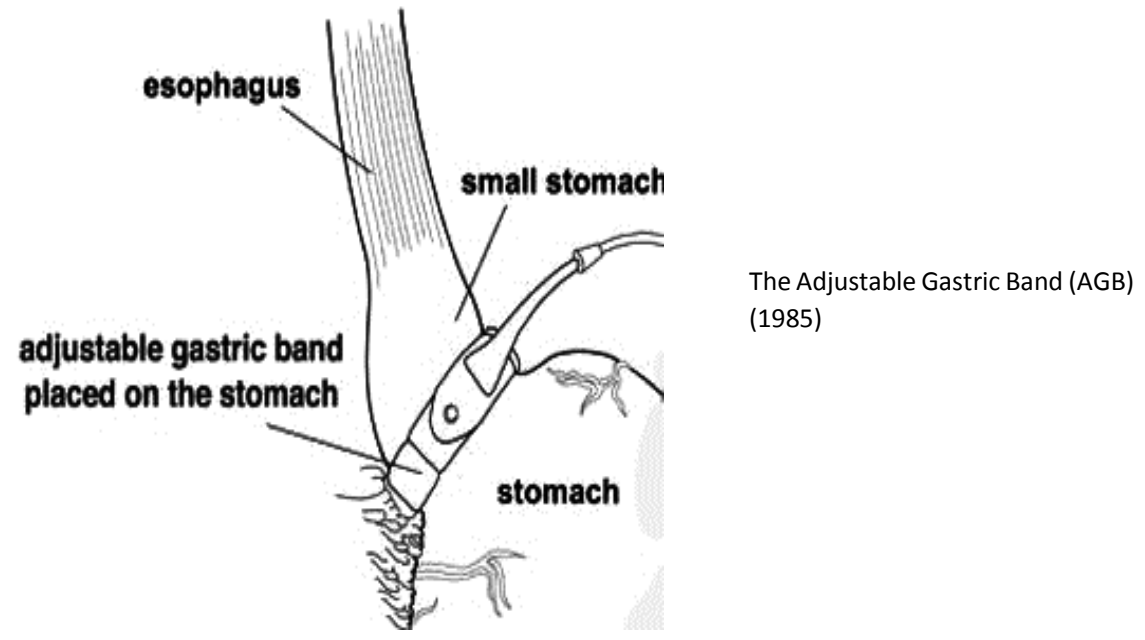

In 1985, at the annual American College of Surgeons meeting in New Orleans, Kuzmak $^{43}$ showed the preliminary results of the first truly reversible and adjustable bariatric procedure. He looped an inflatable band around the upper pole of the stomach and achieved adjustability by connecting the bellow of this silastic band system to a subcutaneous chamber that was easily accessible for puncture and filling with fluid. The adjustable gastric band (AGB) was born. Reversibility was theoretically acquired because the device could be removed like a "belt", theoretically without harming the patient's anatomy. In addition to this benefit, the most significant advantage of the Kuzmak adjustable band gastroplasty was its simplicity and ease of performance. 
Concomitantly, in a different part of the world, another group of surgeons developed a similar procedure. They used a softer band with a larger bellow, but the principle of the "Swedish Band" (SAGB) ${ }^{44}$ was the same as that of the Kuzmak band.The Swedish surgeons declared that the technique was efficient and safe with a reoperation rate of only $4 \%$.

\subsubsection{Advent of laparoscopic weight loss surgery}

At the same time as these new developments in bariatric surgery, a technical advancement had unfolded that would revolutionize the practice of surgery: minimally invasive or laparoscopic surgery. An upgrade of the original technique of directvision laparoscopy to videolaparoscopy suddenly expanded the applicability of laparoscopic procedures to general surgery. In 1987, the Frenchman Mouret ${ }^{45}$ performed the first officially recorded laparoscopic cholecystectomy, a technique that was soon to be adopted by surgeons in the United States ${ }^{46}$ and numerous countries around the world. The surgical community initially stipulated many contraindications to laparoscopic surgery, one of which was morbid obesity. However, thanks to the work of pioneers from across the globe, it soon became evident that videolaparoscopy represented a completely new way of operating with a wide array of applications, including bariatric surgery.

The most significant conceptual change from conventional surgery to modern laparoscopic surgery consisted of the interposition of a video screen between the surgeon and the patient. This development markedly improved the visual acuity of the surgeon, and it allowed virtually all areas in the abdominal and thoracic cavities to be visualized, regardless of how remote the area is or how thick the abdominal wall and perivisceral fat are, as in obese patients. Specially designed long instruments, in turn, assured adequate reachability. Consequently, obesity surgery became one of the most popular (instead of one of the rarest) applications of laparoscopy.

In addition to better access and enhanced vision, laparoscopy provides other specific advantages in obesity surgery.

- Laparoscopy significantly reduces the number of postoperative incisional herni$\mathrm{as}^{47}$ which are a common postoperative complication ${ }^{48}$ after "open" weight loss surgery. Additionally, class I evidence shows that laparoscopy induces fewer adhesions and decreases the incidence of bowel obstruction. ${ }^{51}$

- Especially in obese patients, laparoscopic surgery is associated with reduced pain, ${ }^{49,52}$ a shorter hospital stay and a quicker return to normal activity compared to open techniques.

- The laparoscopic approach is less invasive and benefits physiologically fragile obese patients by inducing less stress, decreasing the cardiopulmonary burden 
and minimizing blood loss. Laparoscopy allows for faster patient mobilization postoperatively. This translates into a reduced risk of pulmonary embolism and atelectasis, which are two significant complications of obesity surgery. ${ }^{50}$

- Importantly, laparoscopy is an excellent diagnostic tool in the case of complications after bariatric surgery. When perioperative complications arise in the obese patient, the classic clinical signs of acute abdomen usually are lacking. ${ }^{21}$ Early diagnosis is usually difficult to achieve in an obese patient using only the usual investigational tools. The bore of a typical computerized tomographic (CT) scanner often is too small to accommodate an obese individual. However, a quick second look is "easily achieved" by laparoscopy. ${ }^{52}$

- A considerable advantage of the laparoscopic approach, especially in obesity surgery, is the possibility of acquiring video footage of the surgical procedure. Video footage obtained during laparoscopic procedures permits objective documentation of the actual surgery. This approach constitutes an invaluable medicolegal tool. Medicolegal aspects are of the utmost importance in bariatric surgery. Despite a thorough explanation of the possible complications before surgery, bariatric patients "forget" about them, ${ }^{53}$ which can stimulate litigation. ${ }^{54}$ Surgeons can now use video footage to document the absence of intraoperative mishaps.

- Finally, video-assisted laparoscopy allows a procedure to be documented in a reproducible and verifiable way, qualifying this technique as an unequaled teaching tool. Operative video can be transmitted either live or as a recording to students both at the bedside and at a distance. ${ }^{55}$ Watching live surgery under better conditions than conventional surgery, especially in obese patients, is an excellent experience for a novice surgeon. Young surgeons can observe how experts deal with unexpected, dangerous and technically challenging operative situations, and they will probably not forget this experience when confronted with similar events in their practice. Consequently, one can verify that codified surgical procedures are reproduced almost exactly all over the world. ${ }^{56}$ For the first time, surgeons can compare the results of operations with the knowledge that each procedure was carried out in a verifiably identical fashion. Results can be linked to specific technical details that are visible to all. It is therefore hardly surprising that bariatric surgery has recently become popular. ${ }^{57}$

In the early days of laparoscopic weight loss surgery, the rather obsolete nonadjustable laparoscopic gastric banding was performed in Italy in $1992 .{ }^{58}$ However, surgeons quite normally turned towards the procedures that were "hot" at the time. In October 1992 our team at the St. Pierre Hospital in Brussels ${ }^{59,60}$ successfully performed the world's first recognized laparoscopic bariatric procedure, an adjustable gastric band gastroplasty (LAGB). After this demonstration of feasibility of laparoscopic weight loss operations, other teams all over the world later repro- 
duced and improved upon this technique. ${ }^{61,62}$ The different "band" manufacturers zealously tried to improve the device and developed larger and softer variations of the Kuzmak and Swedish bands while promoting new access techniques. ${ }^{63}$

Laparoscopic techniques continued to be further refined; consequently, operations of significantly greater complexity were attempted. In 1993, Allan Wittgrove ${ }^{64}$ performed the world's first laparoscopic Roux-en-Y gastric bypass (LRYGB) in the United States.

Currently, all bariatric procedures, including technically demanding operations such as biliopancreatic diversions ${ }^{65}$ can be performed laparoscopically. Considering the specific features of the laparoscopic access one can state that bariatric operations actually should preferably be performed by this approach.

Interestingly, the laparoscopic approach has resurrected certain techniques that had only limited success via the conventional approach. One illustrative example is the laparoscopic sleeve gastrectomy (LSG).The LSG procedure constitutes the laparoscopic translation of the "Magenstrasse and Mill" procedure that was mainly developed in the UK by Johnston. ${ }^{66}$ This technique was first described by McMahon at the IFSO meeting in Crete in September 2001, but this method had actually been previously performed by Gagner ${ }^{67}$ for several years as part of the laparoscopic duodenal switch (DS). The "open" DS, considered a "modern version" of the Scopinaro biliopancreatic diversion, had been developed by Hess and Marceau ${ }^{68,69}$ separately, during the last decade of the past century.

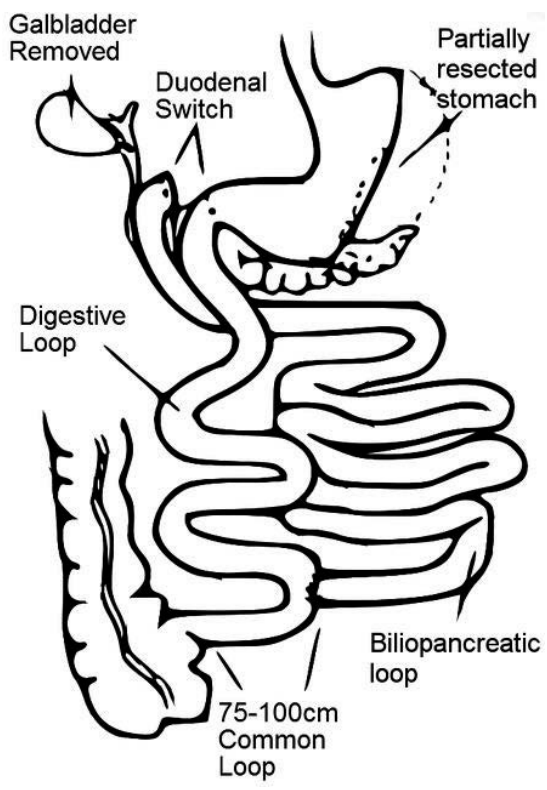

The Biliopancreatic Diversion with Duodenal Switch (BPD-DS) 
In the context of LSG, Gagner had introduced the notion of staged procedures to minimize perioperative complications. ${ }^{70}$ His team demonstrated that, in super-super obese patients [with a Body Mass Index (BMI) over $60 \mathrm{~kg} / \mathrm{m}^{2}$ ], the results were better when only LSG was performed in a first operation. The second part of the surgery, consisting of either a DS (the actual biliopancreatic derivation) or a RYGB, was delayed until the patient had lost considerable weight. After weight loss, patients had better American Society of Anesthesiologists (ASA) scores, thereby resulting in a decreased risk of complications.

Despite the fact that the long-term consequences of the procedure were not known at that time, the alleged relative ease of LSG and the reported multifaceted physiological effects of the procedure created an unprecedented enthusiasm among bariatric surgeons. It appears that, at least in Belgium, LSG is rapidly gaining on LAGB in terms of popularity (Table 1 ).

\begin{tabular}{|c|c|c|c|c|c|c|c|c|c|c|c|c|c|c|c|c|c|c|}
\hline & 1989 & 1990 & 1991 & 1992 & 1993 & 1998 & 1999 & 2000 & 2001 & 2002 & 2003 & 2004 & 2005 & 2006 & 2007 & 2008 & 2009 & 2010 \\
\hline gastric bypass (241452-463) & 483 & 474 & 549 & 515 & 522 & 848 & 1012 & 965 & 1108 & 1503 & 2136 & 3342 & 4034 & 4712 & 4683 & 1151 & 929 & 855 \\
\hline sleeve gastrectomy (241474-485) & 1109 & 995 & 940 & 870 & 755 & 619 & 644 & 580 & 553 & 209 & 482 & 640 & 640 & 603 & 506 & 353 & 313 & 279 \\
\hline gastric banding (241533-544) & 158 & 253 & 693 & 1105 & 1175 & 1873 & 2654 & 2850 & 3487 & 3264 & 4482 & 5495 & 4322 & 3568 & 2725 & 528 & 336 & 285 \\
\hline Mason/Sleeve -tomie (241776-780) & & & & & & & & & & & & & & & 6 & 45 & 33 & 42 \\
\hline Mason/Sleeve -scopie (241791-802) & & & & & & & & & & & & & & & 25 & 395 & 709 & 1042 \\
\hline gastric banding (241813-824) & & & & & & & & & & & & & & & 122 & 1714 & 1692 & 1345 \\
\hline Bypass/Scopinaro -tomie (241835-846) & & & & & & & & & & & & & & & 47 & 432 & 473 & 295 \\
\hline Bypass/Scopinaro-scopie (241850-861) & & & & & & & & & & & & & & & 185 & 3079 & 4519 & 5547 \\
\hline total $\mathrm{n}$ procedures & 1750 & 1722 & 2182 & 2490 & 2452 & 3340 & 4310 & 4395 & \begin{tabular}{|l|}
5148 \\
\end{tabular} & \begin{tabular}{|l|}
4976 \\
\end{tabular} & 7100 & \begin{tabular}{|l|}
9477 \\
\end{tabular} & 8996 & \begin{tabular}{|l|}
8883 \\
\end{tabular} & \begin{tabular}{|l|}
8299 \\
\end{tabular} & \begin{tabular}{|l|}
7697 \\
\end{tabular} & 9004 & 9690 \\
\hline
\end{tabular}

Table 1: Changes in the popularity of bariatric procedures performed in Belgium (Source: National Institute of Health RIZIV/INAMI, Belgium). Some procedures are mentioned twice because of a different approach: tomie stands for laparotomy; scopie stands for laparoscopy

This finding might be surprising, considering the similarity of LSG to VBG, the latter being a procedure that had been solemnly condemned at the turn of the century ${ }^{71}$, despite the efforts of some to popularize the laparoscopic version of $\mathrm{VBG}^{72}$

Actually, it has been established that the success of LSG does not rely solely on the surgeon's choice. Together with the development of the latest bariatric operations, the Internet became available to an increasing number of potential patients. There is no question that much of the popularity of one procedure rather than another is related to patient discussions in support groups, chat rooms and unofficial patient associations ${ }^{73}$ rather than on scientific evidence. As a result, groups of patients insist on being submitted to procedures before evidence exists regarding their sustained efficacy, long-term safety, ${ }^{74,75}$ and influence on the co-morbidities linked to obesity: diabetes mellitus type 2 (DMII), dyslipidemia, hypertension and sleep apnea. $^{76}$

Currently, 3 laparoscopic procedures have emerged all over the world as the most popular bariatric procedures: adjustable gastric band (LAGB), sleeve gastrectomy 
(LSG) and Roux-en-Y gastric bypass (LRYGB). They are the procedures that will be the subject of this work.

\subsection{AIM OF THE THESIS}

Since our team was the first to perform laparoscopic bariatric surgery we have by now accumulated a 20 years' experience in this domain. Hence, based on our experience we dare hope to be entitled to provide an in-depth analysis on the presently most performed laparoscopic bariatric procedures.

Three essential points will be addressed in our study of LAGB, LSG and LRYGB

1. Can one procedure be considered superior over the others?

2. Can the results of the 3 procedures be maintained over the years?

3. If these procedures do not provide the anticipated long-term results, to what extent can they be corrected? Does the fact that laparoscopic procedures produce fewer adhesions than their "open" counterparts allow for better reversibility and interchangeability and provide the patient a safety cushion for the future?

Thus, the aim of the study will be

1. to compare the efficacy of the restrictive procedures (LSG and LAGB)

2. to analyze the overall long-term results of LSG, LAGB and LRYGB, including complications and patient acceptance

3. finally, to evaluate to what extent the procedures are reversible, interchangeable or complementary to each other, as these characteristics could become significant factors in the future care of patients in need of additional bariatric surgery.

In Chapter 2 the technique and mode of action of LAGB, LSG and LRYGB are described.

In Chapter 3 LAGB and LSG are compared by prospectively analyzing 3 years of follow-up in 2 randomly chosen groups of patients who underwent these procedures.

In Chapter 4 the long-term (12-year) results of LAGB are presented in terms of weight loss, the evolution of comorbidities, the incidence of late complications and patient acceptance.

In Chapter 5 the long-term (6+-year) results of LSG are presented including late unwanted effects

In Chapter 6 the long-term (9-year) results of LRYGB are presented in terms of weight loss, the evolution of type 2 diabetes, the incidence of late complications and patient acceptance 
Finally, Chapter 7 addresses the current surgical options for LRYGB revision in case of insufficient weight loss or weight regain.

\subsection{REFERENCES}

1. Zheng W, McLerran DF, Rolland B et al. Association between body-mass index and risk of death in more than 1 million Asians. N Engl J Med. 2011 Feb 24; 364(8):719-29.

2. Padwal RS, Pajewski NM, Allison DB et al. Using the Edmonton obesity staging system to predict mortality in a population-representative cohort of people with overweight and obesity. CMAJ. 2011 Oct4:183(14); E1059-66.

3. Li Z, Bowerman S, Heber D. Health ramifications of the obesity epidemic. Surg Clin North Am. 2005 Aug; 85(4):681-701.

4. Marsk R, Näslund E, Freedman J et al. Bariatric surgery reduces mortality in Swedish men. Br J Surg. 2010 Jun; 97(6):877-83.

5. Althauser TL, Vyeyama K, Simpson RG. Digestion and absorption after massive resection of the small intestine. Gastroenterol. 1949; 12:795.

6. Kremen AJ, Linner JH, Nelson $\mathrm{CH}$. An experimental evaluation of the nutritional importance of proximal and distal intestine. Ann Surg. 1954 Sep;140(3): 439-48.

7. Jensenius $\mathrm{H}$. Results of experimental resections of the small intestine on dogs. Universitätsforlaget 1945; NYT Nordisk Forlog, Copenhagen, Arnold Busck.

8. Payne JH, DeWind LT, Commons RR. Metabolic observations in patients with jejunocolic shunts. Am J Surg. 1963 Aug;106:273-89.

9. Payne JH, De Wind LT. Surgical treatment of obesity. Am J Surg. 1969. 118:141-9.

10. Wiklund B. Fate of weight. Ten-year observations after jejunoileal bypass for obesity. Acta Chir Scand. 1982;148(5);443-52.

11. Scott HW Jr, Sandstead HH, Brill AB et al. Experience with a New Technique of Intestinal Bypass on the treatment of Morbid Obesity. Ann Surg. 1971. 174:560-9.

12. Barry RE, Barisch J, Bray GA et al. Intestinal adaptation after jejunoileal bypass in man. J Clin Nutr. 1977 Jan; 30(1):32-42.

13. Fenyö G, Backman L, Hallberg D. Morphological changes of the small intestine following jejuno-ileal shunt in obese subjects. Acta Chir Scand. 1976;142(2):154-9.

14. Scott HW Jr. Jejunoileal bypass versus gastric bypass or gastroplasty in the operative treatment of obesity. Langenbecks Arch Chir. 1982; 356(1):25-35. 15. Ravitch MM, Brolin RE. The price of jejunoileal bypass. Ann Surg. 1979 Sep;190(3):382-391.

16. McGill DB, Humphreys SR, Boggenstoss AH et al. Cirrhosis and death after jejuno-ileal bypass Gastroenterology. 1972; 63(5):872-7.

17. Scopinaro N, Gianetta E, Civalleri D et al. Bilio-pancreatic bypass for obesity: II. Initial experience in man. Br J Surg. 1979 Sep;66(9):618-2.

18. Scopinaro N, Adami GF, Marinari UM et al. Biliopancreatic diversion. World J Surg. 1998; 22: 936 946.

19. Mason EE, Ito C. Gastric bypass in obesity. Surg Clin North Am. 1967 Dec;47(6):1345-51.

20. Mason EE, Gastric bypass for morbid obesity. Surg Annu. 1979;11:99-126. Review.

21. Mason EE, Printen KJ, Barron P et al. Risk reduction in gastric operations for obesity. Ann Surg. 1979 Aug;190(2):158-65.

22. Ravitch MM, Brown IW, Daviglus GF. Experimental and clinical use of the Soviet bronchus stapling instrument. Surgery. 1959 Jul;46(1):97-108.

23. Ravitch MM, Lane R, Cornell WP et al. Closure of duodenal, gastric and intestinal stumps with wire staples: experimental and clinical studies. Ann Surg. 1966 Apr; 163(4):573-9.

24. Ravitch MM, Steichen FM. A stapling instrument for end-to-end inverting anastomoses in the gastrointestinal tract. Ann Surg. 1979 Jun;189(6):791-7. 
25. Gomez AC. Gastroplasty in morbid obesity. Surg Clin North Am. 1979 Dec;59(6):1113-20.

26. Brolin RE, Ravitch MM. Experimental evaluation of techniques of gastric partitioning for morbid obesity. Surg Gynecol Obstet. 1981 Dec;153(6):877-82.

27. Mason EE. Vertical Banded Gastroplasty for obesity. Arch Surg 1982 May;117(5):701-6.

28. Mason EE, Doherty C, Maher JW et al. Super-obesity and gastric reduction procedures. Gastroenterol Clin North Am. 1987 Sep;16(3):495-502.

29. Negri M, Bendet N, Halevy A et al. Gastric mucosal changes following gastroplasty: a comparative study between vertical banded gastroplasty and silastic ring vertical gastroplasty. Obes Surg. 1995 Nov;5(4):383-6. 30. Gomez CA. Gastroplasty in morbid obesity: a progress report. World J Surg 1981 Nov;5(6):823-8.

31. Mason EE. Why the Operation I Prefer is Vertical Banded Gastroplasty. Obes Surg. 1991 Jun;1(2):181183.

32. Griffen WW Jr, Gastric Bypass for morbid obesity. Surg Clin North Am 1979;59(6):1103-12.

33. Fobi MAL, Johnson LD Bristo, Alexander JL. The "limiting proximal gastric pouch": the evolving solution of morbid obesity. J Natl Med Assoc. 1982 October;74(10): 1005-9.

34. Laws HL, Piantadosi S. Superior gastric reduction procedure for morbid obesity: a prospective, randomized trial. Ann Surg. 1981 Mar;193(3):334-40.

35. Sugerman HJ, Wolper JL. Failed gastroplasty for morbid obesity. Revised gastroplasty versus Roux-Y gastric bypass. Am J Surg. 1984 Sep;148(3):331-6.

36. MacLean LD, Rhode BM, Shizgal HM. Nutrition following gastric operations for morbid obesity. Surg Gynecol Obstet. 1981 Aug;153(2):200-8.

37. Griffen WO Jr, Young VL, Stevenson CC. A prospective comparison of gastric and jejunoileal bypass procedures for morbid obesity. Ann Surg. 1977 Oct;186(4):500-9.

38. Lechner GW, Callender AK. Subtotal gastric exclusion and gastric parititioning: a randomized prospective comparison of one hundred patients. Surgery. 1981 Oct;90(4):637-44.

39. Salameh BS, khoukaz MT, Bell RL. Metabolic and nutritional changes after bariatric surgery. Expert Rev Gastroenterol Hepatol. 2010 Apr;4(2):217-23.

40. Kirby RM, Ismail T, Crowson M, et al. Gastric banding in the treatment of morbid obesity. Br J Surg. 1989May;76(5):490-2.

41. Angelchik JP, Cohen R. A new surgical procedure for the treatment of gastroesophageal reflux and hiatal hernia. Surg Gynecol Obstet. 1979 Feb;148(2):246-8.

42. Jensen HE, Jensen FU. Gastric Banding. A follow-up study. Ugeskr Laeger 1993 Jun 7;155(23):178991.

43. Kuzmak LI, Yap IS, McGuire L et al. Surgery for morbid obesity. using an inflatable band. AORN J. 1990 May;51(5):1307-24.

44. Forsell P, Hellers G. The Swedish Adjustable Gastric Banding (SAGB) for morbid obesity: a 9 year experience and a 4-year follow-up of patients operated with a new adjustable band. Obes Surg. 1997 Aug;7(4):345-51.

45. Litynski GS. Profiles in laparoscopy: Mouret, Dubois and Perissat: the laparoscopic breakthrough in Europe (1987-1988). JSLS. 1999 Apr-Jun;3(2):163-7.

46. Reddick EJ, Olsen DO. Laparoscopic laser cholecystectomy. A comparison with mini-lap cholecystectomy. Surg Endosc. 1989;3(3):131-3.

47. Andersen LP, Klein M, Gögenur I et al. Incisional hernia after open versus laparoscopic sigmoid resction. Surg Endosc. 2008 Sep;22(9):2026-9.

48. Strzelczyk J, Czupriniak L, Loba J, et al. The use of propylene mesh in midline incision closure following gastric-bypass surgery reduces the risk of postoperative hernia. Langenbecks Arch Surg. 2002; 387:294-7.

49. Ceriani V, Lodi T, Porta A et al. Laparoscopic versus open biliopancreatic diversion: a prospective comparative study. Obes Surg. 2010 Oct;20(10):1348-53.

50. Trayner E Jr, Celli BR. Postoperative pulmonary complications. Med Clin North Am. 2001 Sep;85(5):1129-39. 
51. Schnüriger B, Barmparas G, Branco BC et al. Prevention of postoperative peritoneal adhesions: $a$ review of the literature. Am J Surg. 2011 Jan;201(1):111-21.

52. Greenstein AJ, O'Rourke RW. Abdominal pain after gastric bypass: suspects and solutions. Am J Surg 2011 Jun;201(6):819-27.

53. Madan AK, Tichansky DS, Taddeucci RJ. Postoperative laparoscopic bariatric surgery patients do not remember potential complications. Obes Surg. $2007 \mathrm{Jul}$;17(7): 885-8.

54. Cottam D, Lord J, Dallal RM et al. Medicolegal analysis of 100 malpractice claims against bariatric surgeons. Surg Obes Relat Dis. 2007 Jan-Feb;3(1):60-6.

55. Sebajang $H$, Trudeau $P$, Dougall A et al. Telementoring an important enabling tool for the community surgeon. Surg Innov. 2005 Dec;12(4):327-31.

56. Dath D, Regehr G, Birch D et al. Toward reliable operative assessment: the reliability and feasibility of videotaped assessment of laparoscopic technical skills. Surg Endosc. 2004 Dec;18(12):1800-4.

57. Schauer P, Ikramuddin S. Laparoscopic surgery for morbid obesity. Surg Clin North Am. 2001;81(5):1-23

58. Catona A, Gossemberg M, La Manna A et al. Laparoscopic gastric Banding: preliminary series. Obes Surg 1993 May;3(2):207-209.

59. Cadière GB, Bruyns J, Himpens J Laparoscopic Gastroplasty for Morbid Obesity Br J Surg 1994 Oct;81(10):1524.

60. Favretti F, Cadiere GB, Segato G, Bruyns G, De Marchi F, Himpens J, Foletto M, Lise M. Laparoscopic Placement of Adjustable Silicone Gastric Banding: Early experience. Obes Surg. 1995 Feb;5(1):71-73.

61. Catona A, La Manna L, La Manna A, et al. Swedish adjustable gastric banding: a preliminary experience. Obes Surg. 1997 Jun;7(3): 203-5.

62. Fielding GA, Rhodes M, Nathanson LK. Laparoscopic gastric banding for morbid obesity. Surgical outcome in 335 cases. Surg Endosc. 1999 Jun;13(6):550-4.

63. Chevallier JM. Gastric banding using adjustable silastic ring in 2010. Technique, indications, results, and management. J Visc Surg. 2010; 147(5 Suppl):e21-e29.

64. Wittgrove AC, Clark GW, Tremblay LJ. Laparoscopic gastric bypass, Roux-en-Y: preliminary report of five cases. Obes Surg. 1994 Nov;4(4):353-7.

65. Scopinaro N, Marinari GM, Camerini G. Laparoscopic biliopancreatic diversion: technique and preliminary results. Obes Surg. 2002 jun;12(3): 362-5.

66. Johnston D, Dachtler J, Sue-Ling HM, et al. The Magenstrasse and Mill operation for morbid obesity. Obes Surg 2003 Feb;13(1):10-6.

67. Ren CJ, Patterson E, Gagner M. Early results of laparoscopic biliopancreatic diversion with duodenal switch: a case series of 40 consecutive patients. Obes Surg. 2000 Dec;10(6):514-23.

68. Hess DS, Hess DW Biliopancreatic diversion with a duodenal switch Biliopancreatic diversion with a duodenal switch Obes Surg. 1998 Jun;8(3):267-82.

69. Marceau P, Biron S, St Georges R, et al. Biliopancreatic diversion with gastrectomy as surgical treatment of morbid obesity Obes Surg. 1991 Dec;1(4):381-387

70. Regan JP, Inabnet W, Gagner M, et al. Early experience with two-stage laparoscopic Roux-en-Y gastric bypass as an alternative in the super obese patient. Obes Surg. 2003 Dec;13(6):861-4 71.Kalfarentzos F, Kechagias I, Soulikia K, et al. Weight loss following vertical banded gastroplasty: intermediate results of a prospective study. Obes Surg. 2001 Jun;11(3):265-70.

72. van Hout GC, Hagendoren CA, Verschure SK, et al. Psychosocial predictors of success after vertical banded gastroplasty. Obes Surg.2009 Jun;19(6):701-7.

73. Ren CJ, Cabrera I, Rajaram K, Fielding GA. Factors influencing patient choice for bariatric operation. Obes Surg. 2005 Feb;15(2):202-6.

74. BiffI WL, Spain DA, Reltsma AM et al. Responsible development and application of surgical innovations: a position statement of the Society of University Surgeons. JACS 2008(6): 1204-9.

75. de Paula AL, Macedo AL, Prudente AS et al. Laparoscopic sleeve gastrectomy with ileal interposition ("neuroendocrine brake")-pilot study of a new operation. Surg Obes Relat Dis.2006 Jul-Aug;2(4):464-7.

76. Buchwald H, Ikramuddin S, Dorman RB et al. Management of the metabolic/bariatric surgery patient. Am J Med. 2011 Dec;124(12):1099-105 


\section{Chapter 2.}

\section{Adjustable gastric banding, sleeve gastrectomy and Roux-en-Y gastric bypass by laparoscopy: technique and mechanism of action}

Jacques Himpens, MD; Guy-Bernard Cadière,MD, PhD; Giovanni Dapri, MD Department of Gastrointestinal and Obesity Surgery, European School of Laparoscopic Surgery,Saint-Pierre University Hospital, Brussels, Belgium 


\section{$2.1 \quad$ INTRODUCTION}

\subsubsection{Classification of Bariatric Procedures}

Bariatric procedures act on different levels. A number of these procedures restrict the amount of food (thus usually of calories) an individual can ingest. These procedures are called restrictive. Caloric restriction can be obtained by mechanical means, but it can also be achieved by interference with the normal hunger and satiety mechanisms ${ }^{1}$. Other procedures merely reduce the body's capacity to absorb the calories that have been ingested. This effect is achieved by mechanisms that interfere with the normal uptake. These procedures are called malabsorptive ${ }^{2}$. Still other procedures restrict both the intake and the uptake of calories and are called hybrid restrictive-malabsorptive procedures. $^{3}$

\subsubsection{Patient, Team and Trocar Position}

Laparoscopic Adjustable Gastric Banding (LAGB), Laparoscopic Sleeve Gastrectomy (LSG) and Laparoscopic Roux-en-Y Gastric Bypass (LRYGB) are the most popular operative procedures in the treatment of morbid obesity.

For all 3 procedures the patient is placed in the "french" position, with the surgeon between the patient's legs, the assistant being to the patient's left and the cameraman to the patient's right (Fig 1)

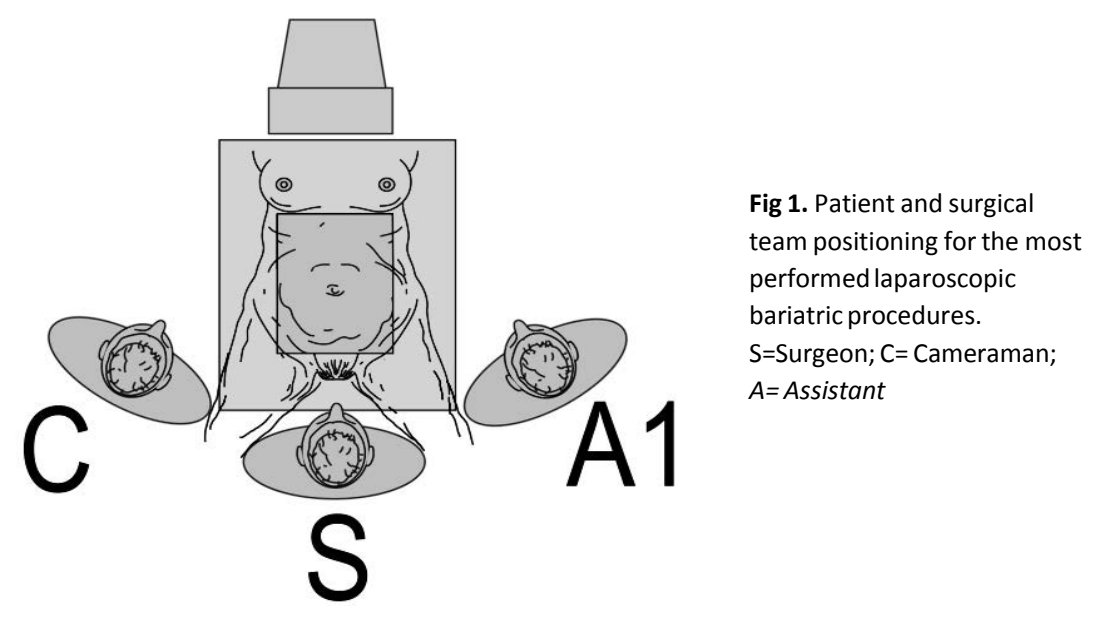


Intraperitoneal access is typically obtained through 5 epigastric trocars (Fig 2).

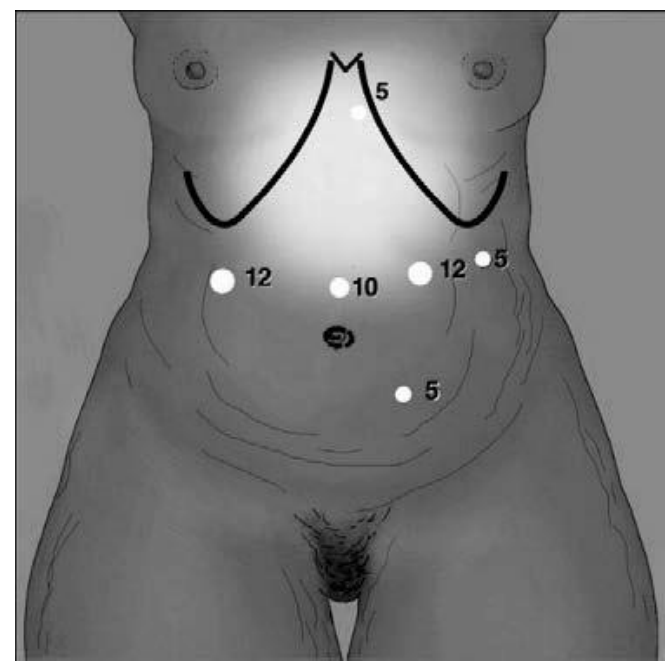

Fig 2. Typical location of the trocars in laparoscopic foregut surgery, including bariatric surgery. The numbers indicate the diameter of the trocar cannulas, in millimeter. The 5 $\mathrm{mm}$ trocar in the left lower quadrant is optional

\subsubsection{Instruments}

The tools used in a laparoscopic bariatric operation are the same as with any advanced laparoscopic procedure. They include a $30^{\circ}$ angled scope connected to a high definition videosystem, regular introducing cannula's or trocars, a high volume $\mathrm{CO}_{2}$ insufflating device, a suction-irrigation device, a highly performant bipolar coagulating system and a regular hook cautery system, atraumatic graspers, a robust needle holder and a linear cutting-stapling device with staple loads of different staple heights. 


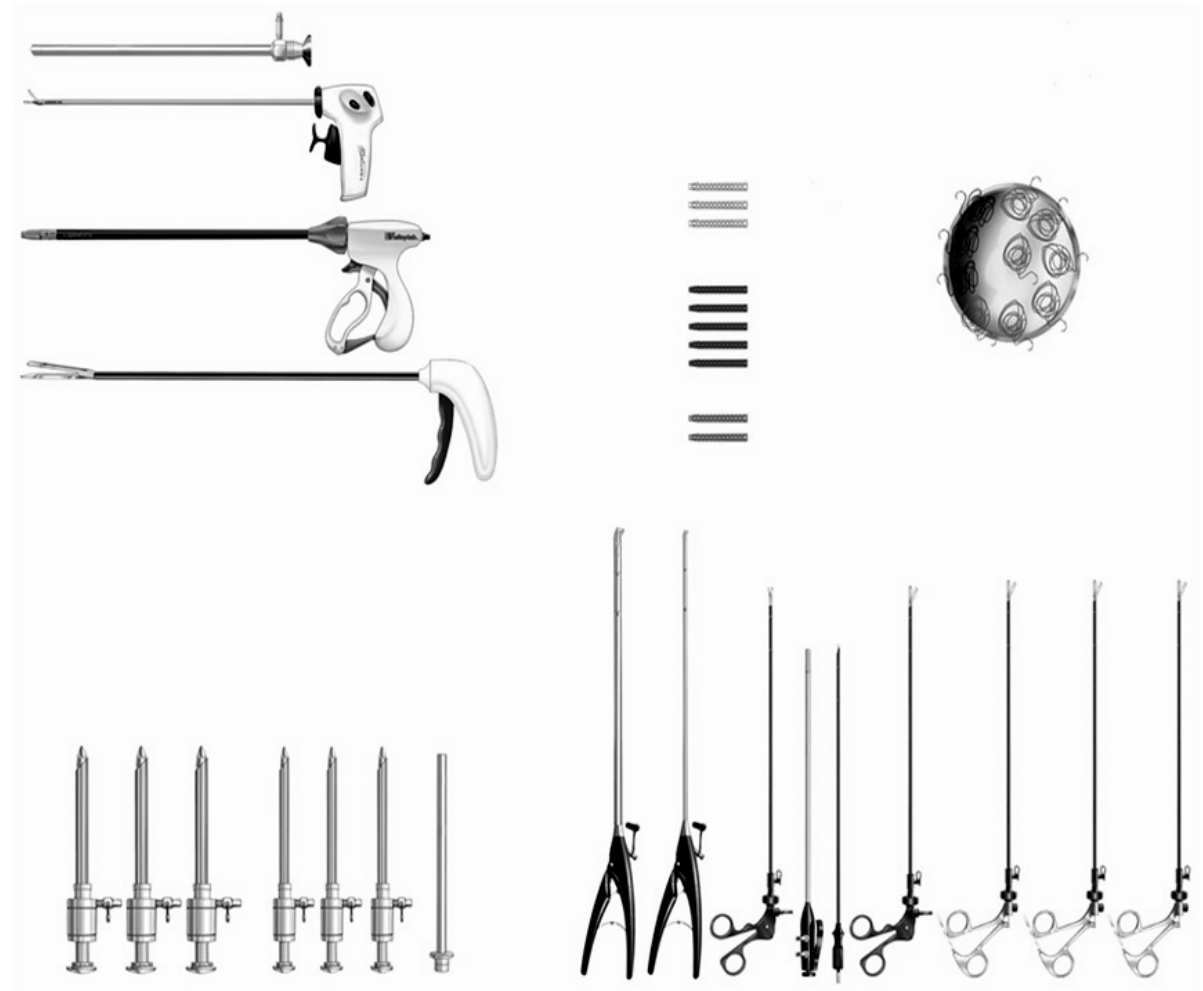

Fig 3. Display of the ancillary tools in laparoscopic bariatric surgery

\subsection{ADJUSTABLE GASTRIC BANDING}

\subsubsection{Technique}

\section{Dissection of the Phrenogastric Ligament and of the Retrogastric Area}

The grasper pulls the gastric fundus caudally to put the phrenogastric ligament under tension. A small window is now created in this ligament using the coagulating hook. This window is usually halfway between the upper pole of the spleen and the esophagus just to the left side of the left crus (Figure A).

The gastrohepatic ligament is opened widely. The base of the right crus covered by the peritoneal sheet (posterior layer of the gastrohepatic ligament) is identified. The peritoneal sheet is incised (Figure B). 


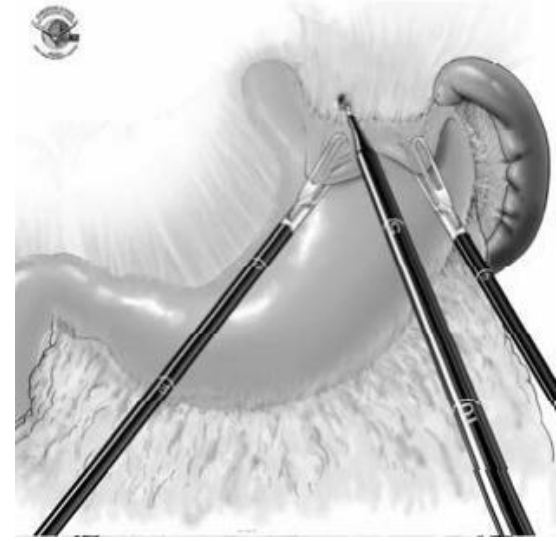

Fig A

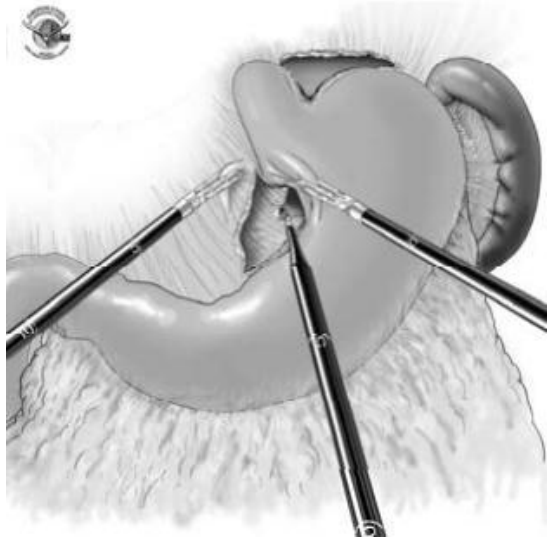

Fig B

\section{Retrogastric Tunnel}

A grasper is advanced under direct vision from the bottom of the right crus to the left crus staying close to the hiatus. The instrument is advanced until its tip becomes visible in the dissection area of the phrenogastric ligament.

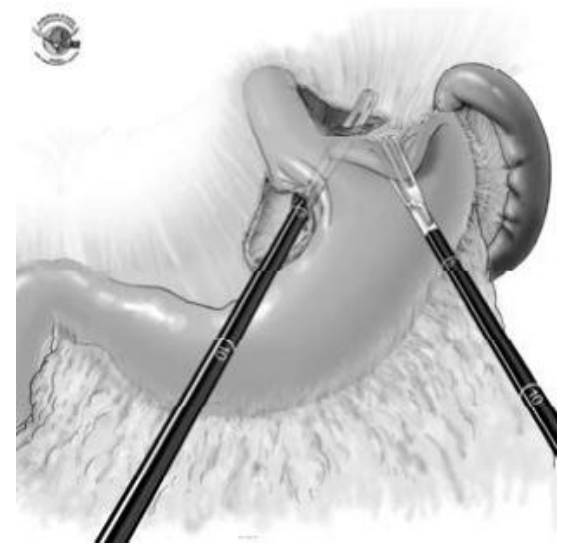

Placement of the Band

An adjustable band including its tubing is introduced into the abdominal cavity through the $15 \mathrm{~mm}$ port. The band is grasped by the grasping forceps and looped around the stomach at the level of the dissection. The tip of the tubing is introduced in the buckle of the band. 


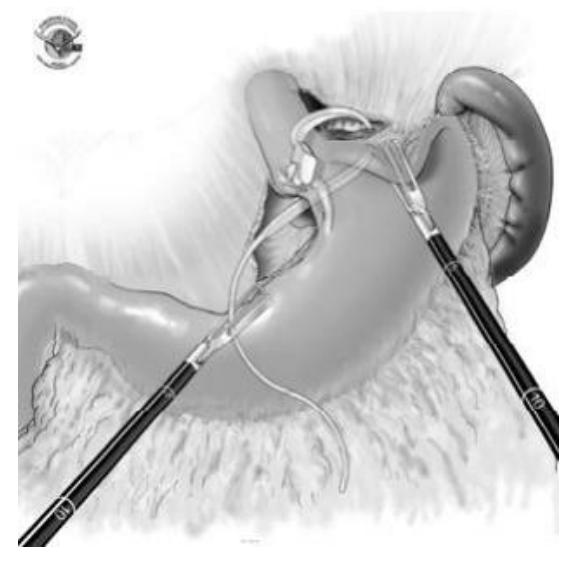

\section{Calibration and Suture Stabilization of the Band}

The anaesthesiologist introduces a balloon tiped orogastric tube inside the stomach; $25 \mathrm{cc}$ of air is insufflated in the balloon. The tube is pulled back until it sits snugly below the gastro-esophageal junction (Figure A).

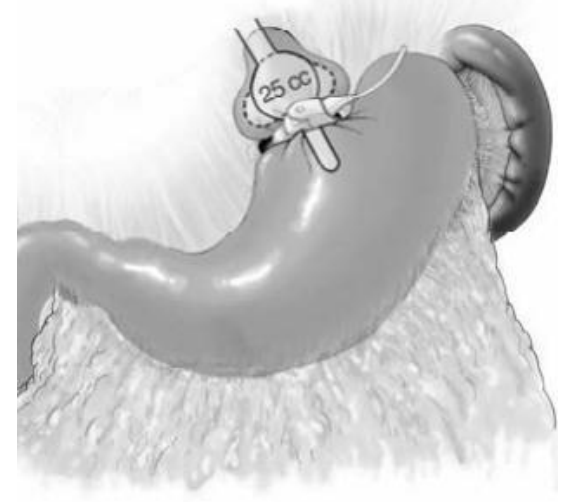

Fig A 


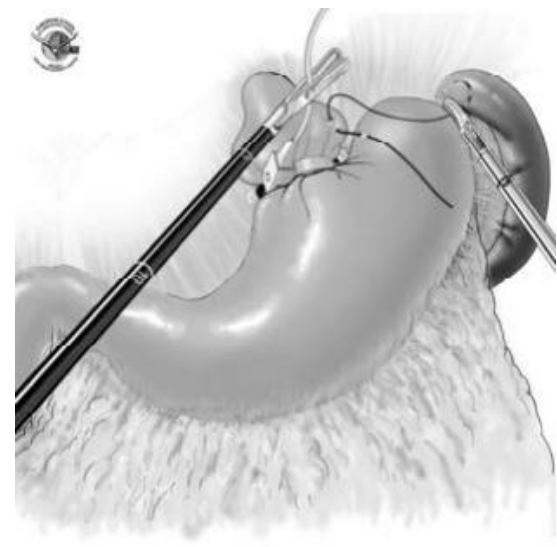

Fig B

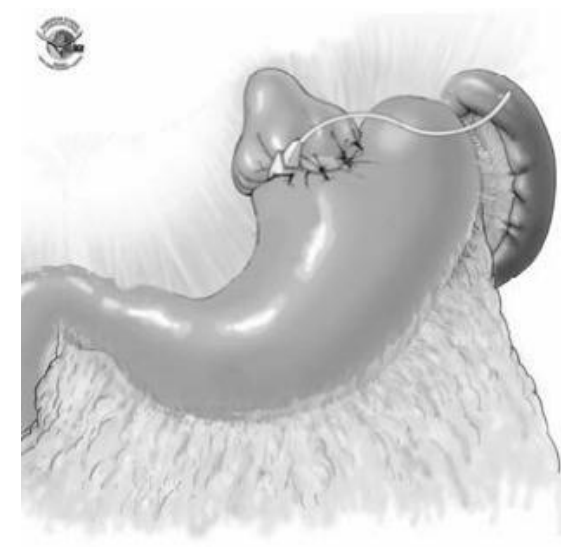

Fig C

The surgeon can now confirm the correct positioning of the band, and the band is tightened around the stomach and locked. Four to five stitches (silk or prolene 2/0) are placed between the serosa of the stomach just above and below the band to avoid slipping (Figure B-C).

\section{Placement and Injection of the Port}

The $15 \mathrm{~mm}$ port is removed, and the non-kinking tube is cut to an appropriate length and connected to the injection port (Figure A).

The port is buried, convex side up, and stitched (ethibond 2/0) to the parietal fascia overlying the costal margin to the left (Figure B).

The band is left deflated. Alternatively, a minimal amount of methylene-blue can be infused into the band through the port, in order to facilitate subsequent fill-up sessions.

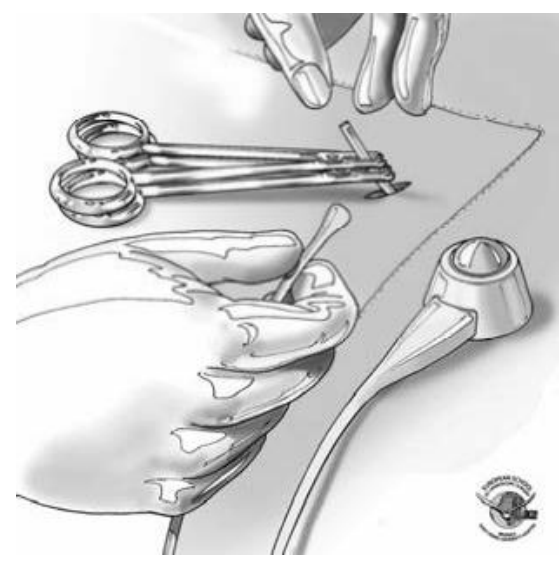

Fig A

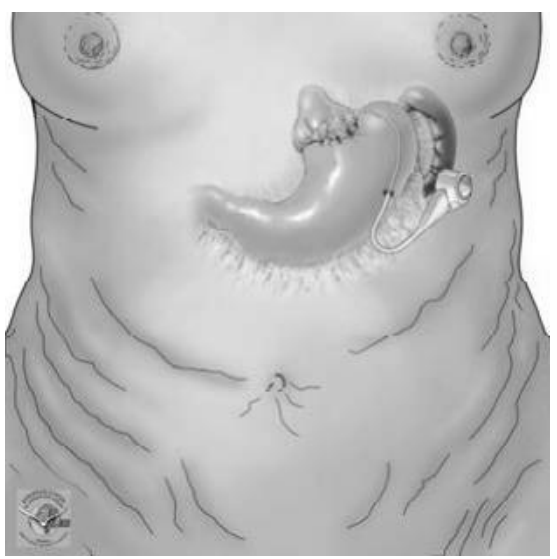

Fig B 


\subsubsection{Mechanism of Action}

There is substantial evidence that restriction is the chief mechanism of action in LAGB. This notion means that LAGB does not interfere with the normal food uptake mechanisms once the food bolus has crossed the mechanical obstacle of the silastic band. ${ }^{4}$ Because of the lack of interference with the absorption mechanisms, LAGB is considered by its proponents to be strictly restrictive and thus the most physiological intervention. Additionally, because the weight loss induced by LAGB is reportedly more gradual than with other procedures, it should allow for a better fat-lean mass redistribution. ${ }^{5}$

Conversely, there is no evidence that LAGB interferes with the hunger-satiety mechanism by reducing the production of active gastrointestinal peptides, such as ghrelin. ${ }^{6}$ The feeling of satiety is probably merely due to the increased pressure created by the passage of the food bolus through the small gastric pouch proximal to the band. ${ }^{7}$ The presence of the band limits the distensibility of the gastric pouch, which is a phenomenon that probably plays an important role in satiety via vagus nerve stimulation. ${ }^{8}$ Considering the mechanism of pressure sensitivity, it appears that LAGB acts as a purely restrictive procedure both by mechanical and by neural satiety-inducing means ${ }^{9}$ without interference with the production of gastrointestinal hormones.

An important theoretical drawback of LAGB is that the restriction is achieved by a foreign object. Similar to other procedures that incorporate a foreign object to achieve a desired function, ${ }^{10,11}$ the different types of adjustable band all share the same problem of potential rejection by the body. Additionally, rather than reinforcing an existing function, the band is placed in a non-physiological position to induce a function that is not native to the area involved. ${ }^{12}$ Suter ${ }^{13}$ observed a high incidence of band loss ( $40 \%$ after 5 years, and increasing with time) in a large sample of patients treated with a LAGB prosthesis. In a prospective 2-center study, Martinet al. ${ }^{14}$ found a 33\% explantation rate 9 years after LAGB. In a long-term study of the Swedish adjustable band, nearly 1 out of 3 patients required a major reoperation for complications related to the band. ${ }^{15}$ Although several authors have recently reported significantly better numbers in term of band loss with newer bands, ${ }^{16}$ all publications regarding this issue to date are cross-sectional at best, and no long-term results are currently available.

\subsection{SLEEVE GASTRECTOMY}

\subsubsection{Technique}

After identification of the Crow's foot, a straight line starting from the most distal branches of the Crow's foot to the greater curve across from this spot is marked 
with the coagulating hook. The lesser sac is accessed through a window made in the greater omentum, $3 \mathrm{~cm}$ to the left of the marking, close to the greater curve of the stomach, within the epiploic arch. This window is extended in a caudal direction in order to mobilize the greater curve up to the marking (Figure A).

The dissection subsequently proceeds cranially in order to completely dissect the omentum off the greater curve.The dissection reaches the base of the left diaphragmatic pillar. The base of the right diaphragmatic pillar should be dissected as well. All retrogastric adhesions must be divided (Figure B).

A first firing of linear stapler (green or black load) divides the greater curve in the direction of the Crow's foot. Other firings of linear stapler (green load) transect the stomach parallel to the lesser curve, from the antrum up to the angle of His. Before the third firing of the stapler, the anesthesiologist pushes down an orogastric tube of $34 \mathrm{Fr}$, to guide the gastric section (Figure C).

A running suture (PDS 1) usually reinforces the staple line (Figure D). The resected greater curve is extracted through the $12 \mathrm{~mm}$ left trocar site.

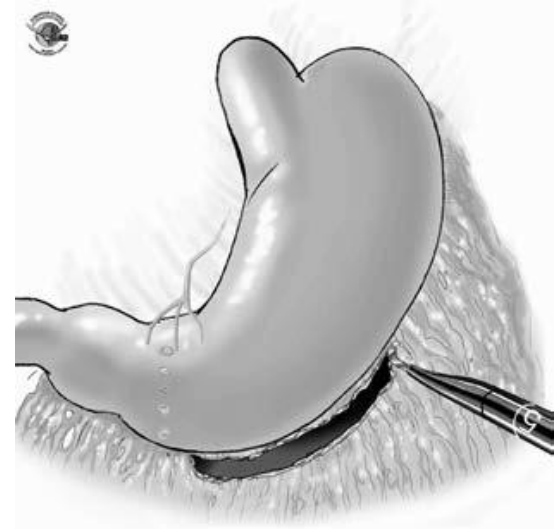

Fig A

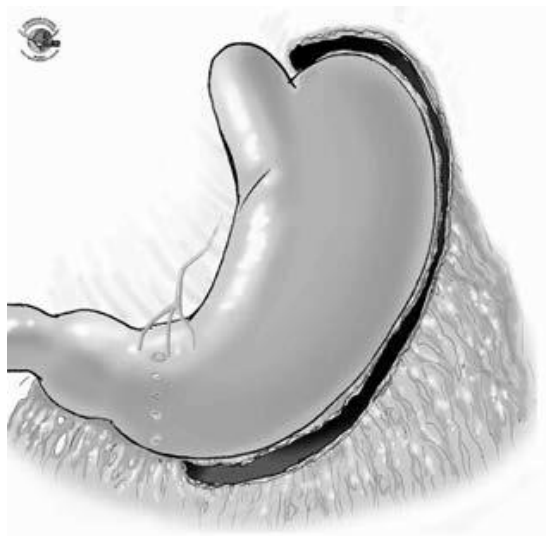

Fig B 


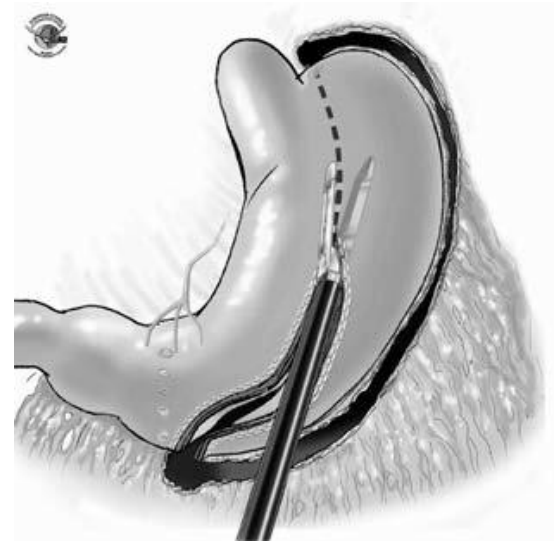

Fig C

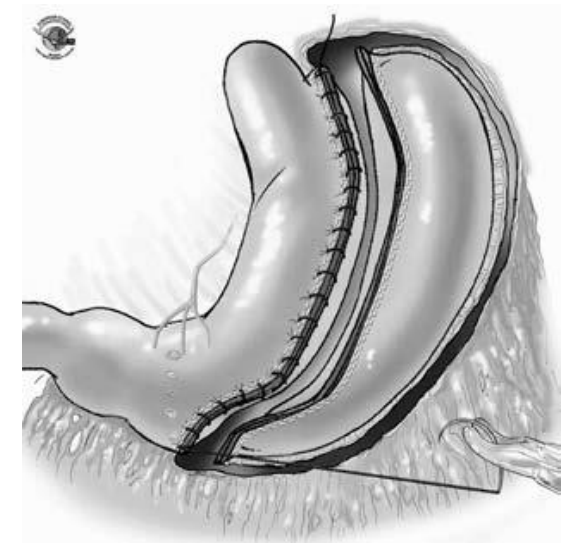

Fig D

\section{Leak Test}

The patient is placed in the Trendelenburg position. The operating field is immersed in saline solution. Compressed air is insufflated into the gastric sleeve by the anaesthesiologist. The absence of air bubbles is testimony to the integrity of the sleeve. Moreover this manoeuvre allows to assess good symmetry of the sleeve.

The procedure is concluded with the placement of a drain along the sleeve up to the upper pole of the spleen and the $12 \mathrm{~mm}$ left trocar site is closed with absorbable suture.

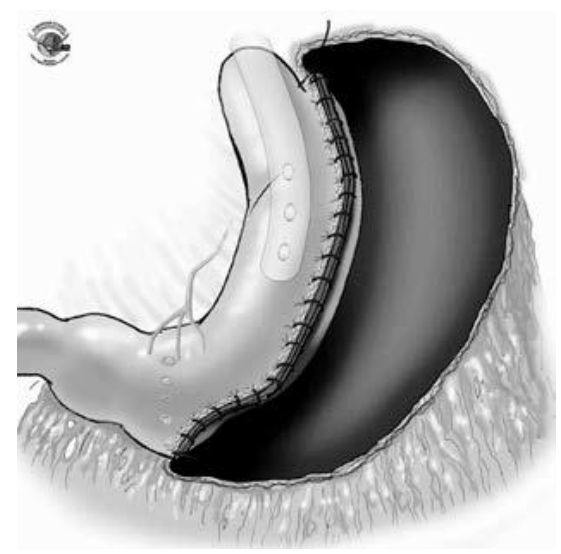




\subsubsection{Mechanism of Action}

Initially, LSG was believed to be a purely mechanically-restrictive operation. In addition to the fact that reducing the volume of the stomach evidently limits the intake of food, the reduction of stomach volume creates a rapid increase in intracavitary pressure when food is ingested, and this pressure induces a sensation of fullness ${ }^{17}$. The mechanism of LSG thus resembles that of LAGB.

There is, however, evidence that, unlike the band, additional factors influence weight loss after LSG. One of the factors influenced by the procedure is gastric emptying. Melissas ${ }^{18}$ was the first to notice that gastric emptying was accelerated after LSG. Although some authors have confirmed the positive influence of LSG on gastric emptying, ${ }^{19,20}$ other investigators have not replicated these findings. ${ }^{21}$ Possible factors affecting gastric emptying that may vary among authors include the preservation of varying volumes of the antrum ${ }^{21}$ and the use of proton pump inhibitors (PPI), which delay gastric emptying and are often not quantified in studies. ${ }^{22}$

After LSG, early satiety is concomitant with a sharp drop in ghrelin. Interestingly, Bohdjalian and Langer ${ }^{23}$ reported in their series that, in the single patient who experienced poor weight loss after LSG, ghrelin levels were unchanged. However, the "ghrelin effect" is not long-lived. Despite the fact that the aforementioned authors witnessed only a slow and insignificant increase of plasma ghrelin levels after 5 years, clinical evidence showed us that the anorexigenic effects of LSG disappear after 3 years (chapter 5 ). This effect had been predicted by Karamanakos et al. ${ }^{24}$ We found that presumably decreased ghrelin levels were concomitant with an increasing number of "wrong" food choices. It appears that quite soon, within some 6 months postoperatively, other distally located intestinal sites begin to produce ghrelin, which is a phenomenon that probably abrogates the effects of the procedure in the long term. ${ }^{25}$ Nevertheless, the ghrelin theory might, at least partly, explain the difference in weight loss experienced by patients after LSG and LAGB. We demonstrated in a prospective randomized study that weight loss is lower after LAGB compared with LSG through the third postoperative year (chapter 3). One of the striking differences between the two procedures is that the craving for sweets is less pronounced after LSG, which could indicate the role of humoral factors in LSG, but not LAGB. 


\subsection{ROUX-EN-Y GASTRIC BYPASS (ANTECOLIC, ANTEGASTRIC)}

\subsubsection{Technique}

\section{Construction of the Gastric Pouch}

The patient is positioned in reversed Trendelenburg position. The phrenogastric ligament is incised at the angle of His. The third vessel, counting down from the gastro-esophageal junction, is identified along the lesser curve. A plane is developed between Latarjet's pedicle and the serosa of the stomach in order to gain access into the lesser sac. The stomach is transected horizontally by a single firing of linear stapler (blue load) (Figure A). The gastric pouch is constructed by further firings of linear stapler (blue load) in the direction of the angle of His (Figure B-C). Care is taken to perform this vertical sectioning as close as possible to the lesser curve to just allow the passage of a $34 \mathrm{Fr}$ gastric tube (Figure D). Usually, a branch of the splenic artery running towards the posterior wall of the stomach constitutes a bleeding hazard. One should stay to the right of this branch.

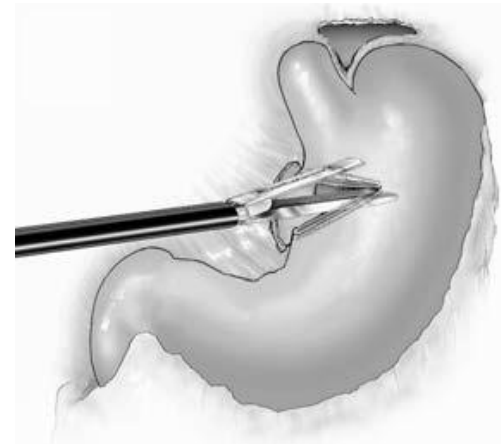

Fig A

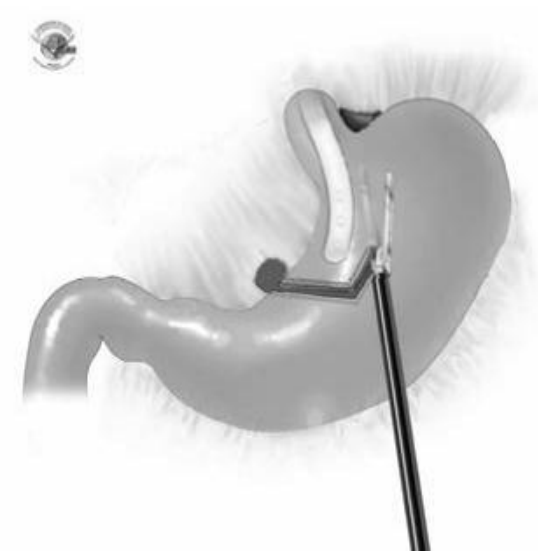

Fig B 


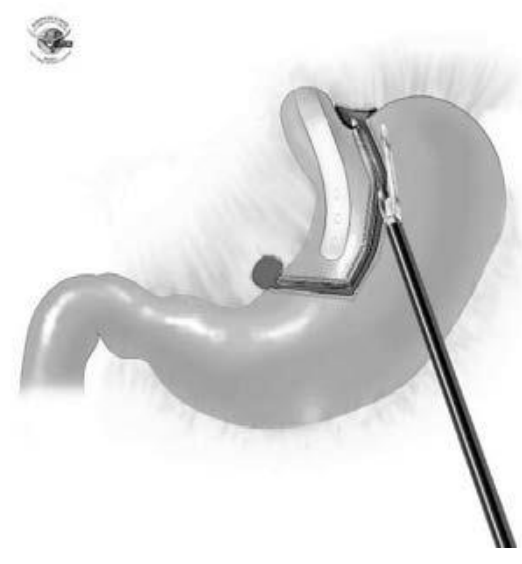

Fig C

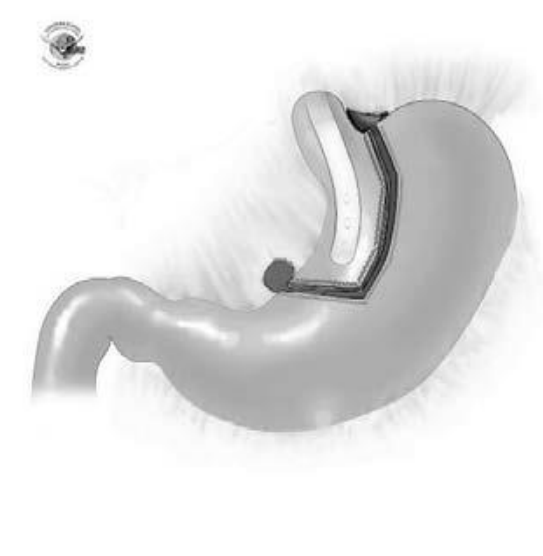

Fig D

Identification of the Biliopancreatic Loop and Measurement of the Alimentary Loop The patient is placed in horizontal position with a little right lateral tilt. The omentum and transverse colon are lifted and swept towards the right. After identification of the angle of Treitz, the small bowel is scrolled down, while the proximal loops are allowed to drop back to the left of the patient, which avoids mesenteric twisting. The aim is to identify the most proximal loop of small bowel that will easily reach the stomach in an antecolic position without any tension. A grasper holds the bowel at this level. The part of the bowel on the patient's right side will become the alimentary loop and is marked superficially with the coagulating hook, the part on the patient's left side will be the biliopancreatic loop (Figure A).

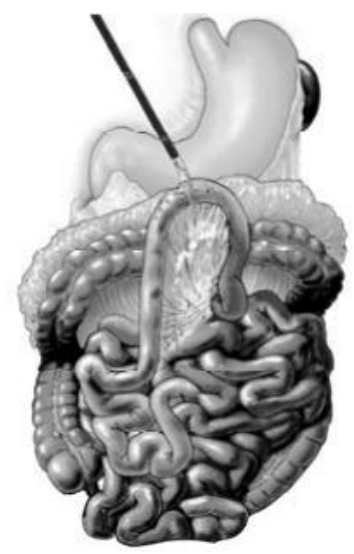

Fig A 
Aprroximately $150 \mathrm{~cm}$ of bowel are measured on the alimentary loop.The alimentary loop at this point can be secured to the biliopancreatic loop with a suture (silk or vicryl 2/0). The suture held by a grasper is elevated to reach the upper part of the stomach (Figure B).

The biliopancreatic and the alimentary loops are opened with coagulating hook (Figure C).

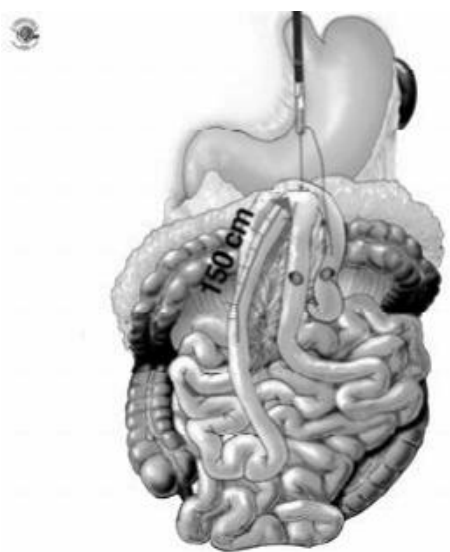

Fig B

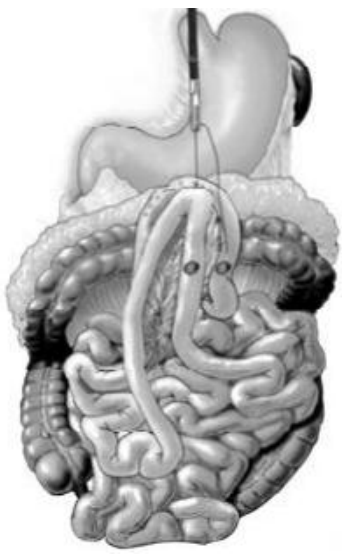

Fig C

Jejuno-Jejunostomy: semi-mechanical side-to-side

Enterotomies for introduction of the staple gun are made on the alimentary and biliopancreatic loops with the coagulating hook (Figure A).

A linear stapler (white load) is introduced into the enterotomies and the stapler is fired (Figure B).

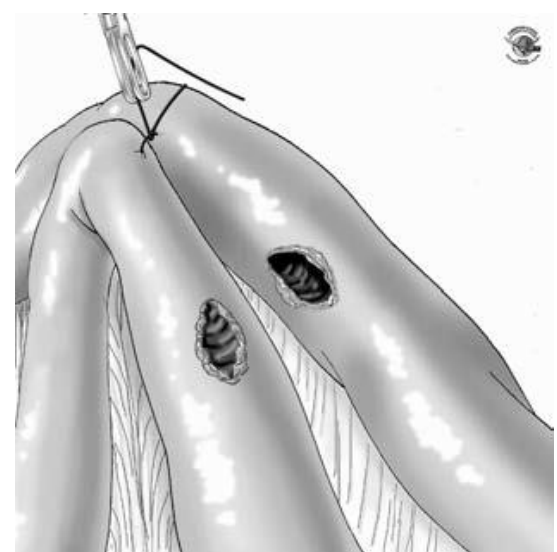

Fig A

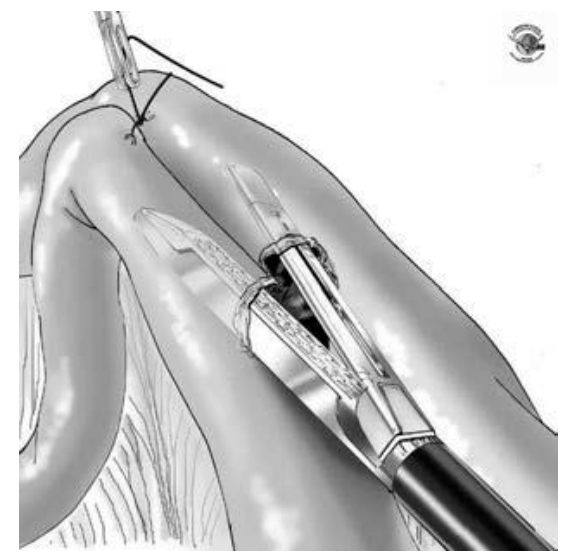

Fig B 
After stapling, the enterotomy opening is closed by a running suture (PDS or silk $2 / 0$ ) with two separate sutures starting at each corner which are then tied together halfway (Figure C-D).

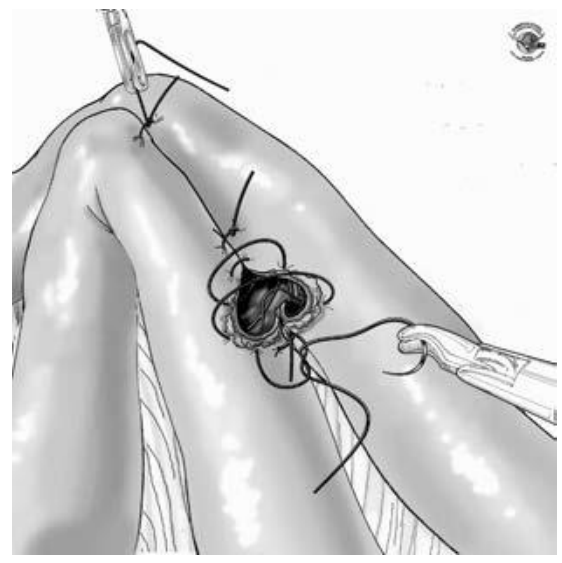

Fig C

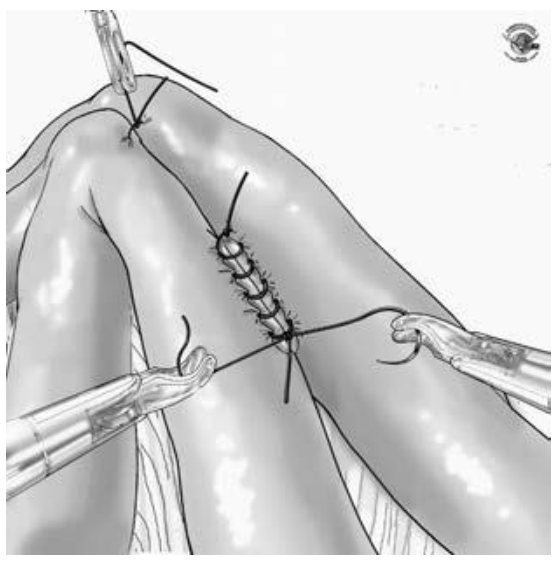

Fig D

Gastrojejunostomy: Linear Mechanical Side to Side

The alimentary limb is lifted towards the gastric pouch by a grasper.The vertical staple line is lifted ventrally and the gastric pouch is opened posteriorly by the coagulating hook and the adjacent alimentary limb is opened as well.(Figure A)

The linear stapler (blue load) is inserted only halfway into the opening in the pouch and the anastomosis is located on the posterior aspect of the pouch. (Figure B)

The alimentary limb is anchored to the gastric pouch by a stitch (silk 2/0). The stapler openings are closed with a running suture (PDS 2/0 or 1). (Figure C)

The bowel between the gastrojejeunostomy and the biliopancreatic limb is sectioned by a firing of linear stapler (white load) (Figure D). 


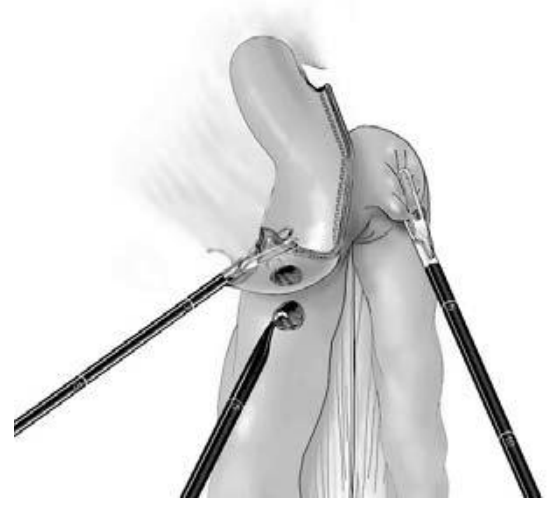

Fig A

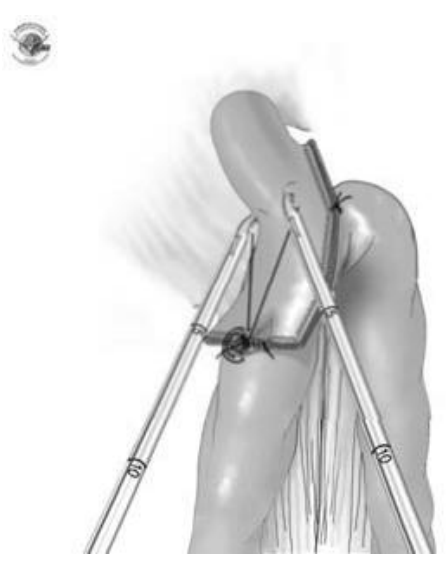

Fig C

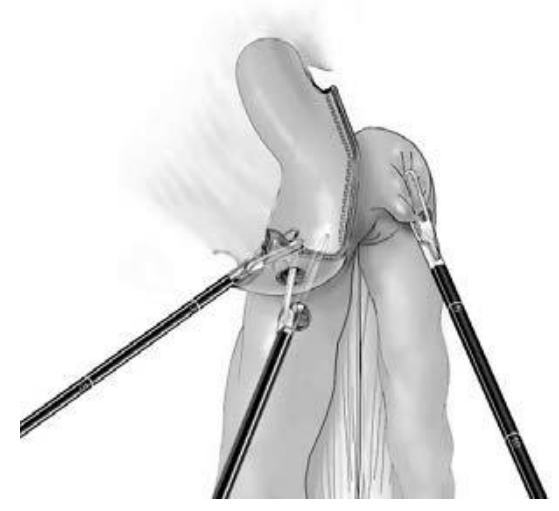

Fig B

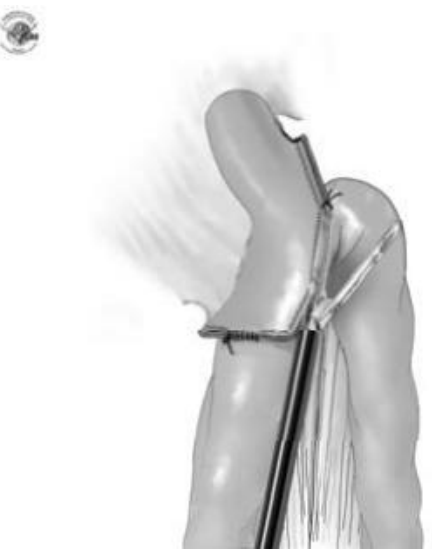

Fig D

\section{Closure of the Mesenteric Defect}

The mesenteric defect, between the alimentary and the biliopancreatic limbs, must be closed after conclusion of the jejunojejunostomy. A purse string stitch (Prolene $2 / 0$ or 1 ) is used for this purpose. A purse string is preferred over a running suture because it allows more mobility of the anastomosis, hence avoiding kinking which is the usual cause of blow out of the remnant stomach. 

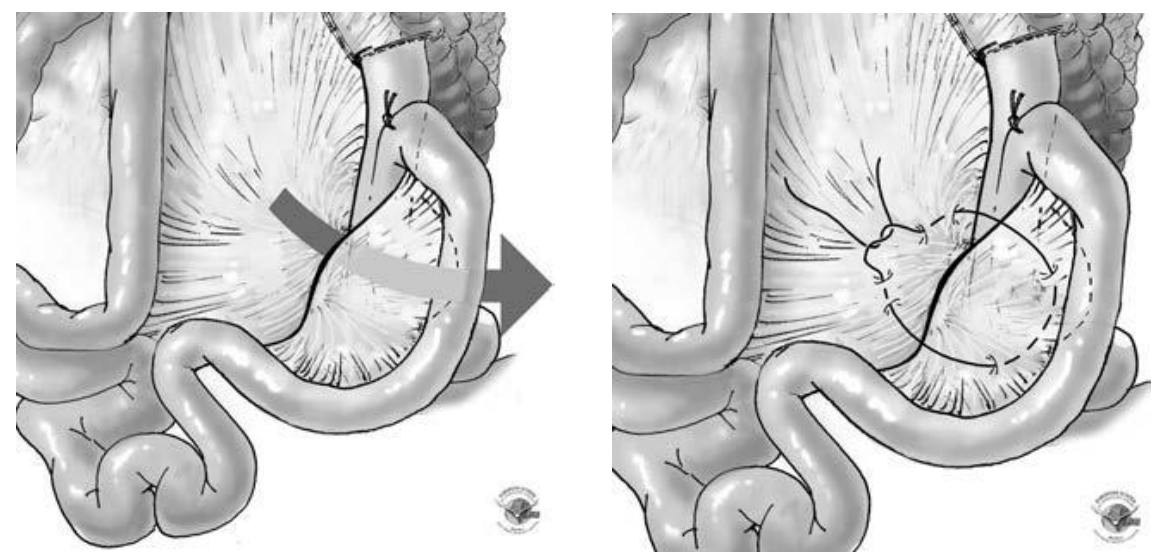

Closure of Petersen's Space

The Petersen's space, a potential defect formed as a result of the procedure between the alimentary limb and the transverse mesocolon, has to be closed in order to prevent an internal hernia. A purse string stitch (Prolene $2 / 0$ or 1 ) is used to close the defect; to perform this purse string the alimentary limb is kept to the patient's left. The transverse colon is identified and lifted cephalad. This exposes the angle of Treitz in the depth of the defect. The purse string is then conducted just to the reflexion of the ligament of Treitz.
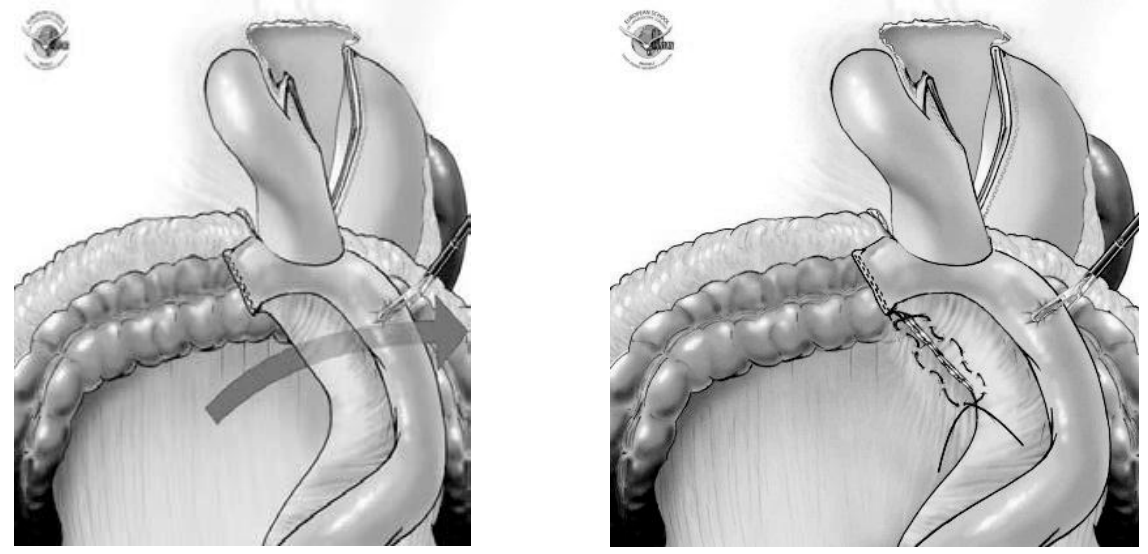

\subsubsection{Mechanism of Action}

The gastric bypass is considered a hybrid restrictive-malabsorptive procedure. ${ }^{11}$

There has, however, been a degree of doubt about the caloric-malabsorptive character of LRYGB. Unlike purely malabsorptive procedures, protein malnutrition is 
not a common finding after "normal length" RYGB. ${ }^{26}$ This merely clinical finding implies that carbohydrate absorption will not significantly be influenced either, because of the similar absorption mechanism for protein and carbohydrate: in all surgical models where food is exposed to bile and pancreatic juices after a delay (as in RYGB), protein and carbohydrate absorption occur by similar active mechanisms confined to the brush border of the small bowel ${ }^{27}$ that is not in contact with bile and pancreatic secretions. Conversely, it has been clearly established that unlike in the cases of protein and carbohydrates, malabsorption does occur for other substances, including copper, iron, zinc, calcium (Ca), vitamin B and vitamin D. ${ }^{28,29} \mathrm{~Pa}-$ tients therefore must receive nutritional supplementation after RYGB to prevent alopecia and dermatitis, due to zinc deficiency; neuritis caused by deficiencies in vitamins B1, B6 and B12 (B12 deficiency also causes alopecia); megaloblastic anemia (vitamin B9 and vitamin B12 deficiency); iron deficiency (ferriprive) anemia; and bone disorders ( $\mathrm{Ca}$ and vitamin $\mathrm{D}$ depletion). ${ }^{30}$

In addition to these unwanted malabsorptive effects, there is evidence that $c a-$ loric malabsorption does occur as well through an impaired uptake of fat. It has been proven that the RYGB reconstruction enhances the loss of fat through the stool. ${ }^{31}$ In patients with any type of duodenal bypass (as in RYGB), food, including fat, is not mixed with biliopancreatic secretions once it leaves the stomach, and fat absorption, unlike protein and starch absorption, can only occur in the common limb of the reconstruction, ${ }^{32}$ where fat is made passively absorbable by mixing with bile salts. (There is evidence that pancreatic enzymes rapidly lose their activity beyond the duodenum when not mixed with food. Consequently, these enzymes play a limited role in fat absorption in $\mathrm{RYGB}^{33}$ ). Obviously, in standard RYGB, the length of the common limb still allows for far more fat absorption than in BPD. ${ }^{34}$

The restrictive part of the bypass construction is related to the reduced volume of the stomach pouch and to a degree of stenosis that is dependent on the size of the gastroenteral anastomosis (GE). Both factors impart a size limitation on the ingested food bolus similar to that observed with VBG. ${ }^{35}$ Unlike VBG, because in RYGB the "stoma" typically is not reinforced, the pace of gastric emptying varies with time because the stoma becomes more compliant. There are, however, indications that the diameter of the anastomosis does not significantly influence weight loss in the long term. ${ }^{36}$ In addition, the pressure at the level of the GE is actually lower than in the gastric pouch and the alimentary limb. ${ }^{37}$ Therefore, considering the modest variation of the pressure distribution across the different elements of the alimentary part, the primary restrictive action of the bypass is probably not simply mechanical, but central. Changes in the levels of the hormone cholecystokinin, which are reportedly unchanged after $\mathrm{LSG}^{38}$ may partially explain the early satiety described after LRYGB. Additionally, it appears that ghrelin levels decline with time after LRYGB, unlike after LAGB, where ghrelin levels increase. ${ }^{39}$ 
An additional cause of reduced caloric intake after LRYGB is the effect of the rapid transit of the food bolus to the more distal small bowel. This state is characterized by anorexia occurring as soon as food is absorbed, which is called the post-cibal syndrome. $^{40}$

The bypass of the duodenum creates a situation in which the ingested food reaches the jejunum without being mixed with the biliary, pancreatic and duodenal secretions. Even though the exact mechanism is not known, the accelerated contact of food, especially carbohydrates, with the jejunal mucosa of the common limb causes a sharp increase in gastrointestinal hormones, especially Glucagon-like Peptide 1 (GLP-1), Peptide YY (PYY) and glucagon. These hormones can cause cold sweats, abdominal pain and general malaise. An increase in the levels of these hormones is followed by an "exaggerated insulin response". ${ }^{41,42}$ This collection of symptoms is described as the "dumping syndrome" and is an exacerbation of the postcibal syndrome. Dumping syndrome may be linked as well with the partial vagotomy performed during the bypass procedure, ${ }^{43}$ but it is not experienced by all patients. Moreover, the dumping syndrome disappears with time in a majority of patients, hence its limited long-term effect on weight loss (chapter 6). The clinical hormoneinduced symptoms that persist after several years and that occur late postprandially resemble more those of a hypoglycemic state.

\section{$2.5 \quad$ REFERENCES}

1. Gass M, Beglinger C, Peterli R. Metabolic surgery: principles and current concepts. Langenbeck's Arch Surg 20110ct;396(7):949-72.

2. O'Brien PE. Bariatric surgery: mechanisms, indications and outcomes; J Gastroenterol Hepatol 2010 Aug;25(8):1358-65.

3. DeMaria EJ, Jamal MK. Surgical options for obesity. Gastroenterol Clin North Am. 2005 Mar;34(1):127-42.

4. Burton PR, Brown WA. The mechanism of weight loss with laparoscopic adjustable gastric banding: induction of satiety, not restriction. Int J Obes (Lond) 2011 Sep;35 Suppl 3:S26-30.

5. Chaston TB, Dixon JB, O'Brien PE. Changes in fat-free mass during significant weight loss: a systematic review. Int J Obes (Lond). 2007; 31(5):743-750.

6. Langer FB, Reza Hoda MA, Bohdjalian A, et al. Sleeve gastrectomy and gastric banding: effects on plasma ghrelin levels. Obes Surg 2005 Aug;15(7):1024-9.

7. Brown $\mathrm{W}$. The role of pressure on the vagus. Postgraduate course $B, X V I$ world congress of the international federation for the surgery of obesity and metabolic disorders, Hamburg, Germany, $31 \mathrm{Au}$ gust 2011

8. Lu X, Guo X, Mattar AG, et al. Distension-induced gastric contraction is attenuated in an experimental model of gastric restraint; Obes Surg 2010 Nov;20(11):1544-51

9. Burton PR, Yap K, Brown WA, et al. Changes in satiety, supra- and infraband transit,and gastric emptying following laparoscopic adjustable gastric banding: a prospective follow-up study. Obes Surg 2011 Feb;21(2):217-23.

10. Kim SP, Sarmast Z, Daignault S, et al. Long-term durability and functional outcomes among patients with artificial urinary sphincters: a 10-year retrospective review from the University of Michigan. J Urol 2008 May; 179(5):1912-6. 
11. Varshney S, Kelly JJ, Branagan G, et al. Angelchik prosthesis revisited. World J Surg 2002 Jan; 26(1):129-33.

12. Himpens J. Laparoscopic adjustable pyloric band with fundoplication in bariatric surgery: technique and preliminary results. Obes Surg 2007 Aug;17(8):1084-90.

13. Suter M, Calmes JM, Paroz A, et al A 10-year experience with laparoscopic gastric banding for morbid obesity: high long-term complication and failure rates. Obes Surg. $2006 \mathrm{Jul}$;16(7):829-35.

14. Martin LF, Smits GJ, Greenstein RJ. Treating morbid obesity with laparoscopic adjustable gastric banding. Am J Surg 2007 Sep;194(3):333-43.

15. Mittermair RP, Obermüller S, Perathoner A,et al Results and complications after Swedish adjustable gastric banding-10 years experience. Obes Surg. 2009 Dec;19(12):1636-4

16. Chevallier JM. Gastric banding using adjustable silastic ring in 2010. Technique, indications, results, and management. J Visc Surg. 2010; 147(5 Suppl):e21-e29.

17. Yehoshua RT, Eidelman LA, Stein M, et al; Laparoscopic sleeve gastrectomy-volume and pressure assessment. Obes Surg 2008 Sep;18(9):1083-8.

18. Melissas J, Koukouraki S, Askoxylakis J, et al. Sleeve gastrectomy- a "food limiting" operation. Obes Surg 2008. Oct;18(10):1251-6.

19. Braghetto I, Davanzo C, Kom O, zt al. Scintigraphic evaluation of gastric emptying in obese patients submitted to sleeve gastrectomy compared to normal subjects. Obes Surg 2009 Nov;19(11):1515-21.

20. Gagner M. Faster gastric emptying after laparoscopic sleeve gastrectomy. Obes Surg 2010 Jul;20(7):964-5

21. Bernstine H, Tzioni-Yehoshua R, Groshar D, et al. Gastric emptying is not affected by sleeve gastrectomy-scintigraphic evaluation of gastric emptying after sleeve gastrectomy without removal of the gastric antrum. Obes Surg 2009 Mar;19(3):293-8.

22. Tougas G, Earnest DL, Chen $\mathrm{Y}$, et al. Omeprazole delays gastric emptying in healthy volunteers: an effect prevented by tegaserol. Aliment Pharmacol Ther 2005 Jul 1;22(1):59-65.

23. Bohdjalian A, Langer FB, Shakeri-Leidenmuhler S, et al. Sleeve gastrectomy as sole and definitive bariatric procedure:5-year results for weight loss and ghrelin. Obes Surg. 2010 May;20(5):535-40.

24. Karamanakos SN, Vagenas K, Kalfarentzos F, et al. Weight loss, appetite suppression, and changes in fasting ghrelin and peptide-YY levels after Roux-en-Y gastric bypass and sleeve gastrectomy: a prospective, double blind study. Ann Surg 2008;247:401-7.

25. Santoro S, Velhote MC, Malzoni CE, et al. Preliminary results from digestive adaptation: a new surgical proposal for treating obesity, based on physiology and evolution. Sao Paulo Med J. 2006;124(4):192-7.

26. Gracia JA, Martinez $M$, Elia $M$, et al. Obesity surgery results depending on technique performed: long-term outcome. Obes Surg 2009 Apr;19(4):432-8.

27. Bonalumi U, Cafiero F, Caponnetto A, et al Protein absorption studies in biliopancreatic bypass patients. Int J Obesity 1981; 5: 543 (abstract).

28. Ziegler O, Sirveaux MA, Brunaud L, et al; Medical follow up after bariatric surgery: nutritional and drug issues. General recommendations for the prevention of nutritional deficiencies. Diabetes Metab 2009 Dec;35(6 Pt 2):544-57.

29. Alvarez-Leite JL. Nutrient deficiencies secondary to bariatric surgery. Curr Opin Clin Nutr Metab Care 2004 Sep;7(5):569-75.

30. Moizé VL, Pi-Sunyer $\mathrm{X}$, Mohari $\mathrm{H}$, et al. Nutritional pyramid for post-gastric bypass patients. Obes Surg 2010Aug;20(8):1133-41.

31. Kumar R, Lieske JC, Collazzo-Clavell ML, et al. Fat malabsorption and increased intestinal oxalate absorption are common after Roux-en-Y gastric bypass surgery. Surgery 2011 May;149(5):645-61.

32. Odstrcil EA, Martinez JG, Santa Ana CA, et al. The contribution of malabsorption to the reduction in net energy absorption after long-limb Roux-en-Y gastric bypass. Am J Clin Nutr 2010 Oct;92(4):70413.

33. Brownlee JA, Forster DJ, Wilcox MD, et al. Physiological parameters governing the action of pancreatic lipase. Nutr Res Rev 2010 Jun;23(1):146-54. 
34. Scopinaro N, Papadia F, Camerini G, et al. A comparison of a personal series of biliopancreatic diversion and literature data on gastric bypass help to explain the mechanisms of resolution of type 2 diabetes by the two operations. Obes Surg 2008 Aug;18(8):1035-8.

35. Kalfarentzos F, Skroubis G, Kehaqias I, et al. A prospective comparison of vertical banded gastroplasty and Roux-en-Y gastric bypass in a non-superobese population. Obes Surg 2006 Feb;16(2):151-8.

36. Gould JC, Garren M, Boll V, et al. The impact of circular stapler diameter on the incidence of gastrojejunostomy stenosis and weight loss following laparoscopic Roux-en-Y gastric bypass. Surg Endosc 2006 Jul;20(7):1017-20.

37. Fandriks $\mathrm{L}$. The role of the smaller stomach. Postgraduate course $B, X V I$ world congress of the international federation for the surgery of obesity and metabolic disorders, Hamburg, Germany, $31 \mathrm{Au}$ gust, 2011.

38. Lee WJ, Chen CY, Chong K, et al. Changes in postprandial gut hormones after metabolic surgery: a comparison of gastric bypass and sleeve gastrectomy. Surg Obes RelatDis 2011 Nov-Dec;7(6):683-90.

39. Korner J, Inabnet W, Febres G, et al. Prospective study of gut hormone and metabolic changes after adjustable gastric banding and Roux-en-Y gastric bypass. Int J Obes (Lond). 2009 Jul;33(7):786-95

40. Eagon JC, Miedema BW, Kelly KA, et al. Postgastrectomy syndromes. Surg Clin North Am. 1992 Apr;72(2):445-65

41. Korner J, Bessler M, Cirilo $L$, et al. Effects of Roux-en-Y gastric bypass surgery on fasting and postprandial concentrations of plasma ghrelin, peptide YY, and insulin. J Clin Endocrinol Metab 2005 Jan;90(1):359-65.

42. Patti ME, Goldfine $A B$. Hypoglycemia following gastric bypass surgery: diabetes remission in the extreme? Diabetologia 2010 Nov; 53(11):2276-9.

43. Frantzides $\mathrm{CT}$, Carlson MA, Shostrom VK, et al. A survey of dumping symptomatology after gastric bypass with or without lesser omental resection. Obes Surg 2011 Feb;21(2):186-93.

44.Valderas JP, Ahuad J, Rubio L, et al. Acarbose improves hypoglycemia following gastric bypass surgery without increasing glucagon-like Peptide 1 levels. Obes Surg. 2012 April;22(4):582-6

\section{MECHANISM OF ACTION OF LAGB, LSG AND LRYGB AT A GLANCE}

\begin{tabular}{|l|l|l|l|}
\hline Procedure & LAGB & LSG & LRYGB \\
\hline Restriction Mechanical & Yes (foreign object) & Yes (pressure I ) & Questionable \\
\hline Malabsorption & No & Yes (Ghrelin) & Yes (Ghrelin, CCK) \\
\hline Adjustability & No & $\begin{array}{l}\text { Questionable } \\
\text { (gastric emptying) }\end{array}$ & Yes (fat, vitamins) \\
\hline Reversibility & Yes & No & No \\
\hline
\end{tabular}

$\mathrm{CCK}=$ cholecystokinin 


\section{Chapter 3.}

\section{A Prospective Randomized Study Between Laparoscopic Gastric Banding and Laparoscopic Isolated Sleeve Gastrectomy: Results after 1 and 3 Years}

Jacques Himpens, MD; Giovanni Dapri, MD; Guy Bernard Cadière, MD, PhD Department of Gastrointestinal and Obesity Surgery, European School of Laparoscopic Surgery,Saint-Pierre University Hospital, Brussels, Belgium

Obesity Surgery. Volume 16, Number 11, November 2006. 


\subsection{ABSTRACT}

Background: Laparoscopic adjustable gastric banding (GB) is the most popular restrictive procedure for obesity in Europe. Isolated sleeve gastrectomy (SG), is less common, but more invasive and with a higher learning curve.The aim of this prospective randomized study was to compare the results of GB and SG after 1 and 3 years of surgery.

Methods: 80 patient candidates for laparoscopic restrictive surgery were operated consecutively and randomly, between January and December 31, 2002, by GB (7M, $33 F)$ or by SG (9M, 31F) (NS). Median age was 36 (20-61) for GB versus 40 (22-65) for SG (NS). After 1 and 3 years: weight loss, feeling of hunger, sweet eating, gastroesophageal reflux were recorded in both groups.

Results: Median weight loss after 1 year was $14 \mathrm{~kg}(-5$ to +38$)$ for GB and $26 \mathrm{~kg}$ ( 0 to 46) for SG ( $P<0.0001)$; and after 3 years was $17 \mathrm{~kg}$ ( 0 to 40$)$ for $\mathrm{GB}$ and $29.5 \mathrm{~kg}$ (1 to 48) for $S G(P<0.0001)$. Median \%EWL at 1 year was $41.4 \%(-11.8$ to +130.5$)$ after $G B$ and $57.7 \%$ ( 0 to 125.5 ) after SG ( $P=0.0004)$; and at 3 years was $48 \%$ ( 0 to 124.8 ) after $G B$ and $66 \%(-3.1$ to +152.4$)$ after SG $(P=0.0025)$. Loss of feeling of hunger after 1 year was registered in $42.5 \%$ of patients with GB and in $75 \%$ of patients with SG ( $P=0.003)$; and after 3 years in $2.9 \%$ of patients with $G B$ and $46.7 \%$ of patients with SG $(P<0.0001)$. Loss of craving for sweets after 1 year was achieved in $35 \%$ of patients with GB and $50 \%$ of patients with SG (NS); and after 3 years in $2.9 \%$ of patients with GB and $23 \%$ of patients with SG (NS). GERD appeared de novo after 1 year in $8.8 \%$ of patients with GB and $21.8 \%$ of patients with SG (NS); and after 3 years in $20.5 \%$ of patients with GB and $3.1 \%$ of patients with SG (NS). Postoperative complications requiring re-operation were necessary for 2 patients after SG. Late complications requiring re-operation after GB included 3 pouch dilations treated by band removal in 2 and 1 laparoscopic conversion to Roux-en- $Y$ gastric bypass (RYGBP), 1 gastric erosion treated by conversion to RYGBP, and 3 disconnections of the system treated by reconnection. Inefficacy affected 2 patients after GB, treated by conversion into RYGBP and 2 patients after SG treated by conversion to duodenal switch.

Conclusion: Weight loss and loss of feeling of hunger after 1 year and 3 years are better after SG than GB. GERD is more frequent at 1 year after SG and at 3 years after GB. The number of re-operations is important in both groups, but the severity of complications appears higher in SG. 


\subsection{INTRODUCTION}

Gastric banding (GB) is the most popular restrictive procedure for morbid obesity in Europe. It is characterized by minimal invasivity, total possibility of reversibility and good weight loss at long-term. ${ }^{1-8}$

Sleeve gastrectomy (SG), described since 1988 by Hess ${ }^{9}$ and Marceau ${ }^{10}$ during the procedure of duodenal switch and since 1993 by Johnston ${ }^{11}$ in an isolated form, is a less common restrictive operation for obesity, with major invasivity and, in our experience, a longer learning curve than GB.

The aim of this prospective randomized study was to compare the laparoscopic adjustable GB and laparoscopic isolated SG in terms of weight loss, feeling of hunger, craving for eating sweets, gastroesophageal reflux disease (GERD), complications and re-operations, reporting the results after 1 year and 3 years.

\subsection{MATERIAL AND METHODS}

Between January 1 and December 31, 2002, 80 patient candidates for a laparoscopic restrictive operation were operated consecutively and randomly assigned to a GB (40) or SG (40). The characteristics of the patients were similar for the two groups:7 males and 33 females (GB) versus 9 males and 31 females (SG) (NS), a median age of 36 years (20-61) for GB versus 40 years (22-65) for SG (NS), and a median BMI of 37 $\mathrm{kg} / \mathrm{m}^{2}$ (30-47) for GB versus $39 \mathrm{~kg} / \mathrm{m}^{2}$ (30-53) for SG (NS). Before surgery, 6 patients $(15 \%)$ of the GB and 8 patients (20\%) of the SG group suffered from GERD, requiring daily medical therapy with proton pump inhibitor (PPI).

After 1 year and 3 years, weight loss, feeling of hunger, craving for eating sweets, GERD, complications and re-operations were recorded in both groups.

Data from clinical visits during follow-up permitted evaluation of the modifications of weight loss $(\mathrm{kg})$, the decrease of $\mathrm{BMI}$ and the progression of \%EWL. The feeling of hunger and the craving for sweets were evaluated with a questionnaire completed by the patients regarding their changes during follow-up (Table 1). The modification of GERD was estimated by the number of the patients on PPI before and at 1 year and 3 years after the procedure.

Barium swallow and blood tests were performed as needed by the clinical status. In case of re-operation, a totally laparoscopic approach was performed.

We performed a descriptive analysis of patients' baseline characteristics per group using frequency tabulations for categorical variables and median and range for continuous variables. Possible differences between groups were assessed using chi-square tests for homogeneity for categorical variables and Mann-Whitney tests for continous variables. 
The primary outcome for the study, measured after 1 and 3 years of follow-up, was defined as the relative weight loss compared to the ponderal excess before treatment and treated as a continuous variable.

Secondary outcomes included hunger sensation, intake of sweets and modifications of GERD, that were measured compared to the baseline status using a binary scale: decrease versus stabilization or increase as well as occurrence of complications and need for a new surgical intervention.

The distribution of the primary outcome was compared between groups using Mann-Whitney tests. For the secondary outcomes, we used chi-square tests for homogeneity or Fisher's exact test if required by sample size. All reported $P$ values are two-tailed, and a $P$ value $<0.05$ was needed to conclude statistical significance.

Table 1. Patient Questionnaire after 1 year and 3 years

- Your feeling of hunger after surgery is: abolished, diminished, the same, augmented, very augmented

- Your craving for sweets after surgery is: abolished, diminished, the same, augmented, very augmented

\subsubsection{Surgical technique}

\section{Laparoscopic Adjustable Gastric Banding}

GB was performed by the pars flaccida approach, using the gastric balloon to calibrate the closure of the device on $25 \mathrm{~mL}$. The band of Heliogast (Helioscopie, Vienne cedex, France) or AMI (Medical Innovation, Gotzis, Austria) was placed.

\section{Laparoscopic Isolated Sleeve Gastrectomy}

After identification of the crow's foot, the stomach was perpendicularly scored. The greater omentum was sectioned close to the gastric wall and medial to the gastroepiploic vessels using the Ligasure device (Tyco, New Haven, CT). The dissection reached the base of the left diaphragmatic pillar which was entirely freed as well as the base of the right diaphragmatic pillar. A first firing of a linear stapler (EndoGIA $60 \mathrm{~mm}$, Tyco, New Haven, CT) blue or green load, divided the greater curvature in the direction of the crow's foot. Other firings of the linear stapler divided longitudinally, from the antrum to the angle of His.

The anesthesiologist passed down a nasogastric tube of 34-French, in order to guide the gastric division. A No. 1 polypropylene running suture reinforced the staple-line. A leak-test with compressed air demonstrated the integrity of the gastric tube. 


\subsection{RESULTS}

The median weight loss after 1 year was $14 \mathrm{~kg}(-5$ to +38$)$ for $\mathrm{GB}$ and $26 \mathrm{~kg}$ ( 0 to 46$)$ for SG ( $P<0.0001)$; and after 3 years was $17 \mathrm{~kg}(0$ to 40$)$ for $\mathrm{GB}$ and $29.5 \mathrm{~kg}$ (1 to 48) for SG $(P<0.0001)$. The median decrease of BMI after 1 year was $15.5 \mathrm{~kg} / \mathrm{m}^{2}$ (5 to 39$)$ for GB and $25 \mathrm{~kg} / \mathrm{m}^{2}$ (0 to 45$)$ for SG $(P<0.0001)$; and after 3 years was $18 \mathrm{~kg} / \mathrm{m}^{2}(0$ to 39 ) for $\mathrm{GB}$ and $27.5 \mathrm{~kg} / \mathrm{m}^{2}$ ( 0 to 48 ) for $\mathrm{SG}(P=0.0004$ ) (Table 2).

Table 2. Median decrease of \%EWL after 1 and 3 years

\begin{tabular}{|c|c|c|}
\hline & 1 year & 3 years \\
\hline $\begin{array}{l}\text { BAND } \\
\text { BMI } \\
\text { SLEEVE }\end{array}$ & $\begin{array}{c}15.5 \mathrm{~kg} / \mathrm{m}^{2}(5-39) \\
25 \mathrm{~kg} / \mathrm{m}^{2}(0-45)\end{array}$ & $\begin{array}{c}18 \mathrm{~kg} / \mathrm{m}^{2}(0-39) \\
27.5 \mathrm{~kg} / \mathrm{m}^{2}(0-48)\end{array}$ \\
\hline $\begin{array}{l}\text { BAND } \\
\% \text { EWL } \\
\text { SLEEVE }\end{array}$ & $\begin{array}{c}41.4 \%(-11.8-+130.5) \\
57.7 \%(0-125.5)\end{array}$ & $\begin{array}{l}48 \%(0-124.8) \\
66 \%(-3.1-+152.4)\end{array}$ \\
\hline
\end{tabular}

The median \%EWL at 1 year was $41.4 \%(-11.8$ to +130.5$)$ after GB and $57.7 \%$ ( 0 to 125.5) after SG ( $P=0.0004)$; and at 3 years was of $48 \%$ (0 to 124.8) after $\mathrm{GB}$ and $66 \%$ $(-3.1$ to +152.4$)$ after SG $(P=0.0025)$ (Table 2$)$.

The loss of feeling of hunger (abolished or diminished in the questionnaire) after 1 year was recorded in $42.5 \%$ of the patients with $\mathrm{GB}$ and $75 \%$ of the patients with SG $(P=0.003)$; and after 3 years this number dropped to $2.9 \%$ of the patients with $G B$ and $46.7 \%$ of the patients with SG $(P<0.0001)$ (Figure 1$)$.

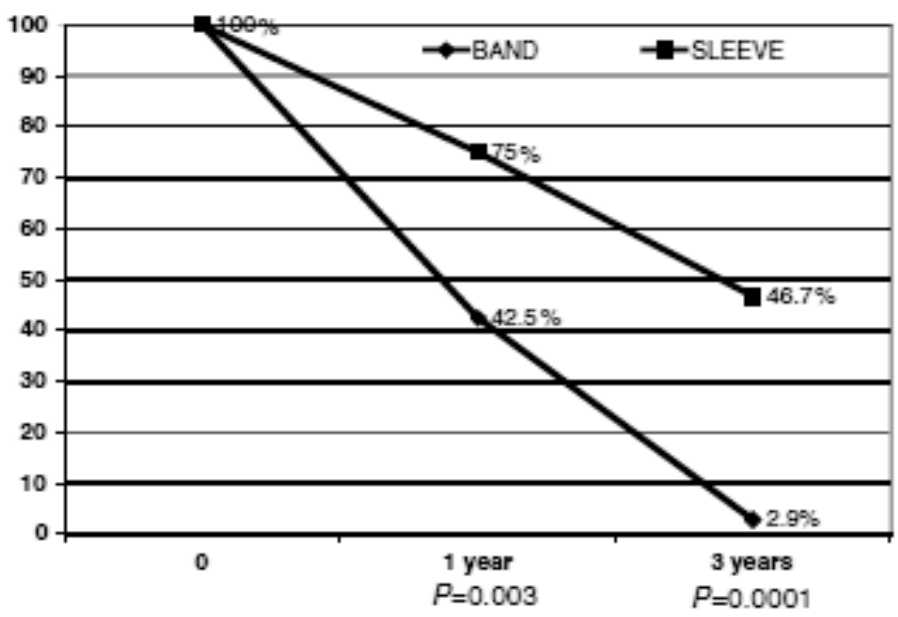

Figure 1. Loss of hunger sensation after 1 and 3 years. 
The loss of craving for sweet eating (abolished or diminished in the questionnaire) after 1 year was reported by $35 \%$ of the patients with GB and by $50 \%$ of the patients with SG (NS); and after 3 years these numbers dropped to $2.9 \%$ of the patients with $\mathrm{GB}$ and $23.3 \%$ of the patients with SG (NS) (Figure 2).

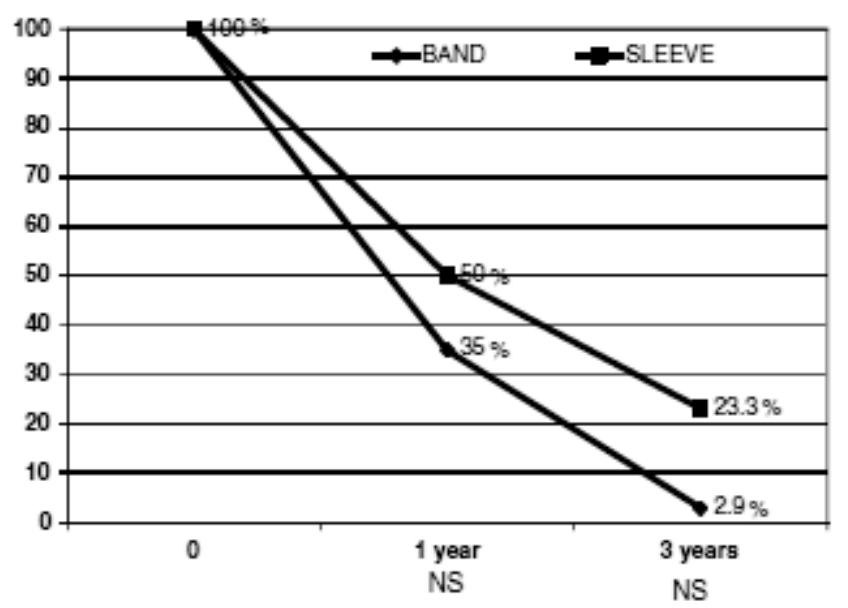

Figure 2. Loss of craving for sweets after 1 and 3 years.

GERD appeared de novo after 1 year in 3 out of 34 patients (8.8\%) with GB and in 7 out of 32 patients (21.8\%) with SG (NS); and after 3 years, in 7 out of 34 patients (20.5\%) with GB and in 1 out of 32 patients (3.1\%) with SG (NS) (Figure 3).

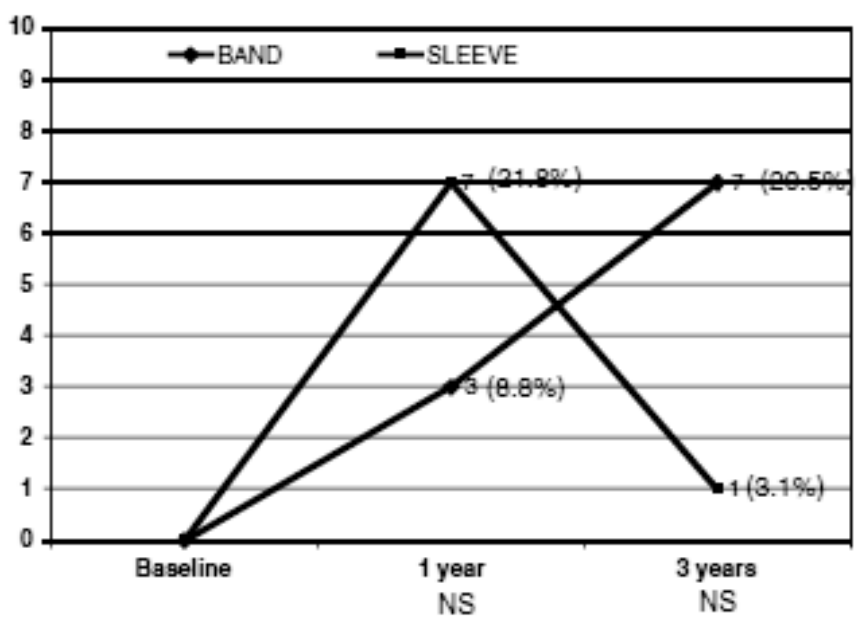

Figure 3. Patients' intake of PPI after 1 and 3 years. (At baseline, 34 patients who underwent GB and 32 patients who underwent SG did not complain of GERD). 
Patients who had been affected by GERD before surgery, noticed its disappearance after 1 year and 3 years, respectively in 5 out of 6 patients (83.3\%) with GB and in 6 out of 8 patients (75\%) with SG (Figure 4).

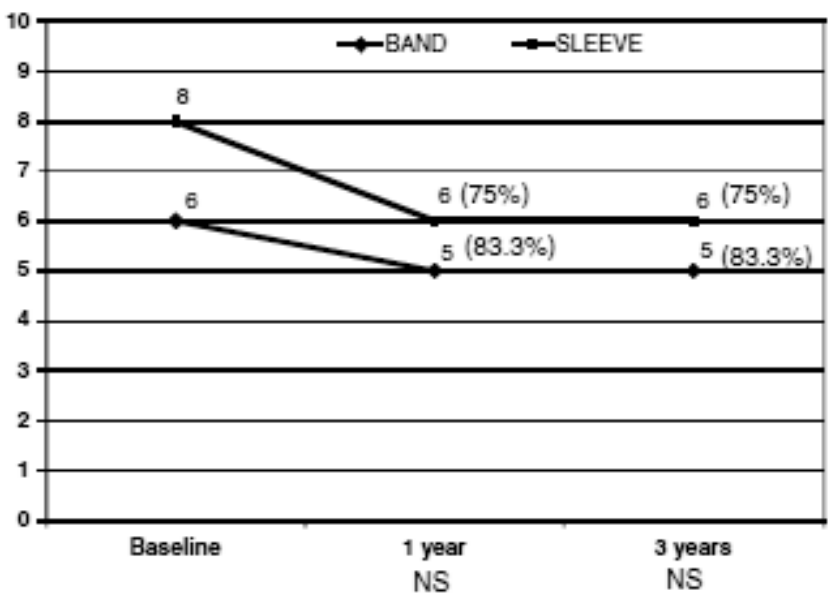

Figure 4. Patients' cessation of PPI after 1 and 3 years.

The complications not requiring an operation at 1 year after GB were shoulder pain in 3 patients (7.5\%), frequent vomiting in 6 patients (15\%), poor choice of alimentation in 2 patients (5\%); and after SG, gastric pain in 2 patients (5\%), frequent vomiting in 1 patient (2.5\%) and deficiency of minerals in 2 patients (5\%). Complications not requiring an operation at 3 years after GB were shoulder pain in 3 patients (8.5\%), frequent vomiting in 10 patients (28.5\%), poor choice of alimentation in 17 patients (48.5\%), gastric ulcer in 1 patient (2.8\%); and after SG, were frequent vomiting in 5 patients (16.6\%), poor choice of alimentation in 8 patients $(26.6 \%)$, and deficiency of minerals in 3 patients (10\%).

The complications requiring re-operation (Table 3 ) were registered postoperatively in 2 patients with SG: 1 intraperitoneal bleed during the first 24 hours (retreated by laparoscopy), and 1 ischemia of the sleeve on the 4th postoperative day (requiring a laparoscopic total gastrectomy).

Concerning the late complications in the group of GB, 3 patients had a gastric pouch dilation treated by band removal in two and one laparoscopic conversion to Rouxen-Y gastric bypass (RYGBP), 2 patients presented an insufficient weight loss treated by conversion into RYGBP, 1 patient presented a gastric erosion treated by conversion into RYGBP, and 3 patients had a disconnection of the port treated by reconnection. In the group of SG, 2 patients presented insufficient weight loss treated by conversion to laparoscopic duodenal switch (DS). 
Table 3. Postoperative late complications and weight loss failure

\begin{tabular}{llll}
\hline \multirow{3}{*}{ BAND } & & No. & Treatment \\
& Postoperative complications & $(-)$ & \\
& Late complications & $(7)$ & 2 band removal, 1 RYGBP \\
& -pouch dilation & $(3)$ & conversion to RYGBP \\
-gastric erosion & $(1)$ & reconnection \\
conversion to RYGBP
\end{tabular}

\subsection{DISCUSSION}

Laparoscopic SG is considered more invasive than GB, and does not have the possibility of "restitutio a integrum", because of vertical subtotal gastrectomy, where the antrum is conserved besides a small part of the upper stomach. \% EWL obtained at 1 and 3 years after GB, are in accordance with data from the literature. ${ }^{4,6,8}$

Our results at 1 year after SG are similar to those reported by Langer, ${ }^{12}$ Baltasar $^{13}$ and Johnston. ${ }^{11}$

Hormonal issues could, firstly, explain the differences in our study between the two procedures in terms of weight loss and of loss of sensation of hunger. Ghrelin, an acylated upper gastrointestinal peptide, is the only orexigenic hormone, where circulating levels decrease with feeding and increase before meals, achieving concentrations sufficient to stimulate hunger and food intake. ${ }^{14}$ This hormone is primarily produced by the enteroendocrine cells of gastric mucosa and to a lesser extent from the duodenum.

The procedure of SG involves resection of the gastric fundus, the predominant part of the stomach in the production of ghrelin, resulting in less stimulation of the hunger center. A recent study by Langer ${ }^{15}$ compared the ghrelin levels in patients submitted to SG and to $G B$, showing in patients with SG a significant decrease in plasma ghrelin at day 1 after surgery, confirmed also after 1 and 6 months, in contrast to no change found in patients with GB. Moreover, in patients with GB, the plasma ghrelin levels 1 and 6 months after surgery appeared increased compared with the preoperative levels of the same group.

Kotidis ${ }^{16}$ measured the serum ghrelin in patients submitted to a SG with DS, before surgery and after 18 months, and concluded that the marked suppression of the hormone seems to be the main cause for the postoperative lack of appetite.

Another mechanism explaining weight loss and differences in loss of hunger sensation between the two groups is a mechanical process, where the appetite is related to gastric emptying. A randomized and double blind trial reported by Berg- 
mann, ${ }^{17}$ showed an association between echographic gastric emptying and appetite, where the more the antrum is expanded the less the feeling of hunger. This mechanism is represented by the new anatomy of the stomach after the procedure of SG (Figure 5).

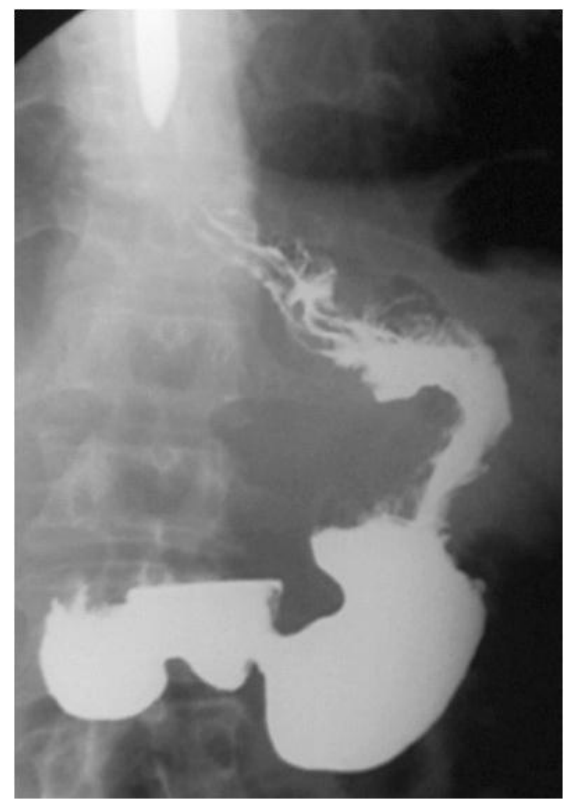

Figure 5. Barium swallow in a patient 1 month after SG.

Gastric emptying may be a significant factor in the evolution of GERD after these procedures. In the group after SG, patients were more affected than patients after GB at 1 year and at 3 years these results were reversed. After SG, a lack of gastric compliance and emptying appeared at 1 year, whereas an increased gastric compliance and clearance was present after 3 years, likely resulting in the reduced incidence of GERD. ${ }^{18}$ 
Figure 6. Barium swallow in a patient 3 years after SG. Arrow points to restored angle of His.

Additional factors involved in GERD after SG could be the anatomical changes in the angle of His, which is one of the gastroesophageal protective mechanisms. ${ }^{19}$ During the procedure of SG, this angle is usually blunted. The frequent consequence is the immediate appearance of GERD in previously asymptomatic patients, as shown by our results. After 3 years, a smaller number of patients with SG complained of GERD, probably because of restoration of the angle of His, as evidenced on barium swallow (Figure 6).

On the other hand, Dixon et $\mathrm{al}^{20}$ have demonstrated a rapid and major improvement of GERD in patients submitted to $G B$, probably because the GB directly acts as an antireflux mechanism. In our series, patients submitted to GB and affected by GERD before surgery, showed an improvement after 1 year, which was confirmed also after 3 years. However, late de novo GERD appeared in $20.5 \%$ of patients with GB. This agrees with the literature, where a high incidence of long-term GERD and esophagitis is reported in patients after GB. ${ }^{21,22}$

A frequent cause of failure of restrictive surgery is said to be sweet eating, appearing de novo or persisting despite the procedure. In our study, craving for sweets reappeared after 3 years, which was more pronounced (but not statistically significant) for $\mathrm{GB}$ than for SG.

We divided the complications into minor and major (requiring re-operation). Our results demonstrated a higher number of minor complications after GB than SG. The shoulder pain can be explained by radiation of pain from the left upper quadrant, where the port is positioned just distal to the costal margin. Frequent vomiting is related to poor alimentary education and less loss of hunger, characterized by the 
sudden and fast filling of the gastric pouch. Regarding the SG, frequent vomiting and poor choice of alimentation are probably related to the same mechanism as with $\mathrm{GB}$, but the mineral deficiency for vitamin B12 and iron is most likely from lower production of intrinsic factor and acid by the reduced stomach.

Both groups encountered major complications, requiring re-operation during the early and late postoperative period. However, whereas the number of major complications was higher after GB than SG, the importance of these complications is less after GB than after SG. After GB, two cases of gastric pouch dilation and three cases of disconnection of the system occurred, concurring with the literature. ${ }^{1,4}$ In the SG group, there were two major complications: one intraperitoneal bleed and one ischemia of the sleeve. The first was treated by relaparoscopy with control of bleeding, and the other was life-threatening and required a total gastrectomy. This ischemia was related to poor vascularization to the sleeve, caused by damage of the left gastric vessels during the initial surgery. To obtain a narrow gastric tube it is mandatory during gastric resection to perform an accurate adhesiolysis between the posterior wall of the stomach and the pancreatic body and tail, and the left gastric artery is at danger during this dissection.

The most important late problem presented in our series was insufficient weight loss, more pronounced after GB than after SG. In cases of GB, one possible treatment is re-operation to a RYGBP. Reports have found good results with RYGBP after failure of GB. ${ }^{23-27}$ Conversion of GB to RYGBP can also be an alternative in cases of other complications, such as gastric pouch dilation and gastric erosion, encountered in 2 of our patients in the GB group. On the other hand, in the case of insufficient weight loss after SG, it appears logical to add a malabsorptive process to the already performed restrictive operation. SG is often considered as the first step of a DS in cases of super-obese patients. ${ }^{28-30}$ We were fortunate not to encounter a case of staple-line dehiscence, which can require challenging treatment. ${ }^{31}$

In conclusion, weight loss and loss of feeling of hunger after 1 year and 3 years were better after SG than GB. GERD was more frequent at 1 year after SG but at 3 years after GB. The number of re-operations was important in both groups, but the severity of complications was higher after SG.

\subsection{REFERENCES}

1. Suter M, Calmes JM, Paroz A et al. A 10-year experience with laparoscopic gastric banding for morbid obesity: high long-term complication and failure rates. Obes Surg 2006; 16: 82935.

2. Buchwald H, Williams SE. Bariatric surgery worldwide 2003. Obes Surg 2004; 14: 1157-64.

3. Weiner R, Blanco-Engert R, Weiner $\mathrm{S}$ et al. Outcome after laparoscopic adjustable gastric banding -8 years experience. Obes Surg 2003; 13: 427-34.

4. Steffen R, Biertho L, Ricklin T et al. Laparoscopic Swedish adjustable gastric banding: a five-year prospective study. Obes Surg 2003; 13: 404-11. 
5. Sarker S, Myesr J, Serot J et al. Three-year follow-up weight loss results for patients undergoing laparoscopic adjustable gastric banding at a major university medical center: does the weight loss persist? Am J Surg 2006; 191: 372-6.

6. Parikh MS, Fielding GA, Ren CJ. U.S. experience with 749 laparoscopic adjustable gastric bands: intermediate outcomes. Surg Endosc 2005; 19:1631-5.

7. Mittermair RP, Weiss H, Nehoda H et al. Laparoscopic Swedish adjustable gastric banding: 6-year follow-up and comparison to other laparoscopic procedures. Obes Surg 2003; 13: 4127.

8. Ponce J, Paynter S, Fromm R. Laparoscopic adjustable gastric banding: 1014 consecutive cases. J Am Coll Surg 2005; 201: 529-35.

9. Hess DS, Hess DW. Biliopancreatic diversion with a duodenal switch. Obes Surg 1988; 8: $267-82$.

10. Marceau P, Hould FS, Simard S et al. Biliopancreatic diversion with duodenal switch. World J Surg 1998; 22: 947-54.

11. Johnston D, Dachtler J, Sue-Ling HM et al. The Magenstrasse and Mill operation for morbid obesity. Obes Surg 2003; 13: 10-6.

12. Langer FB, Bohdjalian A, Felderbauer FX et al. Does gastric dilatation limit the success of sleeve gastrectomy as a sole operation for morbid obesity? Obes Surg 2006; 16: 166-71.

13. Baltasar A, Serra C, Perez N et al. Laparoscopic sleeve gastrectomy: a multi-purpose bariatric operation. Surg 2005; 15: 1124-8.

14. Cummings DE. Ghrelin and the short- and long-term regulation of appetite and body weight. Physiol Behav 2006; 89: 71-84.

15. Langer FB, Reza Hoda MA; Bohdjalian A et al. Sleeve gastrectomy and gastric banding: effects on plasma ghrelin levels. Obes Surg 2005; 15: 1024-9.

16. Kotidis EV, Koliakos G, Papavramidis TS et al. The effect of biliopancreatic diversion with pyloruspreserving sleeve gastrectomy and duodenal switch on fasting serum ghrelin, leptin and adiponectin levels: is there a hormonal contribution to the weight-reducing effect of this procedure? Obes Surg 2006; 16: 554-9.

17. Bergmann JF, Chassany O, Petit A et al. Correlation between echographic gastric emptying and appetite: influence of psyllium. Gut 1992; 33: 1042-3.

18. Carmichael AR, Johnston D, Barker MC et al. Gastric emptying after a new, more physiological antiobesity operation: the Magenstrasse and Mill procedure. Eur J Nucl Med 2001; 28: 1379-83.

19. Lortat-Jacob JL, Robert F. Les malpositions cardiotubérositaires. Arch Mal App Dig 1953; 42: 750-74.

20. Dixon JB, O'Brien PE. Gastroesophageal reflux in obesity: the effect of Lap-band placement. Obes Surg 1999; 9: 527-31.

21. Gutschow $C A$, Collet $P$, Prenzel $K$ et al. Long-term results and gastroesophageal reflux in a series of laparoscopic adjustable gastric banding. J Gastrointest Surg 2005; 9: 941-8.

22. Westling $A$, Bjurling $K$, Ohrvall $M$ et al. Silicone adjustable gastric banding: disappointing results. Obes Surg 1998; 8: 467-74.

23. Mognol P, Chosidow D, Marmuse JP. Laparoscopic conversion of laparoscopic gastric banding to Rouxen- Y gastric bypass: a review of 70 patients. Obes Surg 2004; 14: 1349-53.

24. Kothari SN, DeMaria EJ, Sugerman HJ et al. Lapband failures: conversion to gastric bypass and their preliminary outcomes. Surgery 2002; 131: 625-9.

25. Van Wageningen B, Berends FJ, Van Ramshorst B et al. Revision of failed laparoscopic adjustable gastric banding to Roux-en-Y gastric bypass. Obes Surg 2006; 16: 137-41.

26. Felix EL, Swartz DE. Conversion of laparoscopic Roux-en- Y gastric bypass. Am J Surg 2003; 186: 64851.

27. Weber M, Muller MK, Michel JM et al. Laparoscopic Roux-en-Y gastric bypass, but not rebanding, should be proposed as rescue procedure for patients with failed laparoscopic gastric banding. Ann Surg 2003; 238: 827-34.

28. Mognol P, Chosidow D, Marmuse JP. Laparoscopic sleeve gastrectomy as an initial bariatric operation for high-risk patients: initial results in 10 patients. Obes Surg 2005; 15: 1030-3. 
29. Gagner $M$, Inabnet WB, Pomp A. Laparoscopic sleeve gastrectomy with second stage biliopancreatic diversion and duodenal switch in the superobese. In: Inabnet WB, DeMaria EJ, Ikramuddin S, eds. Laparoscopic Bariatric Surgery. Philadelphia: Lippincott William \& Wilkins. 2005: 143-50.

30. Almogy G, Crookes PF, Anthone GJ. Longitudinal gastrectomy as a treatment for the high-risk superobese patient. Obes Surg 2004; 14: 492-7.

31. Eisendrath P, Cremer M, Himpens J et al. Endotherapy for fistulae of the upper GI tract after laparoscopic bariatric surgery. Abstract, Belgian Week of Gastroenterology, February 9-11, 2006, Oostend, Belgium

\section{CHAPTER THREE AT A GLANCE}

\begin{tabular}{|c|c|c|}
\hline Mid-term ( 3 years) outcome of & LAGB versus & LSG \\
\hline EWL & $48 \%$ & $66 \%$ \\
\hline Complications (GERD) & $20.5 \%$ & $3.1 \%$ \\
\hline Conversions (weight issue/complication) & $\begin{array}{l}15 \% \\
\text { (LRYGB 10\%/ } \\
\text { removal 5\%) }\end{array}$ & $\begin{array}{l}7.5 \% \\
\text { (LDS 5\%/ } \\
\text { gastrectomy 2.5\%) }\end{array}$ \\
\hline Patient acceptance & NA & NA \\
\hline
\end{tabular}





\section{Chapter 4.}

\section{Long-term Outcomes of Laparoscopic Adjustable Gastric Banding}

Jacques Himpens, MD; Guy-Bernard Cadière, MD, PhD; Michel Bazi, MD; Michael Vouche, MD; Benjamin Cadière, MD; Giovanni Dapri, MD Department of Gastrointestinal and Obesity Surgery, European School of Laparoscopic Surgery,Saint-Pierre University Hospital, Brussels, Belgium

Archives of Surgery, Volume 146, Number 7, July 2011 


\subsection{ABSTRACT}

Objective: To determine the long-term efficacy and safety

of laparoscopic adjustable gastric banding (LAGB) for morbid obesity.

Design: Clinical assessment in the surgeon's office in 2009 (>12 years after LAGB).

Setting: University obesity center in Brussels, Belgium.

Patients: A total of 151 consecutive patients who had benefited from LAGB between January 1, 1994, and December 31, 1997, were contacted for evaluation.

Intervention: Laparoscopic adjustable gastric banding.

Main Outcome Measures: Mortality rate, number of major and minor complications, number of corrective operations, number of patients who experienced weight loss, evolution of comorbidities, patient satisfaction, and quality of life were evaluated.

Results: The median age of patients was 50 years (range, 28-73 years). The operative mortality rate was zero. Overall, the rate of follow-up was $54.3 \%$ (82 of 151 patients).

The long-term mortality rate from unrelated causes was 3.7\%. Twenty-two percent of patients experienced minor complications, and 39\% experienced major complications (28\% experienced band erosion). Seventeen percent of patients had their procedure switched to laparoscopic Roux-en-Y gastric bypass. Overall, the (intention- to-treat) mean (SD) excess weight loss was 42.8\% (33.92\%) (range, 24\%$143 \%)$. Thirty-six patients (51.4\%) still had their band, and their mean excess weight loss was $48 \%$ (range, 38\%-58\%). Overall, the satisfaction index was good for $60.3 \%$ of patients. The quality-of-life score (using the Bariatric Analysis and Reporting Outcome System) was neutral.

Conclusion: Based on a follow-up of $54.3 \%$ of patients, LAGB appears to result in a mean excess weight loss of $42.8 \%$ after 12 years or longer. Of 78 patients, 47 (60.3\%) were satisfied, and the quality-of-life index was neutral. However, because nearly 1 out of 3 patients experienced band erosion, and nearly $50 \%$ of the patients required removal of their bands (contributing to a reoperation rate of $60 \%$ ), LAGB appears to result in relatively poor long-term outcomes. 


\section{$4.2 \quad$ INTRODUCTION}

There is substantial evidence that surgery is the only valid treatment for morbid obesity. $^{1,2}$

In recent years, several techniques, many of them laparoscopic, have emerged.

Presently, the most commonly performed techniques are laparoscopic adjustable gastric banding (LAGB) and Roux-en-Y gastric bypass (RYGB), which is also typically performed laparoscopically. ${ }^{3-6}$

Our team performed the first laparoscopic adjustable band gastroplasty in October 1992. ${ }^{7}$ Use of this technique has since grown exponentially, first in Europe and Australia, ${ }^{8-10}$ and subsequently in other parts of the world, including the United States. In Europe, since 2004, we have observed an important shift in treatment awayfrom LAGB and in favor of the gastric bypass. ${ }^{11}$

In contrast, in the United States, an opposite trend has been noted, and in 2009, a greater number of adjustable band procedures were reported compared with gastric bypass procedures. Opponents of the adjustable band claim that this technique can result in a mediocre quality of life and a significant number of complications, and that there is a tendency for patients to regain weight after some years. ${ }^{12,13}$ The purpose of our study is to analyze the long-term ( $\geq 12$ years) effects of LAGB on patients in terms of weight loss, complications, reoperations, satisfaction, quality of life, as well as evolution of comorbidities and receipt of additional related treatments.

\subsection{METHODS}

\subsubsection{Study Design and Patients}

Between January 1, 1994, and December 31, 1997, our team treated 151 consecutive patients for morbid obesity by laparoscopic placement of a $9.75-\mathrm{cm}$ adjustable band (Lap-Band; Bio-Enterics Corp, Carpinteria, California). The decision to engage in bariatric surgery was made in accordance with the National Institutes of Health

guidelines. ${ }^{14}$ Part of this patient cohort was included in the LAGB prelaunch study by the US Food and Drug Administration. ${ }^{15}$ Data were gathered from hospital medical records, postoperative office visit findings, responses to a questionnaire that had been sent to every patient, telephone interviews, and in-office evaluations performed by the authors a few weeks before writing this study.

\subsubsection{Procedures and Measures}

The laparoscopic adjustable band procedure was performed with the so-called perigastric technique. This technique has been extensively described by us and by oth- 
ers. ${ }^{16,17}$ In brief, the patient was explored laparoscopically by means of 5 trocars. Using hook coagulation, we entered the plane between the first vessel and the gastric wall at the lesser curvature of the stomach'supper pole. With smooth dissection, a tunnel was developed posterior to the stomach by advancing a pair of blunt grasping forceps until the tip of the grasper emerged at the angle of His.Care was taken not to enter the lesser sac. Once the grasper tip had been freed at the angle of His, an adjustable band was introduced intraperitoneally after enlarging the left upper quadrant trocar opening. The band tubing was snapped by the grasper tip at the angle of His, and the band was looped around the upper part of the stomach, tightened, and locked. The band was stabilized by 4 sero-serosal stitches of nonresorbable suture material on each part of the band, which was placed to the left of the locking system. The tubing was exteriorized and fixed to the port, which was sutured in place on the anterior abdominal fascia at the level of the enlarged trocar opening in the left upper quadrant.

The band was left deflated for 4 weeks and subsequently gradually inflated under radioscopic control in the radiology suite, over the course of about 4 sessions. Restriction was judged to be sufficient when the patient experienced early satiety while there was still sufficient passage of dye, as evidenced upon barium swallow.

After optimal filling, the patients were seen in the surgeon's office every 3 to 6 months the first year and every 6 months thereafter. Variable outcome measurements included weight loss, the type and number of possible complications, treatment mode, number of reoperations, a satisfaction index (very dissatisfied, somewhat dissatisfied, neutral, pleased, or very pleased), and a quality-of-life score (based on the Bariatric Analysis and Reporting Outcome System). ${ }^{18}$ With the latter evaluation system, a score of up to 5 is given in 5 distinct categories: self-esteem, physical well-being, social life, capacity to work, and sexual health. Points were subtracted for complications and reoperations. Among the long-term complications reported, incisional hernia, port infection, and tubing disconnection were considered minor complications, whereas pouch dilatation, band slippage,band erosion, band intolerance, and infection of the band leading to removal were considered major complications. Band intolerance was defined as complete food intolerance, possibly with esophageal dilation but without objective dilation (from radiography) of the stomach proximal to the band during upper gastrointestinal transit. Pouch dilatation and band slippage were defined similarly, but with radiographdocumented dilation of the stomach proximal to the band.

The data on weight loss included the values documented in the patients' medical records, the values obtained by analysis of the questionnaire, and the values recorded at the final physical examination. In addition, at that time, patients were asked to give an estimate of their yearly weight loss values. The change in weight between 2 recorded values was considered to be linear. A diagnosis of band erosion was determined by the intraluminal appearance of at least part of the band at gas- 
troscopy. Gastroscopy was systematically performed for all patients experiencing discomfort or pain and/or weight gain, or if the fluid inside the band appeared turbid when the band was adjusted.

The evolution of comorbidities was evaluated by changes in treatment modalities, including antidiabetic oral agents, antihypertensive drugs, and continuous positive airway pressure.

\subsubsection{Statistical Analysis}

The McNemar test for paired variables was used for the statistical analysis of treatment evolution. The $t$ test for paired variables was used for analysis of the evolution of weight, body mass index (BMI; calculated as weight in kilograms divided by height in meters squared), and excess weight loss (EWL). Results are represented as mean values, standard deviation, and range or as median values with ranges. Statistical significance was reached at $P<.05$.

\subsection{RESULTS}

Of the 151 patients who had benefited from LAGB between January 1, 1994, and December 31, 1997, 82(54.3\%) were available for full evaluation as a result of a written or telephone reply to the questionnaire and/or an examination in the office by one of the surgeons at the end of 2009. There were 8 men and 74 women, with a mean (SD) age of 50 (0.95) years (range, 28-73 years).

The mean (SD) preoperative weight was 113.57 (18.17) kg (range, 86-180 kg), and the mean (SD) BMI was 41.57 (2.9) (range, 35-57). The operative mortality rate was zero.

The median postoperative follow-up period was 13 years. ${ }^{11-14}$ Three patients (3.7\%) died of causes unrelated to the LAGB: one died of melanoma, one died of lung cancer, and one committed suicide for financial reasons. Forty-eight patients (58.5\%) had minor and/or major complications.

\subsubsection{Minor Complications}

Of the 82 patients, $18(22.0 \%)$ had a total of 29 minor complications: 4 (4.9\%) presented with an incisional hernia, 16 (19.5\%) experienced 23 port-tubing disconnections, and 2 (2.4\%) developed isolated port infection.

\subsubsection{Major Complications}

Of the 82 patients, 32 (39.0\%) had a total of 33 major complications: 9 (11.0\%) had pouch dilatation, 6 of whom had their bands removed and 3 of whom had their 
band repositioned. Twenty-three patients (28.0\%) presented with band erosion, which was diagnosed after a mean (SD) time of 4 (2.9) years (range, 1-11 years).

Of these 23 patients, 17 had their bands removed, 2 had their bands repositioned, 2 were switched to laparoscopic Roux-en-Y gastric bypass (LRYGB), and 2 declined treatment. One patient (1.2\%) developed a band infection.

\subsubsection{Reoperations}

Of the 82 patients, 49 (59.8\%) underwent at least 1 reoperation, either for 1 or more complications or for weight issues (ie, a lack of weight loss or a regaining of weight). One patient (1.2\%) was treated surgically for incisional hernia, 10 patients (12.2\%) needed a total of 13 port-tubing reconnections, 2 patients (2.4\%) required port removal, and 1 patient (1.2\%) had her port replaced. Twelve patients (14.6\%) required band repositioning; the mean (SD) elapsed time between placement and repositioning of the band was 3.6 (3.18) years (range, 2 months to 6 years). Fortyone patients $(50.0 \%)$ needed band ablation for varying reasons: 17 (20.7\%) for band erosion, $5(6.1 \%)$ for pouch dilatation, 2 (2.4\%) for erosion together with pouch dilatation, $1(1.2 \%)$ for perforated bulbar ulcer, and $1(1.2 \%)$ for band infection early in the postoperative course; for 5 patients $(6.1 \%)$, the reason for band removal was unclear, and for 10 patients, the reason was weight gain. Fourteen of the 82 patients (17.1\%) were switched to LRYGB: 10 for weight issues and 4 for band erosion. Band removal and the switch to LRYGB were performed in 1 stage for 11 patients and in 2 stages for 3 patients. The median elapsed time between placement and removal of the band was 9 years. ${ }^{6-12,19}$ Of the 14 patients who switched to LRYGB, all were available for follow-up, and the median duration of follow- up was 5 years (range, 1-7 years). One (7.1\%) of these14 patients needed yet another laparoscopic reoperation with reconstruction of the gastrojejunal anastomosisfor stenosis, which had persisted despite 2 balloon dilatations.

\subsubsection{Weight Loss}

The evolution of the BMI of patients and the evolution of the EWL of patients are represented in Figure $1 A$ and $B$ and Figure $2 A$ and $B$, respectively.

Complete weight loss data after 12 years (as recorded in the surgeon's office) are available for 70 of 151 patients (46.4\%). Mean (SD) weight decreased from 113.57 (18.17) kg (range, 86-180 kg) to 92.82 (23.20) kg (range, 37-165 kg); mean (SD) BMI decreased from 41.57 (5.67) (range, 35-57) to 33.79 (7.52) (range, 16-53) (Figure 1). The mean (SD) percentage of EWL in this group of 70 patients was $42.8 \%$ (33.92\%) (range, 24\%-143\%) (Figure 2).

These latter numbers represent 22 patients who had their band removed without further surgical measures and who experienced EWL of 23\%, 12 patients who 
had an LRYGB after band removal and experienced EWL of $64 \%$, and 36 patients who still had their band in place and who experienced EWL of $48 \%$.

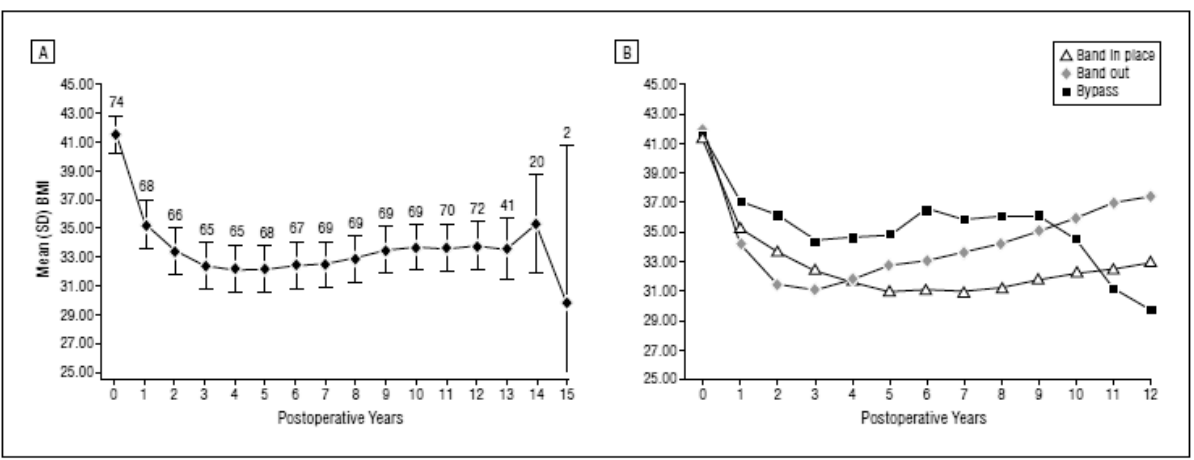

Figure 1.

A, Evolution of the mean (SD) body mass index (BMI; calculated as weight in kilograms divided by height in meters squared) for the entire (intention-to-treat) patient population per year after laparoscopic adjustable gastric banding. The number above each error bar represents the number of patients.

B, Evolution of the mean (SD) BMI per year after laparoscopic adjustable gastric banding for patients who still have their band (band in place), for patients who lost their band without any further measures (band out), and for patients whose band was removed and for whom a gastric bypass was performed (bypass).

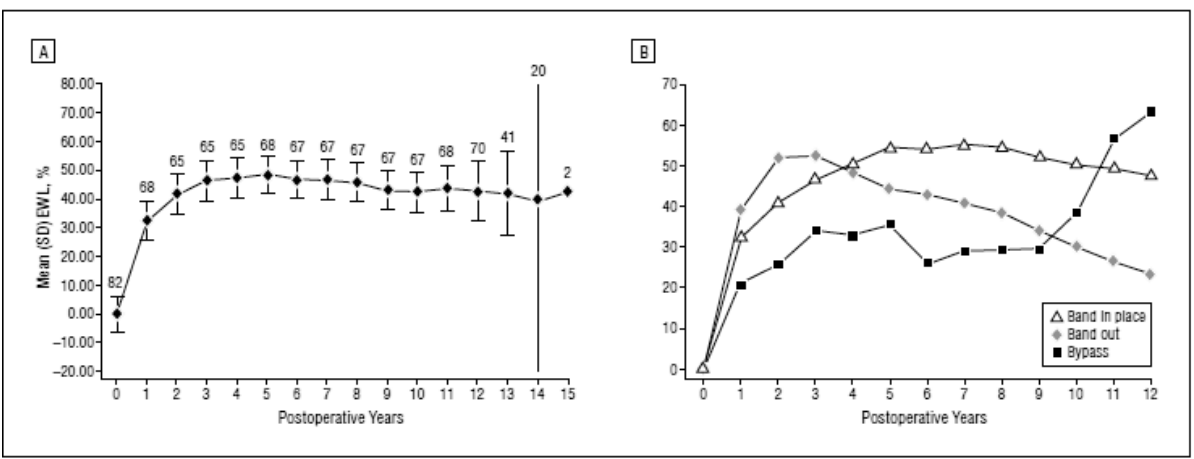

Figure 2.

A, Evolution of the mean (SD) percentage of excess weight loss (EWL) for the entire patient population per year after laparoscopic adjustable gastric banding. Note that, for 2 patients, some confusion exists as to their correct initial weight. Therefore, these patients were omitted in the EWL graph, but they were included in the BMI graphs because their present weight is obviously known. The number above each error bar represents the number of patients.

B, Evolution of the mean (SD) percentage of EWL per year after laparoscopic adjustable gastric banding for patients who still have their band (band in, for patients who losttheir band without any further measures (band out), and for patients whose band was removed and for whom a gastric bypass was performed (bypass). 


\subsubsection{Satisfaction Index and Quality of Life after 12 Years}

Of 78 patients, $47(60.3 \%)$ were either pleased or very pleased with their LAGB, 11 (14.1\%) were neutral, and 20 (25.6\%) were either dissatisfied or very dissatisfied.

\subsubsection{Evolution of Comorbidities}

Of 78 patients, 20 (25.6\%) were treated for arterial hypertension before band insertion, and 23 (29.5\%) were treated for arterial hypertension 12 years after their LAGB $(P=.72)$. Of 78 patients, $5(6.4 \%)$ had type 2 diabetes mellitus before band insertion, and $11(11.2 \%)$ had type 2 diabetes 12 years after their LAGB. Of 78 patients, 2 (2.6\%) needed continuous positive airway pressure for sleep apnea before gastroplasty, and $6(7.7 \%)$ needed continuous positive airway pressure for sleep apnea 12 years after gastroplasty.

Table. Data on Excess Weight Loss, Dilatation, and Erosion in Patients Who Underwent Laparoscopic Adjustable Gastric Banding

\begin{tabular}{|c|c|c|c|c|c|}
\hline \multirow[b]{2}{*}{ Study } & \multirow[b]{2}{*}{ Patients, No. } & \multirow{2}{*}{$\begin{array}{l}\text { Follow-up Period, } \\
\text { Median, y }\end{array}$} & \multicolumn{3}{|c|}{ Patients, \% } \\
\hline & & & Erosion & Dilatation & EWL \\
\hline Tolonen et al, ${ }^{25} 2008$ & 123 & 7 & 3.3 & 6.5 & 44 \\
\hline Martikainen et al, ${ }^{26} 2004$ & 123 & 5 & 9 & 21 & $21-36$ \\
\hline Weiner et al ${ }^{30} 2003$ & 100 & 8 & 0.3 & 4.5 & 54 \\
\hline Suter et al, ${ }^{27} 2006$ & 317 & 6 & 9.5 & 6.3 & 59 (at $5 y$ ) \\
\hline Belachew et al, ${ }^{31} 2002$ & 763 & 4 & 0.9 & 8 & $50-60$ \\
\hline Our study & 82 & 13 & 29.3 & 10.9 & 42 \\
\hline
\end{tabular}

Abbreviation: EWL, excess weight loss.

\subsection{COMMENT}

All 151 patients from the cohort were contacted by certified letter and by telephone. Only 82 responded. This low response rate after 12 years is rather deceiving and could be attributed to a general lack of compliance among this particular patient population. However, it could just as easily be caused by the suboptimal administrative organization in our department, in particular, and in the Belgian health care system, both of which appear to be less effective than the Australian system, for instance, for which extremely high follow-up rates are reported. ${ }^{20}$ Follow- up assiduity is a critical factor for success in bariatric procedures, in general, and in LAGB, in particular. ${ }^{21}$

In addition, LAGB patients lost to follow-up are likely to experience very little weight loss. ${ }^{22}$ Our results must be viewed from this perspective.

Another limitation of our study concerns the surgical technique. Indeed, there is some evidence to suggest that the more recent "pars flaccida" technique and the use of wider, softer bands provide better overall results than the "perigastric" tech- 
nique that we used at the time, especially concerning the erosion rate and the incidences of band slippage and pouch dilatation. ${ }^{23}$

Last but not least, one could object that our results reflect a learning curve among surgeons. However, as mentioned earlier, our department started performing LAGB more than 14 months before the time of the onset of this study and had performed some 50 LAGB procedures at that time. It is generally accepted that the learning curve for an advanced laparoscopic procedure affects some 35 cases. $^{24}$

Despite the aforementioned criticizable aspects of our study, we still think that our results elucidate the long-term outcomes of LAGB. To our knowledge, this is the first study on the outcomes of this procedure after more than 10 years. Our response rate and results actually match those of earlier studies available in the literature. $^{25-27}$ Moreover, because the perigastric technique has been used by a great number of surgical teams in a substantial number of patients everywhere in the world, the outcome concerns several thousands of patients. Furthermore, other prolific authors ${ }^{28}$ were not able to detect a significant difference in the (excellent) results between the perigastric and pars flaccida techniques and are therefore still performing the former.

In our study, 48 patients had complications; however, only 14 of these patients experienced port-tubing disconnection, a minor complication that has become much less frequent with use of the newer band systems. ${ }^{29}$

Of 82 patients available for follow-up, 9 (10.9\%) experienced pouch dilatation. In the literature, long-term results range from $4.5 \%$ to $21 \%$ of patients experiencing pouch dilatation. ${ }^{25-27,30,31}$ Although the perigastric technique might again be a contributing factor, it is noteworthy that many dilatations appeared quite late (mean time, 3.6 years; median time, 2 years) after insertion, which seems to imply other factors. Other possible causes are overinflation of the band ${ }^{32}$ or lack of compliance on the patient's part, ${ }^{33}$ but the natural evolution of a hollow viscus proximal to a stenotic factor cannot be ruled out either. ${ }^{34}$

Twenty-three patients (28.0\%) experienced band erosion which was diagnosed after a median of 4 years. Theoretically, it is not surprising that a rigid structure placed

around a hollow organ would erode in the lumen of the latter, as experienced earlier with the Angelchik prosthesis. ${ }^{35}$ Nevertheless, our numbers are significantly higher than those in the literature. ${ }^{25-27,30,31}$ The culprit here again could be the perigastric technique, with which substantially less tissue is left between the prosthesis and the stomach wall than is left when the pars flaccida technique is used. In contrast, the higher incidence that we found might at least partly be explained by our policy of performing gastroscopy systematically in all patients presenting with weight regain at some point after gastroplasty, even in the absence of other symptoms. This policy might differ from others with a higher threshold for performing endoscopy and consequently a lower detection rate for silent erosion. 
Close to $50 \%$ of the patients lost their band within about 9 years. A substantial number of these patients benefited from LRYGB later on. The morbidity rate due to this switch to LRYGB was relatively low (7\%), and the percentage of EWL was $64 \%$, which compares favorably with the $48 \%$ observed when the band was still in place. This demonstrates the efficiency of the gastric bypass in patients who failed to achieve weight loss after receiving the gastric band.

Global excess weight loss was less than $50 \%$. This relatively low figure might explain the lack of efficacy of the procedure in curing comorbidities among our patients. However, the evolution of these comorbidities must be weighed against their natural evolution during a similar time frame in a non-surgical population.

Of 78 patients, $47(60.3 \%)$ were pleased or very pleased (ie, the satisfaction index) with their LAGB, which is somewhat surprising considering the high number of reoperations and the relatively modest weight loss. The objective final quality-of-life score was 3 , which corresponds to that observed in a normal, non-surgical population. This can be considered a good result because points had been subtracted for complications and reoperations, which were frequent. Both these indices confirm and explain the fact that the public has not rejected the "lap-band" procedure, unlike many of the surgeons in Europe.

To conclude, based on an intention-to-treat evaluation, but with a follow-up of only approximately half of the patients, laparoscopic placement of a $9.75-\mathrm{cm}$ adjustable band (ie, LAGB) appears to induce an excess weight loss of $42.8 \%$ after 12 years. Still, $60.3 \%$ of the patients were satisfied, and the quality-of-life index was comparable to the non-surgical average. However, almost 1 out of 3 patients experienced band erosion, and there was no beneficial influence on comorbidities. Fourteen of 82 patients (17.1\%) were switched to laparoscopic gastric bypass, with good results.

The high failure rate of LAGB, at least in our hands, could be detrimental to its future continued widespread use as a restrictive weight loss operation.

\subsection{REFERENCES}

1. Fobi MAL. Surgical treatment of obesity: a review. J Natl Med Assoc. 2004;96(1): 61-75.

2. Torgerson JS, Sjöström L. The Swedish Obese Subjects (SOS) study: rationale and results. Int J Obes Relat Metab Disord. 2001;25 (suppl 1):S2-S4.

3. Buchwald $\mathrm{H}$, Avidor $\mathrm{Y}$, Braunwald $\mathrm{E}$, et al. Bariatric surgery: a systematic review and meta-analysis. JAMA. 2004;292(14):1724-1737.

4. Colquitt J, Clegg A, Loveman E, et al. Surgery for morbid obesity. Cochrane Database Syst Rev. 2005;(4):CD003641.

5. Tice JA, Karliner L, Walsh J, et al. Gastric banding or bypass? a systematic review comparing the two most popular bariatric procedures. Am J Med. 2008;121(10):885-893.

6. Morino M, Toppino M, Garrone C, Morino F. Laparoscopic adjustable silicone gastric banding for the treatment of morbid obesity. Br J Surg. 1994;81(8): 1169-1170. 
7. Cadière GB, Bruyns J, Himpens J, Favretti F. Laparoscopic gastroplasty for morbid obesity. Br J Surg. 1994;81(10):1524.

8. de Wit LT, Mathus-Vliegen L, Hey C,et al. Open versus laparoscopic adjustable silicone gastric banding: a prospective randomized trial for treatment of morbid obesity. Ann Surg. 1999;230(6):800-807.

9. Chapman $A E$, Kiroff $G$, Game $P$, et al. Laparoscopic adjustable gastric banding in the treatment of obesity: a systematic literature review. Surgery. 2004;135(3):326-351.

10. Luja'n JA, Frutos MD, Hernandez $Q$, et al. Laparoscopic versus open gastric bypass in the treatment of morbid obesity: a randomized prospective study. Ann Surg. 2004;239(4):433-437.

11. Topart P, Becouarn G, Ritz P. One-year weight loss after primary or revisional Roux-en-Y gastric bypass for failed adjustable gastric banding. Surg Obes RelatDis. 2009;5(4):459-462.

12. Mognol P, Chosidow D, Marmuse JP. Laparoscopic gastric bypass versus laparoscopic adjustable gastric banding in the super-obese: a comparative study of 290 patients. Obes Surg. 2005;15(1):7681.

13. Smoot TM, Xu P, Hilsenrath P, et al. Gastric bypass surgery in the United States, 1998-2002. Am J Public Health. 2006;96(7):1187-1189.

14. Gastrointestinal surgery for severe obesity: Proceedings of a National Institutes of Health Consensus Development Conference: March 25-27, 1991, Bethesda, MD. Am J Clin Nutr. 1992;55(2 suppl):487S$619 S$.

15. US Dept of Health and Human Services. US Food and Drug Administration (FDA).Medical Devices. Lap-Band Adjustable Gastric Banding (LAGB) System: P000008. FDA Web site. http://www.fda.gov/MedicalDevices/ProductsandMedicalProcedures/DeviceApprovalsandClearances/ Recently-ApprovedDevices/ucm088965.htm. Accessed February 7, 2011.

16. Favretti F, Cadière GB, Segato G, Himpens J, De Luca M, Busetto L, De Marchi F, Foletto M, Caniato D, Lise M, Enzi G. Laparoscopic banding: selection and technique in 830 patients. Obes Surg. 2002;12(3):385-390.

17. Thornton CM, Rozen WM, So $\mathrm{D}$, et al. Reducing band slippage in laparoscopic adjustable gastric banding: the mesh plication pars flaccida technique. Obes Surg. 2009;19(12):1702-1706.

18. Oria HE, Moorehead MK. Bariatric Analysis and Reporting Outcome System (BAROS). Obes Surg. 1998;8(5):487-499.

19. Hinojosa MW, Varela JE, Parikh D, et al. National trends in use and outcome of laparoscopic adjustable gastric banding. Surg ObesRelat Dis. 2009;5(2):150-155.

20. Burton PR, Brown WA, Laurie C, et al. Criteria for assessing esophageal motility in laparoscopic adjustable gastric band patients: the importance of the lower esophageal contractile segment. Obes Surg. 2010;20(3):316-325.

21. Busetto L, Segato G, De Marchi F, et al. Postoperative management of laparoscopic gastric banding. Obes Surg. 2003;13(1):121-127.

22. te Riele WW, Boerma D, Wiezer MJ, et al. Long-term results of laparoscopic adjustable gastric banding in patients lost to follow-up. Br J Surg. 2010;97(10):1535-1540.

23. O'Brien PE, Dixon JB, Laurie C, Anderson M. A prospective randomized trial of placement of the laparoscopic adjustable gastric band: comparison of the perigastric and pars flaccida pathways. Obes Surg. 2005;15(6):820-826.

24. Oomen MW, Hoekstra LT, Bakx R, Heij HA. Learning curves for pediatric laparoscopy: how many operations are enough? the Amsterdam experience with laparoscopic pyloromyotomy. Surg Endosc. 2010;24(8):1829-1833.

25. Tolonen $\mathrm{P}$, Victorzon M, Mäkelä J. 11-year experience with laparoscopic adjustable gastric banding for morbid obesity: what happened to the first 123 patients? Obes Surg. 2008;18(3):251-255.

26. Martikainen T, Pirinen E, Alhava E, et al. Long-term results, late complications and quality of life in a series of adjustable gastric banding. Obes Surg. 2004;14(5):648-654.

27. Suter M, Calmes JM, Paroz A, Giusti V. A 10-year experience with laparoscopic gastric banding for morbid obesity: high long-term complication and failure rates. Obes Surg. 2006;16(7):829-835. 
28. Favretti F, Segato G, Ashton D, et al. Laparoscopic adjustable gastric banding in 1,791 consecutive obese patients: 12-year results. Obes Surg. 2007;17(2): 168-175.

29. Zieren J, Menenakos C, Paul M, Müller JM. Prevention of catheter disconnection after laparoscopic adjustable gastric banding. J Laparoendosc Adv Surg Tech. 2004;14(2):77-79.

30. Weiner R, Blanco-Engert R, Weiner S, et al. Outcome after laparoscopic adjustable gastric banding: 8 years experience. Obes Surg. 2003;13(3):427-434.

31. Belachew $\mathrm{M}$, Belva $\mathrm{PH}$, Desaive $\mathrm{C}$. Long-term results of laparoscopic adjustable gastric banding for the treatment of morbid obesity. Obes Surg. 2002;12(4): 564-568.

32. Blachar A, Blank A, Gavert N, et al. Laparoscopic adjustable gastric banding surgery for morbid obesity: imaging of normal anatomic features and postoperative gastrointestinal complications. $A m \mathrm{~J}$ Roentgenol. 2007;188(2):472-479.

33. Poole N, Al Atar A, Bidlake L, et al. Pouch dilatation following laparoscopic adjustable gastric banding: psychobehavioral factors (can psychiatrists predict pouch dilatation?). Obes Surg. 2004;14(6):798-801.

34. Sherwinter DA, Gupta A, Cummings LS, et al. Experimental in vivo canine model for gastric prolapse of laparoscopic adjustable gastric band system. Surg Obes Relat Dis. 2010;6(1):68-71.

35. Purkiss SF, Argano VA, Kuo J, Lewis CT. Oesophageal erosion of an Angelchik prosthesis: surgical management using fundoplication. Eur J Cardiothorac Surg. 1992;6(9):517-518.

\section{CHAPTER FOUR AT A GLANCE}

\begin{tabular}{|ll}
\hline Long-term (12 years) outcomes of LAGB \\
-EWL: & $48 \%$ (band in place) \\
-Complications & $28 \%$ erosions \\
& $11 \%$ pouch dilation \\
-Conversions & $17 \%$ conversions to LRYGB \\
& $15 \%$ band repositioning \\
& $50 \%$ band removal \\
-Patient acceptance: & satisfaction index $60.3 \%$ \\
& BAROS 3.0
\end{tabular}




\section{Chapter 5.}

\section{Long-term Results of Laparoscopic Sleeve Gastrectomy for Obesity}

Jacques Himpens, MD, Julie Dobbeleir, MD, and Geert Peeters, MD

Division of Bariatric Surgery, AZ St-Blasius, Dendermonde, Belgium.

Annals of Surgery, Volume 252, Number 2, August 2010 


\subsection{ABSTRACT}

Objective: To determine the mid- and long-term efficacy and possible side effects of laparoscopic sleeve gastrectomy as treatment for morbid obesity.

Summary Background Data: Laparoscopic sleeve gastrectomy is still controversial as single and final treatment for morbid obesity. Some favorable short-term results have been published, however long-term results are still lacking.

Methods: In the period between November 2001 and October 2002, 53 consecutive morbidly obese patients who, according to our personal algorithm, were qualified for restrictive surgery were selected for laparoscopic sleeve gastrectomy. Of the 53 patients, 11 received an additional malabsorptive procedure at a later stage because of weight regain. The percentage of excess weight loss (EWL) was assessed at 3 and 6 years postoperatively. A retrospective review of a prospectively collected database was performed for evaluation after 3 years. Recently, after the sixth postoperative year, patients were again contacted and invited to fill out a questionnaire.

Results: Full cooperation was obtained in 41 patients, a response rate of $78 \%$. Although after 3 years a mean EWL of $72.8 \%$ was documented, after 6 years EWL had dropped to $57.3 \%$, which according to the Reinhold criteria is still satisfactory. These results included 11 patients who had benefited from an additional malabsorptive procedure (duodenal switch) and 2 patients who underwent a "resleeve" between the third and sixth postoperative year.

Analyzing the results of the subgroup of 30 patients receiving only sleeve gastrectomy, we found a 3 -year \%EWL of $77.5 \%$ and $6+$ year $\% \mathrm{EWL}$ of $53.3 \%$. The differences between the third and sixth postoperative year were statistically significant in both groups. Concerning long-term quality of life patient acceptance stayed good after $6+$ years despite the fact that late, new gastro-esophageal reflux complaints appeared in $21 \%$ of patients.

Conclusions: In this long-term report of laparoscopic sleeve gastrectomy, it appears that after $6+$ years the mean excess weight loss exceeds $50 \%$.

However, weight regain and de novo gastroesophageal reflux symptoms appear between the third and the sixth postoperative year. This unfavorable evolution might have been prevented in some patients by continued follow-up office visits beyond the third year. Patient acceptance remains good after $6+$ years. 


\subsection{INTRODUCTION}

Surgical treatment for morbid obesity has witnessed a significant evolution since the advent of laparoscopy. Numerous operations with a plethora of variations are presently advocated as method of choice to treat morbid obesity.

Laparoscopic sleeve gastrectomy (LSG) was originally intended as bridging procedure for super obese patients awaiting definitive bariatric intervention. Recently, after early promising results, sleeve gastrectomy was proposed as potential single and final treatment for morbid obesity by several authors. ${ }^{1-3}$

To our knowledge, long-term efficacy of the LSG procedure as intended final treatment for morbid obesity has not yet been demonstrated.

We present the $6+$ years results after LSG.

\subsection{METHODS}

\subsubsection{Study Design and Patients}

A total of 53 consecutive patients selected for restrictive surgery underwent LSG as treatment for morbid obesity in the period between November 2001 and October 2002. Inclusion criteria for bariatric surgery followed $1991 \mathrm{NIH}$ guidelines; the choice of a restrictive procedure was based on our personal algorithm ${ }^{4,5}$. Some individuals in our series had dropped under the limit of 35 body mass index (BMI) at the time of surgery as a result of a strenuous fat-free and carbohydrate poor diet in view of the operation. ${ }^{4}$ All patients had been evaluated by a multidisciplinary team. Sleeve gastrectomy had been chosen amid an array of laparoscopic weight loss operations offered at our department (LSG, adjustable band, Roux-en-Y gastric bypass, biliopancreatic derivation by duodenal switch (DS) or according to Scopinaro). Choice was based on our empirically established algorithm. ${ }^{5}$ In brief, all patients who were thought to be volume eaters and who were not diabetic nor subject to significant gastroesophageal reflux disease (GERD), benefited from LSG intended as final treatment. (At the time adjustable band gastroplasty was still performed for the same indication, but only as part of a specific study, unrelated to the present one. Therefore, this study does represent consecutive patients with no other form of selection.)

Patients were followed up postoperatively in the office on a regular basis until 3 years after operation. The patients were again contacted by telephone after the sixth postoperative year and were invited to fill out a questionnaire. 


\subsubsection{Procedures and Measures}

LSG was performed following the technique described earlier using systematically a $34 \mathrm{Fr}$ bougie ${ }^{6}$. With this technique, the antrum was spared, starting the gastric resection about $6 \mathrm{~cm}$ proximal to the pylorus.

This study was carried out in an effort to evaluate quality of life (QOL) and possible side effects as well as efficacy for weight loss at least 6 years after LSG.

QOL was evaluated using the Bariatric Analysis and Reporting Outcome System (BAROS) score. The BAROS evaluates the results of obesity treatments by analyzing 3 psychomedical aspects: weight loss, changes in comorbidities, and QOL. Up to 3 points are allowed for each category, points are deducted for complications and reoperations. ${ }^{7}$ The QOL evaluation included symptoms of GERD as well. GERD was considered significant when the patient mentioned regular use of prescriptionproton pump inhibiting agents.

Weight assessment that had been recorded after 3 years was now re-evaluated after $6+$ years. Weight loss was registered as change in BMI and \% excess weight loss (EWL).

Data were analyzed using MedCalc statistical software. Comparison of means from continuous variables was performed using paired 2-tailed Student $t$ test. Results are represented as mean \pm standard deviation (SD), $\pm 95 \%$ confidence interval. Statistical significance was defined as $P<0.05$.

\section{$5.4 \quad$ RESULTS}

\subsubsection{Patient Characteristics}

A total of 53 consecutive patients who were qualified for restrictive surgery, according to our personal algorithm we used at that time, underwent LSG for weight reduction in the period between November 2001 and October 2002. All relevant data, gathered from the responses to the questionnaire, were collected by one of the authors (J.D.) between December 2008 and January 2009. Full evaluation was possible in 41 patients (30 women and 11 men, 3/1 ratio), meaning a follow-up at $6+$ years in $78 \%$ of the patients. Four patients ( 3 women and 1 man) refused to cooperate, 8 patients could not be traced. All 12 patients who could not be evaluated were included in the data in an effort to provide intention-to-treat results.

Median age at surgery was 44 years (range, 28-71; SD, 11.0). Median preoperative BMI was $39.0 \mathrm{~kg} / \mathrm{m}^{2}$ (range, 31-57; SD, 5.4). Five patients suffered from arterial hypertension, 1 patient was diabetic type II. One patient had mentioned preoperative GERD symptoms.

Of the 41 patients, 11 underwent completion of a DS procedure because of weight regain some time between the third and sixth postoperative year. These 
latter patients were included in the study according to the intention-to-treat regimen.

Two other patients needed a re-sleeve operation because of weight regain combined with pouch dilatation as demonstrated on upper gastrointestinal (GI) series, and were included as well (intention-to-treat).

Data were analyzed in the over all patient groups, thus including patients with completion of DS and re-sleeve and of patients who were treated by LSG alone.

Table 1. Difference Between Mid- and Long-Term Effect of LSG on \%EWL and BMI

\begin{tabular}{|c|c|c|c|c|}
\hline & $0 \mathrm{yr}$ & $3 \mathrm{yr}$ & $6 \mathrm{yr}$ & $\mathbf{P}$ \\
\hline \multicolumn{5}{|l|}{ Stand alone LSG $(n=30)$} \\
\hline Mean BMI $( \pm S D)$ & $39.9( \pm 5.9)$ & $26.6( \pm 4.3)$ & $31.1( \pm 6.2)$ & $0.0001^{*}$ \\
\hline $95 \% \mathrm{CI}$ & $37.7-42.1$ & $25.0-28.2$ & $28.8-33.4$ & \\
\hline Mean \% EWL $( \pm S D)$ & & $77.5 \%( \pm 19.8)$ & $53.3 \%( \pm 28.3)$ & $<0.0001^{*}$ \\
\hline $95 \% \mathrm{Cl}$ & & $70.1-84.9$ & $42.7-63.9$ & \\
\hline \multicolumn{5}{|c|}{ LSG + duodenal switch $(\mathrm{n}=11)$} \\
\hline Mean BMI $( \pm S D)$ & $38.4( \pm 4.0)$ & $29.3( \pm 6.4)$ & $26.7( \pm 6.2)$ & $0.3490^{*}$ \\
\hline $95 \% \mathrm{Cl}$ & $35.7-41.1$ & $24.9-33.6$ & $21.9-31.5$ & \\
\hline Mean \% EWL $( \pm S D)$ & & $59.9 \%( \pm 34.9)$ & $70.8 \%( \pm 29.5)$ & $0.5680^{*}$ \\
\hline $95 \% \mathrm{Cl}$ & & $63.4-83.4$ & $48.1-93.4$ & \\
\hline \multicolumn{5}{|c|}{ Stand alone LSG and LSG + duodenal switch $(n=41)$} \\
\hline Mean BMI $( \pm S D)$ & $39.5( \pm 5.5)$ & $27.3( \pm 5.0)$ & $30.1( \pm 6.5)$ & $0.0050^{*}$ \\
\hline $95 \% \mathrm{CI}$ & $37.7-41.2$ & $25.7-28.9$ & $27.9-32.2$ & \\
\hline Mean \% EWL $( \pm S D)$ & & $72.8 \%( \pm 25.6)$ & $57.3 \%( \pm 29.1)$ & $0.0017^{*}$ \\
\hline $95 \% \mathrm{Cl}$ & & $64.7-80.9$ & $47.9-66.8$ & \\
\hline
\end{tabular}

*Comparison of means using paired 2-tailed student $t$ test.

LSG indicates laparoscopic sleeve gastrectomy; EWL, excessive weight loss; BMI, body mass index; SD standard deviation; Cl, confidence interval.

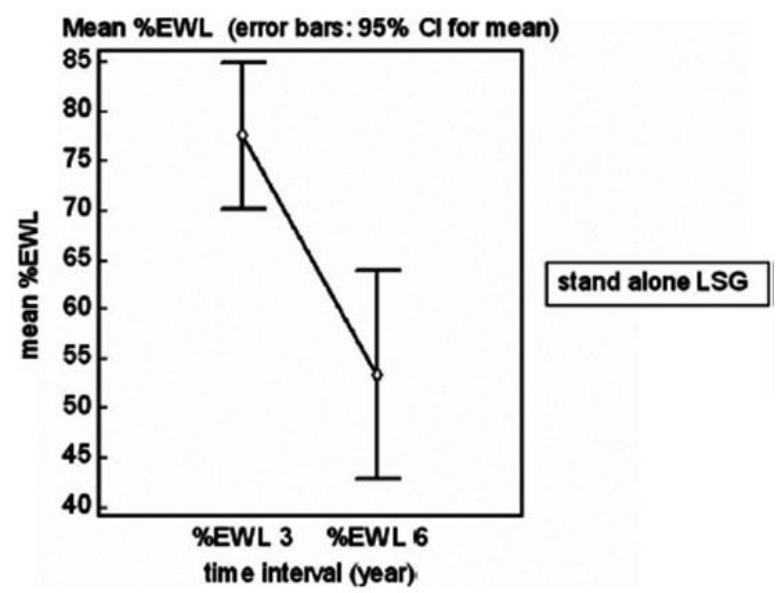

Figure 1. Difference in mean \%EWL between 3 and 6 years postoperatively for stand-alone sleeve gastrectomy. 


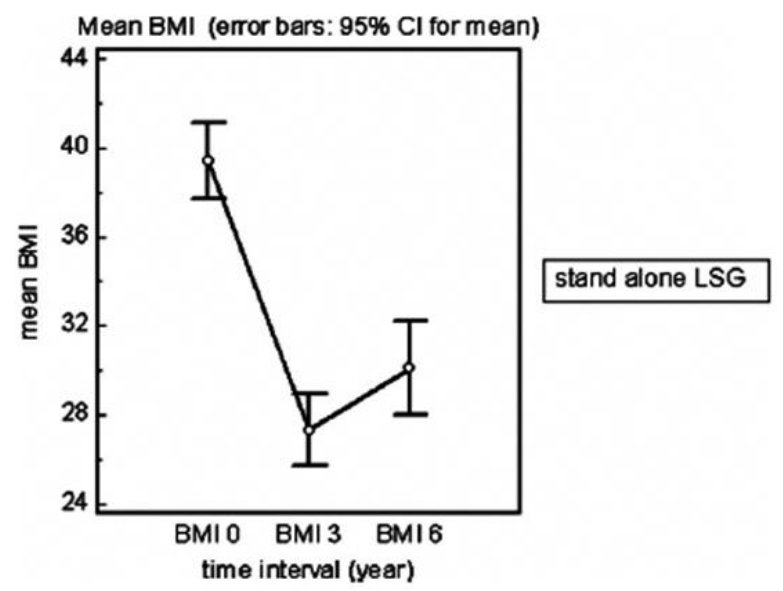

Figure 2. Difference in mean BMI between 3 and 6 years postoperatively for stand-alone sleeve gastrectomy.

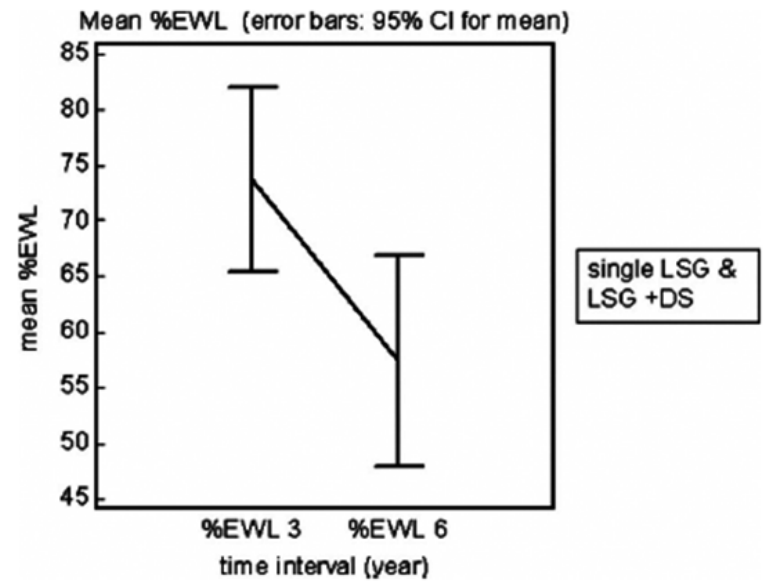

Figure 3. Difference in mean \%EWL between 3 and 6 years postoperatively for over all population (stand-alone LSG and LSG + DS). 


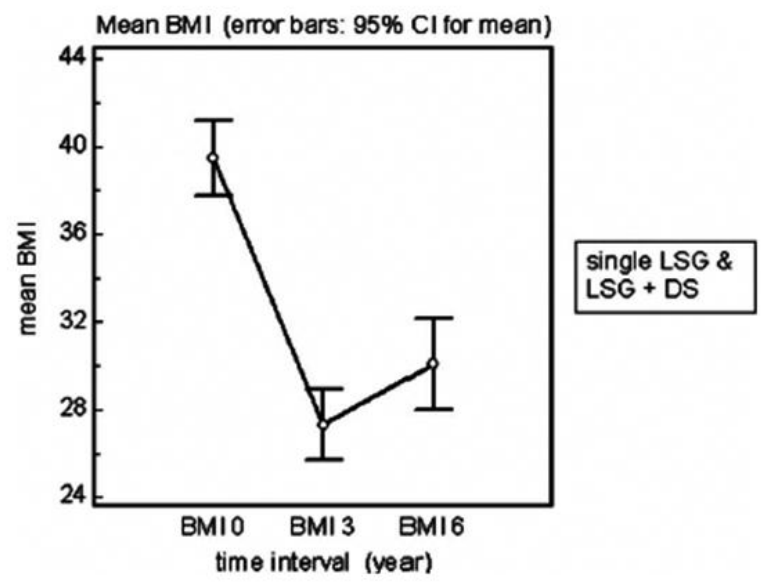

Figure 4. Difference in mean BMI between 3 and 6 years postoperatively for over all population (stand-alone LSG and LSG + DS).

\subsubsection{Efficacy}

At 3 years postoperatively, an over all mean EWL of $72.8 \%$ had been recorded in our series (Table 1, Fig. 3). After the sixth postoperative year weight regain was observed in 31 cases (75.6\%), resulting in a residual over all mean EWL of 57.3\% (Table 1, Figs.1-4). The difference in weight loss, expressed as EWL, between the third and sixth postoperative year was statistically significant for the entire group as well as for the subgroup of patients where LSG was the sole procedure (Table 1).

Median BAROS quality of life score after 6+ years was 5(range, -2-9; SD, 2.7; 95\% confidence interval, 4-6).

One patient suffering from diabetes type II had resolution of the disease. Of 5 patients, 2 with arterial hypertension became and stayed normotensive.

Of 53 patients, 23 (43.4\%) either were lost for follow-up or refused to respond to our questionnaire $(n=12$ ) or needed another procedure, and should be considered dissatisfied with the sleeve gastrectomy procedure. These 23 patients combined with those who did not reach $50 \%$ excess weight loss, according to Reinhold criteria, were considered objective failures. ${ }^{8}$ At 3 years, an objective failure rate of $47 \%$ was noted, which reached up to $64 \%$ after the sixth postoperative year (Tables 2, 3). 
Table 2. Objective Success After 3 yr, Intention-to-Treat After Stand-Alone Sleeve Gastrectomy.

\begin{tabular}{|l|l|l|}
\hline & SuccesS & Failure \\
\hline $\begin{array}{l}\text { Evaluated } \\
\text { patients:n=41 }\end{array}$ & $\begin{array}{l}\text { LSG:>50\%EWL } \\
n=28\end{array}$ & $\begin{array}{l}\text { LSG:<50\%EWL } n=2 \\
\text { LSG+DS: EWL } 50 \% \\
n=11\end{array}$ \\
\hline $\begin{array}{l}\text { No evaluation } \\
\text { possible: } n=12\end{array}$ & & $\begin{array}{l}\text { Lost for follow-up: } n=4 \\
\text { No cooperation: } n=8\end{array}$ \\
\hline $\begin{array}{l}\text { Total } \\
n=53\end{array}$ & $25 / 53=53 \%$ & $25=47 \%$ \\
\hline
\end{tabular}

LSG indicates laparoscopic sleeve gastrectomy; EWL, excessive weight loss; DS, duodenal switch

Table 3. Objective Success After 6 yr, Intention-to-Treat After Stand-Alone Sleeve Gastrectomy.

\begin{tabular}{|l|l|l|}
\hline & SuccesS & Failure \\
\hline $\begin{array}{l}\text { Evaluated } \\
\text { patients:n=41 }\end{array}$ & $\begin{array}{l}\text { LSG:>50\%EWL } \\
n=19\end{array}$ & $\begin{array}{l}\text { LSG:<50\%EWL } n=11 \\
\text { LSG+DS: EWL } 50 \% \\
n=11\end{array}$ \\
\hline $\begin{array}{l}\text { No evaluation } \\
\text { possible: } n=12\end{array}$ & & $\begin{array}{l}\text { Lost for follow-up: } n=4 \\
\text { No cooperation: } n=8\end{array}$ \\
\hline $\begin{array}{l}\text { Total } \\
n=53\end{array}$ & $19 / 53=36 \%$ & $34 / 53=64 \%$ \\
\hline
\end{tabular}

LSG indicates laparoscopic sleeve gastrectomy; EWL, excessive weight loss; DS, duodenal switch

\subsubsection{Postoperative Morbidity}

Major morbidity, meaning leakage, stenosis, bleeding, or incisional hernia occurred in $12.2 \%$ of all patients (Table 4). There were no surgery-related deaths. One patient died of colon cancer 4 years after LSG. Gastroesophageal complaints were reported after 6 +years (Table 5). About $18 \%$ of patients in the stand-alone LSG group and $21 \%$ of patients in the over-all group mentioned occasional vomiting, and respectively $23 \%$ to $26 \%$ of patients reported frequent episodes of GERD.

Table 4. Major Complications Related to Sleeve Gastrectomy.

\begin{tabular}{lc}
\hline Complication & Patients (\%) \\
\hline Leak & $2 / 41(4.9 \%)$ \\
Stenosis & $1 / 41(2.4 \%)$ \\
Bleeding & $1 / 41(2.4 \%)$ \\
Incisional hernia & $1 / 41(2.4 \%)$ \\
\hline
\end{tabular}


Table 5. Gastro-esophageal Complaints at 6 yr Postoperatively.

\begin{tabular}{lcc}
\hline & Preoperative & Postoperative \\
\hline Stand alone sleeve gastrectomy & & \\
$\quad$ Gastroesophageal reflux & $3.3 \%$ & $23 \%$ \\
$\quad$ Vomiting & $0 \%$ & $18 \%$ \\
Stand alone sleeve gastrectomy and sleeve & & \\
$\quad$ gastrectomy + duodenal switch & $0 \%$ & $26 \%$ \\
$\quad$ Gastroesophageal reflux & $0 \%$ & $21 \%$ \\
$\quad$ Vomiting & & \\
\hline
\end{tabular}

\subsection{DISCUSSION}

Our patient group is representative for the average bariatric population in Belgium in 2001 to $2002 .^{9}$ Patients were selected according to the $1991 \mathrm{NIH}$ guidelines.

Weight assessment was made after 3 and 6 years after sleeve gastrectomy. Data after the sixth postoperative year were derived from a telephone questionnaire. Telephone surveys are generally considered biased in the sense that patients tend to underestimate their weight. One should therefore be aware that the actual final BMI could be even higher than the ones we worked with in our database, meaning that true late weight regain could be even more pronounced.

Between 2001 and 2002, the only available long-term data about this type of restrictive procedure came from Johnston et al and concerned the Magenstrasse and Mill, an open "sleeve-like" procedure. ${ }^{10}$ Since then, as far as we know, no longterm results of the currently performed LSG operation have yet been reported. Some reports with medium-term follow-up, including ours, showed a promising $\%$ EWL after 1 and 2 years. Ranges of respectively $\pm 62 \%$ and $\pm 72 \%$ have been reported. ${ }^{1-3,6}$

According to the present study, the mean long-term EWL at 6+years after LSG remains above $50 \%$ both in the pure LSG as the LSG + DS group. Considering the Reinhold criteria, these results are considered satisfactory. ${ }^{8}$ However, despite this acceptable final result, our series did show significant weight regain between the third and the sixth postoperative year.

In fact, although the number of our patient cohort is rather small, difference in $\%$ EWL after 3 and 6 years appears to be statistically highly significant. Moreover, weight regain is probably even higher than our results indicate. Indeed, 11 of our patients (26\%) did benefit from a complementary DS procedure between the fourth and sixth postoperative year, and hence no longer presented LSG as stand-alone procedure. In accordance with the intention-to-treat principle, these patients were included in the $6+$ year results, which avoided selecting out the patients with favor- 
able results (the ones who did not need an additional weight loss procedure). However, even in the latter subgroup with favorable results, the difference in EWL at 3 and $6+$ years still reached statistical significance.

Of 53 patients, 23 either were lost for follow-up or refused to respond to our questionnaire $(n=12)$ or needed another procedure $(n=11)$. This means that $43.4 \%$ of our patients were not satisfied with the procedure of simple sleeve gastrectomy. Objective failure rates at 3 and $6+$ years were $47 \%$ and $64 \%$, respectively (Tables 2 , 3 ). These results should be compared with the numbers after other bariatric procedures as gastric bypass, vertical banded gastroplasty, or gastric banding.

Thus, LSG appears to be subjected to weight regain after more than 3 years. This is similar to what has been reported earlier in other purely restrictive bariatric surgical procedures. ${ }^{11-15}$ Recently, Scozzari et al reported excess weight loss after adjustable gastric banding of $42 \%$ at 3 years, $33 \%$ at 5 years, and $30 \%$ at 7 years. The same study reported an EWL after vertical banded gastroplasty (VBG) of $61 \%, 57 \%$, and $53 \%$, respectively. ${ }^{11}$ Thus, long-term results of VBG are quite similar to our longterm findings after LSG. This is interesting because short-term results seem to be better after LSG than after VBG. This difference may partly be explained by suppression of ghrelin obtained by the resection of the gastric fundus in LSG but not in VBG. ${ }^{16-19}$ However, the hope that removal of the ghrelin-producing fundus could guarantee long lasting weight loss, appears to be vain. Most likely, hyperactivity of previously silent ghrelin-producing cells, scattered over the gastrointestinal tract, annihilates the early effect of fundic resection which at least partly could explain weight regain after LSG. ${ }^{16}$ This loss of "appetite suppression effect" of LSG in longterm follow-up had been predicted before. ${ }^{17}$

Another issue intervening in early weight loss after LSG is increased gastric emptying which, combined with decreased gastric acid secretion, causes incomplete digestion after LSG. ${ }^{17,20,21}$ Increased gastric emptying is associated with higher levels of glucagon-like-peptide-1, a glucose-regulating insulin-enhancing agent, which has been linked to weight loss and resolution of type II diabetes mellitus. ${ }^{22-26}$ This salutary effect on gastric emptying is however likely to diminish after time, once the sleeved stomach regains compliance which will permit the patient to ingest larger volumes more frequently. ${ }^{17}$

Late weight regain can be induced by purely dietary factors as well, like changes in eating behavior by shifting toward "easy" highly caloric food stuffs. Purely dietary flaws can probably be detected and possibly could have been treated by frequent follow-up visits aiming at repeated patient education and motivation. This issue has been demonstrated before in other restrictive procedures, especially adjustable gastric banding. ${ }^{27-29}$ It is noteworthy that in our series weight regain coincided with the interruption of the office visits after 3 years. 
This confirms that loss of continuous support and control is likely to play an important role in weight regain. Consequently, continued office visits should be strongly encouraged.

There is general apprehension that, rather than regaining normal compliance, the sleeved stomach might dilate over time. Dilatation of the stomach allows the patient to consume larger volumes of food, hence induces weight regain. On late postoperative barium upper GI series, performed because of weightregain, some patients presented "neo-fundus" formation (Fig. 5).

Actually, 2 patients in our series successfully benefited from a resleeve procedure for "fundus regeneration" as proposed by Baltasar et al (Fig. 5). ${ }^{30}$

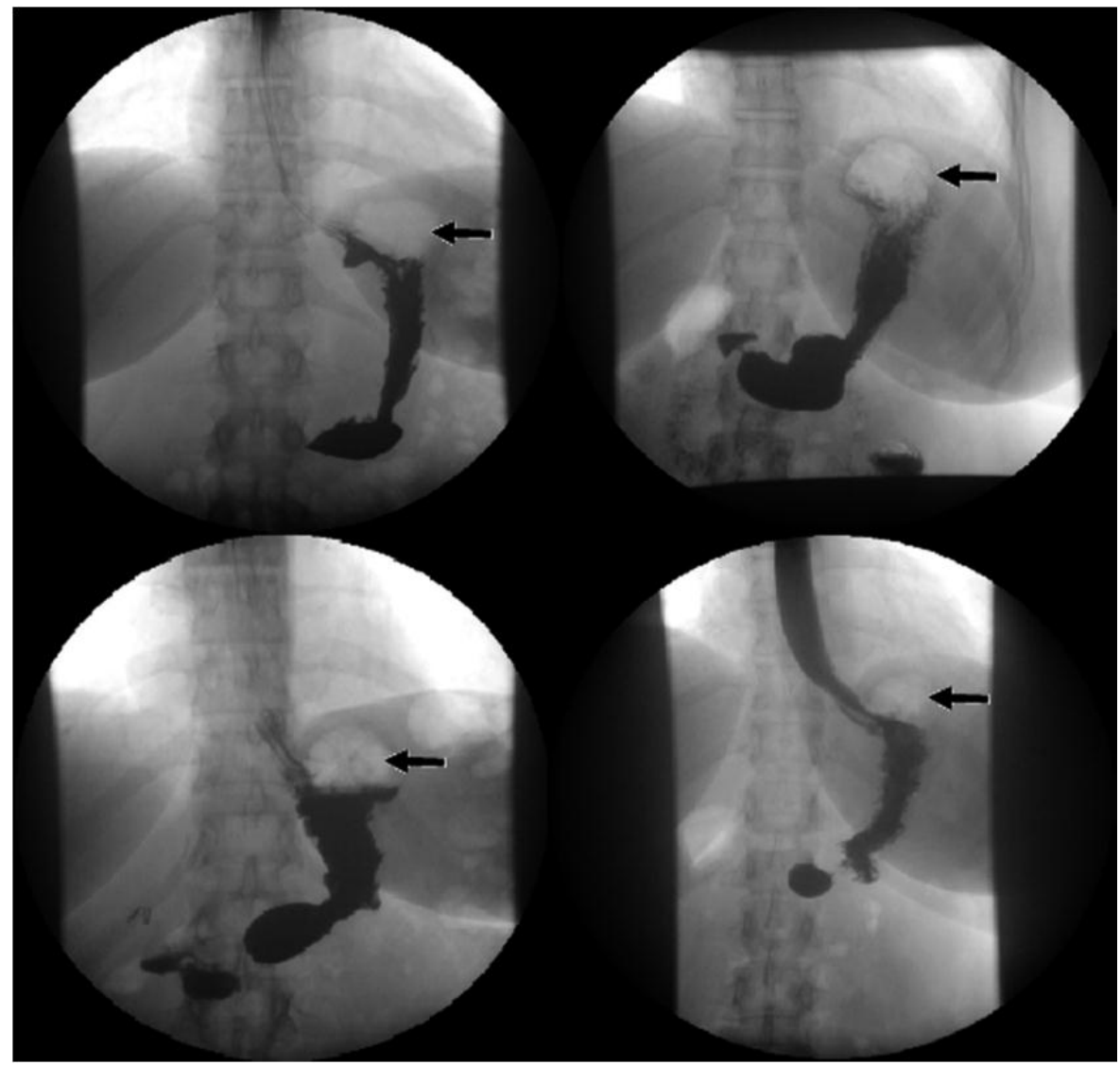

Figure 5. Upper GI series showing "neo-fundus"formation.

Four different cases of neofundus formation (black arrow) illustrated on upper GI series. The 2 cases above presented neo-fundus during the study and underwent a re-sleeve procedure. The other 2 cases (beneath) were diagnosed with neo-fundus in later follow-up, respectively 7 and 8 year after LSG. 
In our opinion, neofundus formation can be caused by leaving too much fundus at the time of operation in an effort to avoid fistulas. During sleeve gastrectomy, the critical point is at the angle of His. When at this point the surgeon for safety reasons decides to staple away from the left crus this might result in a sleeve-tube with a conical rather than a cylindrical shape. Following Laplace's law (combined with a relative distal downstream stenosis), this might result in proximal dilatation and "neofundus" formation. This neofundus issue could be important as it causes both weight regain and GERD. Further investigation is warranted for this specific issue.

Besides weight regain, patients with neofundus can experience the effects of relative mid-stomach stenosis. This stenosis causes stasis of food whereas the growing surface of acid producing mucosa increases acid production. Both conditions are known to cause GERD. Actually, we did observe increased GERD complaints after 6 +years as compared with the 3 years results we reported earlier. GERD diagnosis was made based on the regular use of proton pump inhibiting agents. In general clinical practice, GERD is mostly diagnosed by GERD-based complaints. ${ }^{31}$ Ambulatory $\mathrm{pH}$ measurement obviously would have been preferable for evaluating GERD, however this was difficult to arrange in our study because of local reimbursement issues. We demonstrated earlier a $22 \%$ incidence of post-LSG GERD after 1 year which came down to $3 \%$ after 3 years. ${ }^{6}$ From the present study, it appears that GERD presents a biphasic pattern after LSG. The first peak develops during the first postoperative year and disappears before the third postoperative year, most likely thanks to increased gastric compliance and improved gastric emptying. ${ }^{17,20,21,32}$ A second peak of GERD shows up later on and might be linked with the appearance of a neofundus. As far as treatment options is concerned, DS is not very helpful because in our series GERD occurred after full DS as well.

Despite the relatively high incidence of postoperative persistent GERD and vomiting, patient acceptance of LSG is still quite good as indicated by a mean BAROS of 5 , which testifies a good QOL even more than 6 years postoperatively.

To conclude, LSG is a safe, effective, and by the patients well-accepted bariatric procedure, but it appears to be associated with weight regain and quite often with reflux symptoms in long-term follow-up. Weight regain could probably be at least partly avoided by tighter follow-up. Weight regain, but not GERD after LSG can be managed successfully by completion of a DS procedure at a later stage.

\subsection{REFERENCES}

1. Arias E, Martinez PR, Ka Ming Li V, et al. Mid-term follow-up after sleeve gastrectomy as a final approach for morbid obesity. Obes Surg. 2009;19:544-548.

2. Menenakos E, M Stamou K, Albanopoulos K, et al. Laparoscopic sleeve gastrectomy performed with intent to treat morbid obesity: a prospective single-center study of 261 patients with a median follow-up of 1 year. Obes Surg. 2010;20(3):276-282. 
3. Gumbs A, Gagner M, Dakin G, et al. Sleeve gastrectomy for morbid obesity. Obes Surg. 2007;17:962969.

4. NIH Conference. Gastrointestinal surgery for severe obesity. Proceedings of a National Institutes of Health Consensus Development Conference. Bethesda, MD, March 25-27, 1991

5. Cadière GB, Himpens J, Dapri G. Atlas of Laparoscopic Obesity Surgery. ISBN Nr 978-2-9600728. Imprimerie Lesaffre, Tournai, Belgium; 2007.

6. Himpens J, Dapri G, Cadière GB. A prospective randomized study between laparoscopic gastric banding and laparoscopic isolated sleeve gastrectomy: results after 1 and 3 years. Obes Surg. 2006;16:1450 -1456. 7. Oria HE, Moorehead MK. Bariatric analysis and reporting outcome system (BAROS). Obes Surg. 1998;8:487-499.

8. Reinhold RB. Critical analysis of long-term weight loss following gastric bypass. Surg Gynecol Obstet. 1982;155:385-394

9. Ceelen W, Walder J, Cardon A. Surgical treatment of severe obesity with a low-pressure adjustable gastric band: experimental data and clinical results in 625 patients. Ann Surg. 2003;237:10-16.

10. Johnston D, Dachtler J, Sue-Ling HM, et al. The Magenstrasse and Mill operation for morbid obesity. Obes Surg. 2003;13:10-16.

11. Scozzari G, Farinella E, Bonnet G, et al. Laparoscopic adjustable silicone gastric banding vs laparoscopic vertical banded gastroplasty in morbidly obese patients: long-term results of a prospective randomized controlled clinical trial. Obes Surg. 2009;19:1108-1115.

12. Camerini G, Adami G, Marinari GM, et al. Thirteen years of follow-up in patients with adjustable silicone gastric banding for obesity: weight loss and constant rate of late specific complications. Obes Surg. 2004;14:1343-1348.

13. Gracia JA, Martínez $M$, Elia $M$, et al. Obesity surgery results depending on technique performed: long-term outcome. Obes Surg. 2009;19:432-438.

14. Balsiger BM, Poggio JL, Mai J, et al. Ten and more years after vertical banded gastroplasty as primary operation for morbid obesity. J Gastrointest Surg. 2000;4:598-605.

15. Suter M, Calmes JM, Paroz, et al. A 10-year experience with laparoscopic gastric banding for morbid obesity: high long-term complication and failure rates. Obes Surg. 2006;16:829-835.

16. Langer FB, Reza Hoda MA, Bohdjalian, et al. Sleeve gastrectomy and gastric banding: effects on plasma ghrelin level. Obes Surg. 2005;15:1024-1029.

17. Karamanakos SN, Vagenas K, Kalfarentzos F, et al. Weight loss, appetite suppression, and changes in fasting and postprandial ghrelin and peptide-YY levels after Roux-en-Y gastric bypass and sleeve gastrectomy: a prospective, double blind study. Ann Surg. 2008;247:401-407.

18. Kotidis EV, Koliakos GG, Baltzopoulos VG, et al. Serum ghrelin, leptin and adiponectin levels before and after weight loss: comparison of three methods of treatment--a prospective study. Obes Surg. 2006;16:1425-1432.

19. Cummings DE, Shannon $\mathrm{MH}$. Roles for ghrelin in the regulation of appetite and body weight. Arch Surg. 2003;138:389-396.

20. Melissas J, Koukouraki S, Askoxylakis J, et al. Sleeve gastrectomy: a restrictive procedure? Obes Surg. 2007;17:57-62.

21. Melissas J, Daskalakis M, Koukouraki S, et al. Sleeve gastrectomy -a "food limiting" operation. Obes Surg. 2008;18:1251-1256.

22. Basso N, Leonetti F, Mariani P, et al. Early hormonal changes after sleeve gastrectomy in diabetic obese patients. Obes Surg. 2010;20(1):50-55.

23. Nauck MA. Unraveling the science of incretin biology. Am J Med. 2009; 122(supp/ 6):S3-S10.

24. Drucker DJ, Nauck MA. The incretin system: glucagon-like peptide-1 receptor agonists and dipeptidyl peptidase-4 inhibitors in type 2 diabetes. Lancet. 2006;368:1696-1705.

25. Meier JJ, Gallwitz B, Salmen S, et al. Normalization of glucose concentrations and deceleration of gastric emptying after solid meals during intravenous glucagon like peptide 1 in patients with type 2 diabetes. J Clin Endocrinol Metab. 2003;88:2719-2725 
26. Willms B, Werner J, Holst JJ, et al. Gastric emptying, glucose responses, and insulin secretion after a liquid test meal: effects of exogenous glucagon-like peptide-1 (GLP-1)-(7-36) amide in type 2 (non insulin-dependent) diabetic patients. J Clin Endocrinol Metab 1996;81:327-332

27. Dixon JB, Laurie $\mathrm{CP}$, Anderson $\mathrm{ML}$, et al. Motivation, readiness to change, and weight loss following adjustable gastric band surgery. Obesity. 2009;17:698-705.

28. Pontiroli $A E$, Fossati $A$, Vedani $P$, et al. Post-surgery adherence to scheduled visits and compliance, more than personality disorders, predict outcome of bariatric restrictive surgery in morbidly obese patients. Obes Surg. 2007;17:1492-1497.

29. Chevallier JM, Paita M, Rodde-Dunet $M H$, et al. Predictive factors of outcome after gastric banding: a nationwide survey on the role of center activity and patients' behavior. Ann Surg. 2007;246:1034 1039.

30. Baltasar A, Serra C, Perez N, et al. Re-sleeve gastrectomy. Obes Surg.2006;16:1535-1538.

31. Fujiwara Y, Takahashi S, Arakawa T, et al. A 2008 questionnaire-based survey of gastroesophageal reflux disease and related diseases by physicians in East asian countries. Digestion. 2009;80:119 128.

32. Yehoshua RT, Eidelman LA, Stein M, et al. Laparoscopic sleeve gastrectomy-volume and pressure assessment. Obes Surg. 2008;18:10

\section{CHAPTER FIVE AT A GLANCE}

$\begin{array}{ll}\text { Long-term (6 years) } & \text { outcomes of LSG } \\ \text {-EWL: } & 53.3 \%(77.5 \% \text { at } 3 \text { years) } \\ \text { Complications } & 23 \% \text { GERD } \\ & 2 \% \text { stenosis } \\ \text { Conversions } & 32 \% \text { conversions (LDS27\%, re-sleeve } 5 \%) \\ \text { Patient acceptance: } & \text { satisfaction index } 56.6 \%\end{array}$

BAROS 5.0 


\section{Chapter 6.}

\section{Long Term Results of Laparoscopic Roux-en-Y Gastric Bypass: Evaluation after 9 Years}

Jacques Himpens*० $M D$, Anneleen Verbrugghe ${ }^{\circ} \mathrm{MD}$, Guy-Bernard Cadière* MD, $\mathrm{PhD}$, Wouter Everaerts ${ }^{\circ} \mathrm{MD}, \mathrm{PhD}$, Jan-Willem Greve ${ }^{\circ \circ} \mathrm{MD}, \mathrm{PhD}$

From the European School of Laparoscopic Surgery, Brussels, Belgium * St Pierre University Hospital, Brussels, Belgium 'St Blasius General Hospital, Dendermonde, Belgium

${ }^{\circ}$ Atrium Medical Center, Heerlen, The Netherlands

Journal of Obesity Surgery. Volume 22 Number 10, October 2012. 


\subsection{ABSTRACT}

Objective: To evaluate the long term results of laparoscopic Roux-en-Y gastric bypass (LRYGB).

Methods: The 126 consecutive patients treated by LRYGB between January $1^{\text {st }} 2001$ and December $31^{\text {st }} 2002$ were analyzed in August 2011.

Results: Seventy-seven patients (61.1\%), including 18 who had had previous bariatric surgery, were available for evaluation after $9.4+0.6$ years (range 8.7-10.9). Eight patients (10.4\%) suffered from diabetes mellitus type 2 (DMII) at the time of surgery. Initial BMI was $40.3+7.5(24.5-66.1) \mathrm{kg} / \mathrm{m}^{2}$. There was no postoperative mortality, but 2 patients died of causes unrelated to the surgery. Some $9 \%$ of the patients suffered from internal herniation. Overall \% excess Body Mass Index Lost (\%EBMIL) was $56.2+29.3 \%$ (-78.8-117.9), down from a maximum of $88.0+29.6 \%$ (19.7-197.1), that had been obtained after a median of 2.0 (1-8) years. The bypass was effective for diabetes control in $85.7 \%$ of the affected patients, but $27.9 \%$ developed new-onset diabetes. The weight regain in this latter patient group was not different from that of the non-diabetic group. Four patients required hospitalization for hypoglycemic syndrome. Two patients underwent bypass reversal for problems linked to glucose metabolism. Patient quality of life (QOL) was fair. The patient satisfaction remained good in $76 \%$ of the cases.

Conclusions: The long term outcome after primary and revisional LRYGB shows weight regain starting after some 2 years but final \% EBMIL and patient satisfaction were still acceptable. The procedure was effective in terms of diabetes control, but a significant number of patients developed new-onset DMII or severe hypoglycemia symptoms requiring in-hospital treatment 


\subsection{INTRODUCTION}

Due to the obesity epidemic, the search for an adequate surgical option for weight reduction is a priority. In 1999, we decided to surgically treat morbid obesity by laparoscopic Roux en Y gastric bypass (LRYGB) in selected cases based on the unsatisfactory long term results of the laparoscopic adjustable band gastroplasty (LAGB) ${ }^{1}$ and because laparoscopic gastric bypass was emerging at the time as a valuable bariatric option. ${ }^{2}$ After the unavoidable ${ }^{2,3}$ learning curve, we performed LRYGB routinely starting in 2000 and followed the codification of the procedure that we had achieved. ${ }^{4}$ The purpose of this retrospective study was to analyze the long term results of the "mature" LRYGB procedure performed in our department, which is a high volume bariatric unit. Considering the recent introduction of gastric bypass as a "metabolic" operation, ${ }^{5,6,7}$ the outcome of diabetes is discussed as well.

\subsection{METHODS}

Between January 1, 2001 and December 31, 2002, 126 patients underwent LRYGB in our department of obesity surgery. The patients were selected for this procedure instead of another laparoscopic operation based on an empirically established algorithm (table 1); in addition, patients who, despite adequate conservative measures, experienced insufficient weight loss or suffered from a complication after another bariatric procedure they had undergone in the past, were treated by LRYGB as a revisional procedure.

The preoperative work-up consisted of extensive blood-work, an abdominal ultrasound, a dietary and psychological evaluation and an endocrinology consultation.

The LRYGB procedure involved the creation of a very small gastric pouch, a biliary $\operatorname{limb}$ of approximately $50 \mathrm{~cm}$ and a Roux $\operatorname{limb} 150 \mathrm{~cm}$ in length, placed in an antecolic, antegastric position. In primary cases, the anastomosis was performed by a circular mechanical technique using a $25 \mathrm{~mm}$ anvil introduced perorally. ${ }^{8}$ In case of revisional LRYGB the anastomosis was preferably hand-sewn. ${ }^{8}$ The mesenteric defect and the Petersen defect were both systematically closed using a purse string of non-resorbable suture material. After discharge from the hospital, the patients were advised to refrain from eating fast sugars and to take multivitamins, calcium and zinc. The patients were urged to come for a check-up, including extensive blood work, every 3 months the first year after surgery, every 6 months the second and the third years, and once every year thereafter.

In August 2011, the patients were called to the office for clinical evaluation and blood work. This study was approved by the ethical committee of the hospital and the costs involved were entirely paid for by one of the authors $(\mathrm{JH})$.

The patients who declined to visit the office were approached by telephone and asked to answer a questionnaire addressing the following important outcomes: 
weight loss progress, changes in dietary habits, quality of life with special attention to procedure-related side-effects, satisfaction with the procedure and, finally, the progression of DMII. DMII was diagnosed on clinical grounds when oral antidiabetic agents and/or insulin were taken by the patient, and on blood analysis when a value of fasting plasma glucose $>105 \mathrm{mg} / \mathrm{dl}$ and/or glycated hemoglobin (HbA1c) $>6.0 \%$ was documented. The patients were weighed in the office and changes in weight were plotted against previous recordings in their charts. Changes in weight between two recordings were considered linear. In cases of telephone contact, changes in weight were evaluated by recording and plotting the most recent weight reported by the patient with the weight values that were previously recorded.

Patient quality of life (QOL) was evaluated according to the Bariatric Analysis and Reporting Outcome System (BAROS) score, which evaluates the results of obesity treatment by analyzing 3 psychomedical aspects: weight loss, changes in comorbidities and QOL. ${ }^{9}$ In this system, up to 3 points are allowed for each category, and points are deducted for reoperations and complications.

Patient satisfaction with the procedure was evaluated by answering "yes" or "no" to the simple question "Would you undergo the operation again?". This is a straightforward means of evaluation when a variety of continuous and categorical variables intervene to establish a final subjective impression. ${ }^{10}$

Table 1. Empirically Established Bariatric Algorithm as we used in 2001-2002.

\section{BARIATRIC ALGORITHM}

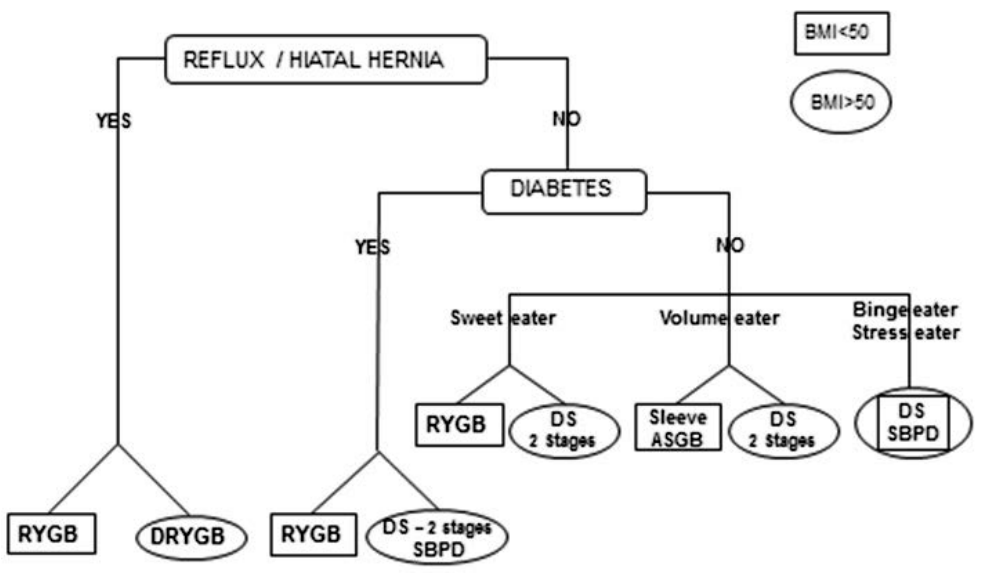

Legend: RYGB = Roux-en-Y gastric bypass; DRYGB= distal Roux-en-Y gastric bypass; DS= duodenal switch; SBPD= Scopinaro biliopancreatic diversion; Sleeve= sleeve gastrectomy; BMI= Body Mass Index 


\section{$6.4 \quad$ STATISTICS}

Microsoft Excel was used for data management. The McNemar test for paired variables was used for the statistical analysis of categorical data. The $t$ test for paired variables was used for analysis of changes in weight, body mass index (BMI; calculated as weight in kilograms divided by height in meters squared), and \% excess BMI lost (\% EBMIL), calculated as the difference between the initial and the postoperative $\mathrm{BMI}$ divided by the preoperative BMI in excess of 25 (considered the ideal BMI) multiplied by 100 . Results are represented as mean values, standard deviation, and range, or median values with the range. Statistical significance was reached at $p$ $<0.05$. Statistical analysis was done with SPSS statistical software (SPSS Inc., Chicago, II, USA).

\subsection{LONG-TERM RESULTS}

Data were obtained for 77 patients (61.1\%). Sixty one $(79.2 \%)$ of the patients were women. The mean age was $38.9+10.6(17-64)$ years at the time of surgery, and the initial BMI was $40.3+7.5(24.5-66.1) \mathrm{kg} / \mathrm{m}^{2}$. The low BMI of some of the patients can be explained by the fact that 18 of the patients $(23.4 \%)$ had previously undergone at least one bariatric procedure and 3 of them required reinterventions for health problems other than weight issues, namely gastro-esophageal reflux disease (GERD). Fifteen had undergone laparoscopic adjustable band gastroplasty (LAGB) including the 3 patients with intractable GERD, 1 had had a laparoscopic sleeve gastrectomy (LSG), 1 a vertical banded gastroplasty (VBG) and 1 a laparoscopic jejuno-ileal bypass (JIB).

Of the 77 patients, 8 (10.4\%) were diabetic at the time of LRYGB. All of these patients underwent the bypass as a primary procedure. Two ( 1 man) were treated with insulin, and 6 (1 man) were treated with at least one oral antidiabetic agent.

Mean follow-up was $9.4+0.6(8.7-10.9)$ years.

Two patients (2.6\%), died of unrelated causes: one diabetic patient died of metastatic colonic and prostate cancer in his seventh postoperative year and one patient committed suicide in the ninth postoperative year due to marital problems unrelated to her surgery.

Fifty-one of the 75 surviving patients (68.0\%) were interviewed and examined in the office by three of the authors (JH, AV, WE) and complete fasting blood work was performed. This group included all the patients who had the LRYGB as a revisional procedure, except for the patient who had had a JIB. The remaining 24 patients were evaluated based on answers to the standardized questionnaire obtained over the telephone. 
Reoperations specific for the bypass procedure

Seven patients $(9.3 \%)$ suffered an internal herniation that occurred after a median of 4.8 years (1-9) after LRYGB. This condition was approached successfully by laparoscopy in all cases. It was not possible to determine the exact site of the hernia (mesenteric defect or Petersen) based on the operative notes.

One patient with primary LRYGB developed a perforated benign ulcer of the gastric remnant 9 years postoperatively, and was treated laparoscopically.

Two patients underwent laparoscopic hiatal hernia repair; however, one of them, who previously had had LAGB, required a laparoscopic revision of the hiatal repair and subsequently needed an esophageal plastic stent (Polyflex, Boston Scientific, Natick, MA, USA) for stenosis at the hiatus. The final outcome was good.

One patient developed a gastrogastric fistula 9 years after revisional LRYGB after LAGB and was treated by laparoscopic subtotal gastrectomy of the remnant.

Three patients who had undergone primary LRYGB required reoperation for metabolic issues. One severely diabetic patient was treated by distalization of her bypass after 3 years (the alimentary limb was reimplanted approximately $150 \mathrm{~cm}$ proximal to the ileocecal valve). Two patients required reversal of their primary bypass after 9 years for glycemia issues, including one with severe symptoms of documented paradoxical postprandial hypoglycemia and one with new-onset DMII that was extremely difficult to adjust because of non-compliance with the dietary restrictions.

\section{Long-term weight loss}

Overall $\mathrm{BMI}$ at the time of the study had reached a plateau at a mean of $30.0+6.0$ $\mathrm{kg} / \mathrm{m}^{2}(19.7-50.5)$ after a nadir at $25.1+5.1 \mathrm{~kg} / \mathrm{m}^{2}(17.5-40.1)$ that was obtained after a median of 2.0 years (1.0-8.0). The maximum excess \% BMI loss (\% EBMIL) was $88.0+29.6 \%(-19.7-197.1)$, while the $\%$ EBMIL at the time of the study averaged $56.2+29.0 \%(-78.8-118.0)$. The difference between the maximum and actual \% EBMIL was statistically different $(p<0.0001)$. The progression of BMI can be found in table 3.

If we exclude the patients who had the bypass as a revisional procedure, we find a similar weight loss pattern: the patients' overall BMI at the time of the study was $29.5+5.5 \mathrm{~kg} / \mathrm{m}^{2}(21.2-42.8)$, after a minimum of $24.4+4.5 \mathrm{~kg} / \mathrm{m}^{2}(17.5-39.2)$, obtained after 2.0 years (1.0-7). The maximum \%EBMIL was $90.3+18.7 \%(52.0-130.0)$ and the final \%EBMIL was $62.9+23.0 \%(12.9-104.1)$. The weight loss progression (maximum \%EBMIL and final \%EBMIL) in the group of primary LRYGB was statistically not different from the progression in the entire group $(p=0.433$ and $p=0.115$ respectively) 
Table 2. Progression of the Body Mass Index (BMI) with time after laparoscopic Roux-en-Y gastric bypass in our cohort of 75 surviving patients. The red arrow represents the mean BMI.

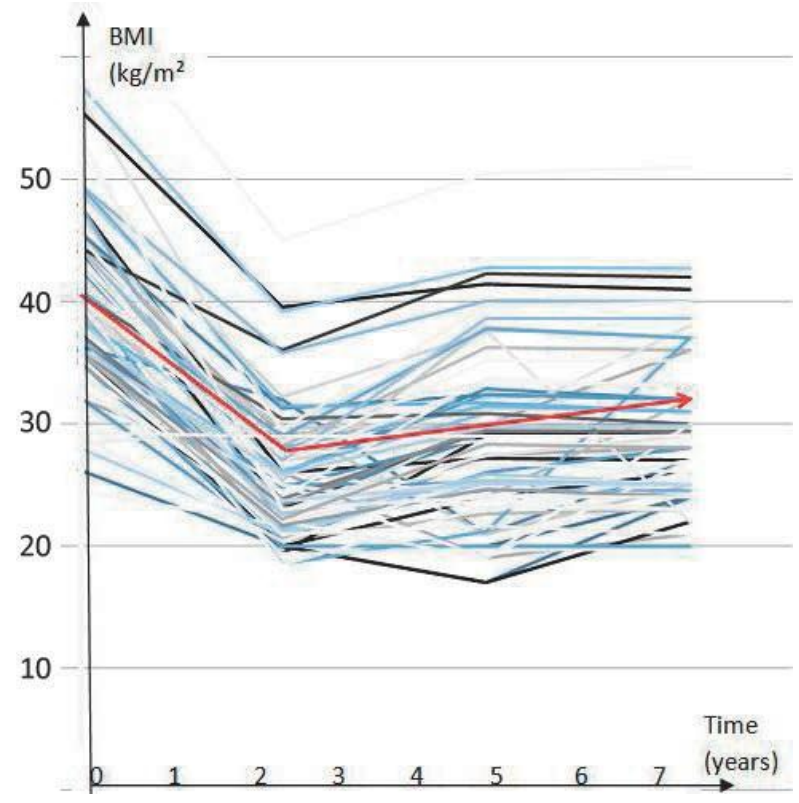

Long-term results for DMII and glucose metabolism

Of the 8 preoperatively diabetic patients, one died of cancer. One male insulindependent patient who had a $96.7 \%$ EBMIL was in full remission. Another female insulin-dependent patient was able to discontinue her insulin injections after distalization of the bypass, although she still required oral treatment at the time of the study despite a $61.1 \%$ EBMIL. Of the 5 remaining surviving patients treated with oral antidiabetic agents, 4 (80\%) were.in biochemical remission. For the fifth patient no blood work was available but the patient reported being treated with 2 oral antidiabetic drugs at the time of the study.

In contrast, 9 patients who were not diabetic preoperatively were being treated for DMII at the time of the study. Thus, 9 years after the LRYGB procedure, the incidence of treated DMII was $15.7 \%(11 / 75)$ versus $9.3 \%(7 / 75)$ preoperatively $(p=0.0724)$.

Of the 68 surviving patients who preoperatively did not suffer from DMII, 45 (66.2\%) were evaluated by blood analysis. Their outcome can be found in table 3 . Fifteen of the 45 patients (33.3\%) presented biochemical evidence of new onset DMII, but only 5 of the 15 patients were actually being treated for this condition. Four additional patients for whom blood work was not available reported being treated for DMII, hence at least $27.9 \%(19 / 68)$ of the patients who were not diabetic 
preoperatively developed at least biochemical diabetes in the 9 years following the LRYGB procedure.

In analyzing the link between the weight changes and the appearance of DMII in the 19 patients, final \% EBMIL in the subgroup of the "de-novo diabetic" patients averaged $57.8+26.0 \%$ (10.9-117.9) [maximum \% EBMIL was 94.2+34.5\% (48.0197.1)]. This value was not statistically different from the group of 49 individuals who had no history of DMII and who did not develop DMII [\% EBMIL 55.0+31.5\% (78.8-104.1), $p=0.7371$ ][maximum\% EBMIL 87.6+28.8\% (-19.7-130.0), $p=0.423$ ].

In analyzing the demographics of the 19 new-onset diabetics, all but 4 patients were women (78.9\%) and the age at operation was $40.1+9.8$ years (28.3-57.0). In the group who remained disease-free, 39 of the 49 patients were women $(79.6 \%)$ and the age was $39.0+11.3(17.0-64.0)$ years $(p=0.921)$.

In analyzing the possible influence of previous weight loss operations, 4 patients in the redo- group ( 3 after LAGB and 1 after LSG) developed DMII (4/18=22.2\%). The incidence of new-onset diabetes in the group of revisional LRYGB was not statistically different from the incidence after primary bypass $(15 / 50=30.0 \%)(p=0.309)$.

Table 3. Progression of de novo type 2 diabetes in the 68 surviving, preoperatively non-diabetic patients some 9 years after Roux-en-Y gastric bypass. Distinction is made between the primary and redo-cases and between the diagnostic approach: blood work (dark squares) and history (white squares). DMII was diagnosed when glycated hemoglobin ( $\mathrm{HbA1c}$ ) was $>6.0 \%$ and/or fasting plasma glucose was $>105 \mathrm{mg} / \mathrm{dl}$ on blood analysis OR when the patients were taking antidiabetic drugs according to their general practitioner.

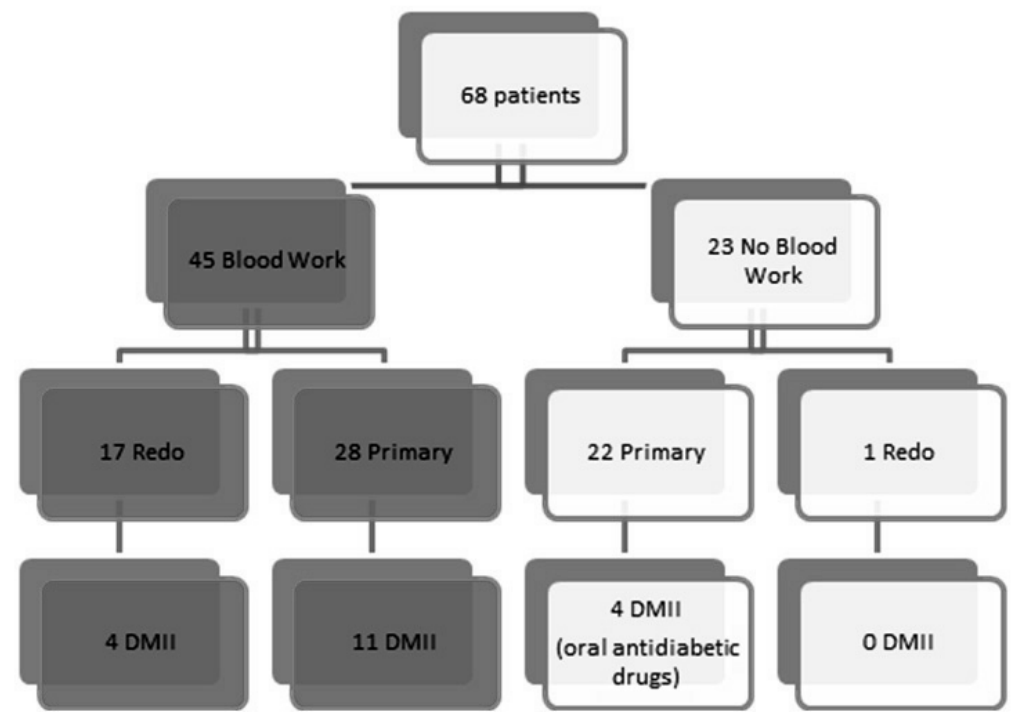

DMII= type 2 diabetes

Primary=patients who underwent the bypass as a first procedure

Redo=patients who underwent the bypass after another bariatric procedure 
Of the 49 patients who never suffered from DMII, 3 required hospitalization for seizures objectively linked to hypoglycemia (glycemic value under 50 milligram/dl during the insult). A fourth patient required reconversion of her bypass for intractable documented hypoglycemic spells. Reconversion was performed in an additional new-onset DMII patient for unmanageable plasma glucose fluctuations. For both patients, an oral glucose tolerance test (OGTT) was performed some 2 weeks after reconversion and was normal.

\section{Long-term QOL and patient satisfaction}

-The BAROS score was $2.03+1.96(-2-7)$, which represents a "fair" result (9). Fiftyseven of the patients $(76.0 \%)$ were happy or very happy with the procedure and indicated that they would opt to have the operation again.

\subsection{DISCUSSION}

There are several limitations to this study.

1. There was a follow-up rate of approximately $60 \%$ in this cohort, which may seem relatively low. However, the follow-up rate of patients highly depends on the health care system and its reimbursement policy for office visits. Follow-up rates of over $90 \%$ are typically reached in Sweden ${ }^{10}$ and Australia, ${ }^{11}$ but not in Europe or in the United States. Higa in the United States reported a follow-up rate of $26 \%$ after 10 years, but only $7 \%$ of patients were actually seen in the office ${ }^{12}$. Nevertheless, patient follow-up plays an important role in bariatric surgery, and patients lost to follow-up tend to lose less weight. ${ }^{13}$ There is extensive literature emphasizing the need for adequate follow-up to obtain better clinical results after bariatric surgery, particularly for restrictive operations. ${ }^{14,15}$ Recently, the literature has mentioned, however, that compliance with office visits is less important for LRYGB than for LAGB. ${ }^{16}$

2. The study is retrospective. Despite the fact that the patients were consecutive and that the database was maintained in a prospective manner, many patients were not seen for a long period of time prior to being seen in the office or interviewed by telephone in August 2011. Because of these factors, changes in weight over time can only be estimated for a number of the patients. Data gathered from telephone interviews must be approached with caution, as patients have the tendency to underestimate their weight ${ }^{17}$ or, conversely, they may underestimate their weight loss and exaggerate possible side effects and complications in cases of animosity towards the surgeon for whatever reason. ${ }^{18}$ Concerning the data on DMII and hypoglycemia we limited the information on the patients interviewed by telephone to objectively verifiable elements, such as the use of antidiabetic agents confirmed by the patient's general practitioner and the data recorded during a hospital stay for symptoms of hypoglycemia. 
3. The initial mean BMI of the patients in our series was lower than the values generally mentioned for LRYGB in the literature. ${ }^{19}$ This could be an important factor in terms of glucose metabolism. There is evidence that glycemic control by RYGB is not as good in patients with lower BMls compared to more obese patients. ${ }^{20}$ This might be an indication that we cannot extrapolate our results to the entire morbidly obese community.

4. Our cohort consisted of patients who had undergone either primary or revisional LRYGB. It has been advocated by some that patients do less well after redosurgery. ${ }^{21}$ However, a growing number of patients in Western Europe undergo LRYGB as a revisional procedure, and excluding them would possibly have skewed the outcomes in a modern bariatric practice. In addition, we and others have demonstrated that the results in terms of weight loss do not differ after primary versus redo-bypass, despite an increased number of complications $22,23,24$.

Despite our policy of closing the defects, the incidence of internal hernias (IH) after LRYGB (9.3\%) is alarming. Most authors advise the systematic closure of all possible mesenteric defects during the procedure. ${ }^{25,26}$ According to the literature, nonclosure of the defects with the LRYGB technique as used in this study results in an internal hernia rate of $6.9 \% .{ }^{27}$ Higa $^{12}$ recently demonstrated that after his team adapted the policy of systematic closure of both the mesenteric and the Petersen defect with non-resorbable material, the occurrence of $\mathrm{IH}$ after transmesocolic antegastric LRYGB dropped from $16 \%$ to less than $1 \%$. Conversely, the team around Rosenthal claims that the chances of developing an IH are low and do not justify the additional time and possible complications required for the closure. ${ }^{28}$ The series presented in this study had an incidence of IH after antegastric antecolic LRYGB that is considerably higher than previously reported. When patients were re-explored for $\mathrm{IH}$, the polypropylene material that we had used could be seen, but it had obviously cut through the tissues and usually both defects had reopened. Alternative ways of closure are worth investigating. ${ }^{29,30}$

Two patients developed a hiatal hernia $(\mathrm{HH})$ with significant GERD, that required surgical intervention. The appearance of new-onset GERD linked to the development of a $\mathrm{HH}$ after bypass is not a new finding. Repeated dissection of the hiatus can however be hazardous, especially after redo-bypass, as one of our patients experienced.

Bypassing the stomach is usually considered a valid treatment for GERD ${ }^{31}$ but does not necessarily protect the patient from ulcer disease. Anastomotic ulcers ${ }^{32}$ as well as perforating disease at the level of the anastomosis or of the remnant, as encountered by 1 patient in this series, have extensively been described in the literature, ${ }^{33,34}$ and constitute definite indications for surgical reintervention. 
The Roux en $Y$ gastric bypass is a hybrid restrictive-malabsorptive procedure. ${ }^{35,36,37}$ The laparoscopic version has become a well-established bariatric procedure and produces persistent, positive results. ${ }^{38}$ In accordance with the findings of others, and in contrast with the findings of others, ${ }^{21}$ we found a comparable weight loss pattern in primary and revisional LRYGB.

In this series, the overall results of weight loss over the 9 years post-primary and post-revisional LRYGB seem to deteriorate after 2 years.

Different mechanisms can influence changes in weight loss, ${ }^{39}$ including the development of a gastro-gastric fistula as we encountered in one of our patients some 9 years postoperatively. ${ }^{40}$

The majority of our patients suffering from DMII greatly benefitted from the procedure. The salutary effect of RYGB on DMII has been widely described. ${ }^{41,43,44,45}$ This effect can be explained by the enhanced secretion of incretins secondary to the duodenal exclusion and to the rapid transition of food stuffs to the distal small bowel. ${ }^{41}$ An additional important factor intervening in the remission of DMII is the weight loss induced by the procedure. ${ }^{42,43}$ One patient experienced improvement of her diabetic condition after benefitting from significant additional weight loss after distalization of the bypass.

Interestingly, none of our patients experienced a recurrence of their condition despite some weight regain, a condition that has been linked to the re-emergence of DMII. ${ }^{45,46}$ On the other hand, we found an unexpectedly high incidence of newonset diabetes. The cause of this evolution is not clear and, according to our data, cannot be explained by weight regain, gender, age, or previous bariatric interventions. One obvious reason, again, could be poor eating habits. ${ }^{14}$

Obviously, the number of patients suffering from new onset diabetes must be weighed against the normal progression of the disease in an obese population over a 9 year period. According to the literature, the incidence of diabetes in an obese population that underwent gastric bypass is comparable to the incidence in the general population. ${ }^{10}$ In the Western world, the incidence of new onset DMII is approximately $4 \%$ over 10 years. ${ }^{48}$ For obese and morbidly obese patients, however, this number increases significantly, ${ }^{49,50}$ but the odds of developing DMII do not change significantly if the patients' BMI remains below $30 \mathrm{~kg} / \mathrm{m}^{2}{ }^{48}$ In our study, the "new-diabetics" reached a final BMI of just $31 \mathrm{~kg} / \mathrm{m}^{2}$. With this value, the incidence of DMII we observed was far higher than expected given the odds.

We found that the bypass construction can generate the hypoglycemic syndrome as was found in at least 4 of our patients. The exaggerated insulin response to an oral glucose challenge, which is typical for patients following RYGB and might be responsible for the early remission of $\mathrm{DMII},{ }^{51,52}$ can result in this condition. The relative risk for developing this syndrome is seven times higher after bypass than in the general population. ${ }^{53,54}$ The consequences can be devastating in that hypoglycemia-induced loss of consciousness or seizures can lead to fatal driving accidents 
and mishaps on the work floor. ${ }^{55}$ Possible treatment modes for the hypoglycemic syndrome are a strict low carbohydrate diet, which is difficult to implement in this population, ${ }^{47}$ and drugs including acarbose, diazoxide, octreotide and calciumchannel blocking agents. ${ }^{57}$ When needed, surgical treatment can consist of the addition of a restrictive component, ${ }^{39}$ reincorporation of the duodenum in the digestive circuit $^{58}$ or reconstitution of the gastrointestinal continuity. ${ }^{59}$ More radical options include pancreatic resections as initially proposed, ${ }^{60}$ but the use of such formidable surgery is questionable because neuroglycopenia usually is not caused by a pancreatic cell hyperplasia. ${ }^{61}$ We prefer to proceed to laparoscopic reconstitution of the anatomic integrity, as we described previously ${ }^{62}$ and as proposed by Mc Laughlin et al. ${ }^{63}$ We proved the efficacy of this appraoch in 1 of our patients suffering from documented invalidating recurrent hypoglycemia and who remained unresponsive to stringent dietary restrictions and to an expensive octreotide treatment.

We successfully extrapolated this therapeutic option to another patient who suffered from poorly adjustable insulin dependent DMII occurring de novo after PLRYGB. This patient was extremely poorly disciplined in terms of dietary restrictions. We assumed that undoing the duodenal exclusion might result in less postprandial fluctuations in autogenous insulin, hence in a better controllable DMII. Since test-gastrostomy feedings allowed for better glycemic control in this patient, we went ahead and converted the bypass back to normal anatomy. This approach proved useful as demonstrated by a normal postoperative OGTT. The patients' QOL (BAROS) score was 2.03, which indicates a moderate QOL. ${ }^{9}$ This score is remarkably less than the score recently reported by Suter. ${ }^{64}$ Our less favorable outcome can be explained by the high number of long term complications and re-operations and by the substantial incidence of fluctuating glucose plasma values, which is a highly symptomatic clinical condition. Overall, patient satisfaction remained high. We found a similar phenomenon in our patients after LAGB $^{1}$ and LSG, ${ }^{17}$ despite modest results in terms of weight loss. Obese patients appear to be happy with themselves provided they are convinced that they made a substantial effort to correct their condition. ${ }^{65,66}$ This underscores the social character of obesity as a crippling psychological disease that is lived through the eyes of "the other". ${ }^{67}$ The bariatric patient finds him/herself more accepted after the surgery, even when the results are not necessarily good. ${ }^{68}$

\subsection{CONCLUSION}

The results from this study suggest that LRYGB, performed as a primary or as a revisional procedure, induces an acceptable long term weight loss, as expressed by an overall \% EBMIL of 56.2. Despite our policy of closing the potential internal hernia defects, $9 \%$ of the patients required laparoscopic reintervention for internal hernia. While LRYGB is salutary for patients suffering from DMII preoperatively, the patients 
appear to be at significant risk for developing new onset diabetes several years after LRYGB. In addition, hypoglycemic symptoms may warrant hospital treatment for some additional patients. However, the overall quality of life is acceptable and the satisfaction of the patients remains quite high.

\subsection{REFERENCES}

1. Himpens J, Cadière GB, Bazi M, et al. Long term outcomes of laparoscopic adjustable gastric banding. Arch Surg $2011 \mathrm{Jul} ; 146(7): 802-7$

2. Jonson W, DeMaria E. Surgical treatment of obesity. Curr Treat Options Gastroenterol 2006 Apr; 9(2):167-74

3. Oomen MW, Hoekstra LT, Bakx R, et al. Learning curves for pediatric laparoscopy: how many operations are enough? The Amsterdam experience with laparoscopic pyloromyotomy. Surg Endosc 2010; 24(8):1829-33

4. Cadière GB, Himpens J, Dapri G in: Atlas of laparoscopic obesity surgery, COELIO ASBL Brussels, editors, 2007

5. Buchwald $\mathrm{H}$, Estok R, Fahrbach $\mathrm{K}$, et al. Weight and type 2 diabetes after bariatric surgery: systematic review and meta-analysis. Am J Med 2009 Mar; 122(3):248-56

6. Shukla AP, Ahn SM, Patel RT et al. Surgical treatment of type 2 diabetes: the surgeon perspective. Endocrine. 2011 Aug 13.

7. Pories WJ, Mehaffey JH, Staton KM. The surgical treatment of type two diabetes mellitus. Surg Clin North Am. 2011 Aug; 91(4):821-36.

8. Himpens J. The gastrojejunostomy in laparoscopic Roux-en-Y gastric bypass. Semin Laparosc Surg 2004 Sep; 11(3):171-7

9. Oria HE, Moorehead MK. Bariatric analysis and outcome reporting system (BAROS). Obes Surg 1998; 8: 487-99

10. Plecka Östlund M, Marsk R, Rasmussen F, et al. Morbidity and mortality before and after bariatric surgery for morbid obesity compared with the general population. Br J Surg 2011 Jun; 98(6):811-6

11. Haal JC, Watts JM, O’Brien PE, et al. Gastric surgery for morbid obesity. Ann Surg 1990 Apr; 211(4):419-27

12. Higa K, Ho T, Tercero F, et al. Laparoscopic Roux-en-Y gastric bypass: 10 -year follow-up. Surg Obes Relat Dis 2011 Jul-Aug; 7(4): 516-25

13. te riele WW, Boerma D, Wiezer MJ, et al. Long-term results of laparoscopic adjustable band in patients lost to follow-up. Br J Surg 2010 Oct; 97(10):1535-40

14. Kruseman $M$, Leimgruber $A$, Zumbach $F$, et al. Dietary, weight, and psychological changes among patients with obesity, 8 years after gastric bypass. J Am Diet Assoc 2010 Apr; 110(4):527-34

15. Busetto L, Segato G, De Marchi F. Postoperative management of laparoscopic gastric banding. Obes Surg 2003; 13(1):121-27

16. El Chaar M, McDeavitt K, Richardson S, et al. Does patient compliance with preoperative bariatric office visits affect postoperative excess weight loss? Surg Obes Relat Dis 2011 Nov-Dec;7(6):743-8

17. Himpens J, Dobbeleir J, Peeters G. Long-term Results of Laparoscopic Sleeve Gastrectomy for Obesity. Ann Surg. 2010 Aug; 252(2):319-24

18. Narchet FM, Meissner CA, Russano MB. Modeling the influence of investigator bias on the elicitation of true and false confessions. Law Hum Behav 2011; 35(6):452-65

19. Buchwald $\mathrm{H}$, Vidor $\mathrm{Y}$, Braunwald $\mathrm{E}$, et al. Bariatric surgery: a systematic review and meta-analysis. JAMA 2004 Oct 13; 292(14):1724-37

20. Fried M, Ribaric G, Buchwald JN, et al. Metabolic surgery for the treatment of type 2 diabetes in patients with $\mathrm{BMl}<35 \mathrm{~kg} / \mathrm{m}^{2}$ : an integrative review of early studies. Obes Surg 2010 Jun; 20(6):776-90 
21. Radtka JF 3rd,Puleo FJ, Wang I, et al. Revisional bariatric surgery: who, what, where, and when? Surg Obes Relat Dis 2010 Nov-Dec;6(6):635-42

22. Cadière $G B$, Himpens J, Bazi $M$, et al. Are laparoscopic gastric bypass after gastroplasty and primary laparoscopic bypass similar in terms of results? Obes Surg 2011Jun;21(6):692-8

23. Topart $P$, Becouarn G, Ritz P. One-year weight loss after primary or revisional Roux-en-Y gastric bypass for filed adjustable gastric banding. Surg Obes Relat Dis 2009 Jul-Aug;5(4):459-62

24. te Riele WW, SZE YK, Wiezer MJ, et al. Conversion of failed laparoscopic gastric banding to gastric bypass as safe and effective as primary gastric bypass in morbidly obese patients. Surg Obes Relat Dis 2008 Nov-Dec;4(6):735-9

25. de la Cruz-Munoz N, Cabrera JC, Cuesta M, et al. Closure of mesenteric defect can lead to decrease in internal hernias after Roux-en-Y gastric bypass. Surg Obes Relat Dis 2011 Mar-Apr; 7(2):176-80

26. Steele KE, Prokopowicz GP, Magnuson T, et al. Laparoscopic antecolic Roux-en-Y gastric bypass with closure of internal defects leads to fewer internal hernias than the retrocolic approach. Surg Endosc 2008 Sep; 22(9):2056-61

27. Abasbassi M, Pottel H, Deylgat B, et al. Small Bowel Obstruction after AntecolicAntegastric Laparoscopic Roux-en-Y Gastric Bypass without Division of Small Bowel Mesentery: A Single-Centre, 7-Year Review. Obes Surg 2011 Dec;21(12):1822-7

28. Cho $M$, Pinto $D$, Carrodequas $L$, et al. Frequency and management of internal hernias after laparoscopic antecolicantegastric Roux-en-Y gastric bypass without division of the small bowel mesentery or closure of the mesenteric defects: review of 1400 consecutive cases. Surg Obes Relat Dis 2006 Mar-Apr; 2(2):87-91

29. Ahmed AR, Rickards G, Husain S et al. Bioabsorbable glycolide copolymer staple-line reinforcement decreases internal hernia rate after laparoscopic Roux-en-Y gastric bypass. Obes Surg 2008 Jul; 18(7):797-802

30. Silecchia G, Boru CE, Mouiel J, et al. Clinical evaluation of fibrin glue in the prevention of anastomotic leak and internal hernia after laparoscopic gastric bypass: preliminary results of a prospective, randomized multicenter trial. Obes Surg 2006 Feb; 16(2):125-31

31. Reavis KM. Management of the obese patient with gastroesophageal reflux disease. Thorac Surg Clin 2011 Nov;21(4):489-98

32. Garrido Jr. AB, Rossi M, Lima Jr. SE, et al. Early marginal ulcer following Roux-en-Y Gastric Bypass under proton pump inhibitor treatment: prospective multicentric study. Arq Gastroenterol 2010 AprJun;47(2):130-4

33. Kalaiselvan R, Exarchos G, Hamza N, et al. Incidence of perforated gastrojejunal anastomotic ulcers after laparoscopic gastric bypass for morbid obesity and role of laparoscopy in their management. Surg Obes Relat Dis 2012 Jul-Aug;8(4):423-8

34. Chin EH, Hazzan D, Sarpel U, et al. Laparoscopic repair of a perforated marginal ulcer 2 years after gastric bypass. Surg Endosc 2007 Nov;21(11):2110

35. Fobi MAL, Lee H, Holness R, et al. Gastric bypass operation for obesity World J Surg 1998 Sep;22(9):925-35

36. Flanagin BA, Mitchell MT, Thistlethwaite WA, et al. Diagnosis and treatment of atypical presentations of hiatal hernia following bariatric surgery. Obes Surg 2010 Mar;20(3):386-92

37. Junior WS, do Amaral JL, Nonino CB. Factors related to weight loss up to 4 years after bariatric surgery. Obes Surg 2011 Nov;21(11):1724-30

38. Tucker ON, Szomstein S, Rosenthal R. Surgical management of gastro-gastric fistula after divided laparoscopic Roux-enY gastric bypass for morbid obesity. J Gastrointest Surg 2007 Dec;11(12):1673-9

39. Dapri G, Cadière GB, Himpens J. Laparoscopic placement of non-adjustable silicone ring for weight regain after Roux-en-Y gastric bypass. Obes Surg 2009 May;19(5):650-4

40. Buchwald $\mathrm{H}$, Estok R, Fahrbach $\mathrm{K}$, et al. Weight and type 2 diabetes after bariatric surgery: systematic review and meta-analysis. Am J Med 2009 Mar; 122(3):248-56

41. Shukla AP, Ahn SM, Patel RT et al. Surgical treatment of type 2 diabetes: the surgeon perspective. Endocrine. 2011 Oct;40(2):151-61 
42. Pories WJ, Mehaffey JH, Staton KM. The surgical treatment of type two diabetes mellitus. Surg Clin North Am. 2011 Aug;91(4):821-36

43. Leslie DB, Dorman RB, Serrot FJ, et al. Efficacy of the Roux-en-Y gastric bypass compared to medically managed controls in meeting the American Diabetes Association composite end point goals for management of type 2 diabetes mellitus. Obes Surg 2012 Mar;22(3):367-74

44. Buchwald H, Ikramuddin S, Dorman RB, et al. Management of the metabolic/bariatric patient Am J Med. 2011 Dec;124(12):1099-105.

45. Di Giorgi M, Rosen DJ, Choi JJ, et al. Re-emergence of diabetes after gastric bypass in patients with mid- to long-term follow-up. Surg Obes Relat Dis 2010 May-Jun;6(3): 249-53

46. Chikungowo SM, Wolfe LG, Doddson $P$, et al. Analysis of factors associated with durable remission of diabetes after Roux-en-Y gastric bypass. Surg Obes Relat Dis 2010 May-Jun;6(3):254-9

47. Ludwig Ds, Majzoub JA, Al-Zahrani A, et al. High Glycemic Foods, Overeating, and Obesity. Pediatrics 1999 Mar; 103(3):E26

48. Bonora E, Kiechl S, Willeit J, et al. Population-based incidence rates and risk factors for type 2 diabetes in white individuals. The Bruneck study. Diabetes 2004 July;53(7):1782-9

49. Lindström J, Tuomilehto J. The Diabetes Risk Score. A practical tool to predict type 2 diabetes risk. Diabetes Care 2003 March;26(3):725-31

50. Mokdad AH, Ford ES, Bowman BA, et al. Prevalence of Obesity, Diabetes, and Obesity-Related Health Risk Factors, 2001. JAMA 2001 Jan;289(1):76-9

51. Patti ME, Goldfine $A B$. Hypoglycemia following gastric bypass surgery: diabetes remission in the extreme? Diabetologia 2010 Nov; 53(11):2276-9

52. Rabiee A, Magruder JT, Salas-Carillo R, et al. Hyperinsulinemic hypoglycemia after Roux-en-Y gastric bypass: unraveling the role of gut hormonal and pancreatic endocrine dysfunction. J Surg Res 2011 May15;177(2):199-205

53. Salehi M, Prigeon RL, D’Alessio DA. Gastric bypass surgery enhances glucagon-like Peptide 1stimulated postprandial insulin secretion in humans. Diabetes $2011 \mathrm{Sep}$;60(9):2308-14

54. Roslin M, Damani T, Oren J, et al. Abnormal glucose tolerance testing following gastric bypass demonstrates reactive hypoglycemia. Surg Endosc 2011 Jun; 25(6):1926-32

55. Cox DJ, Ford D, Gonder-Frederick L, et al. Driving mishaps among individuals with type 1 diabetes: a prospective study. Diabetes Care 2009 Dec; 32(12): 2177-80

56. Saunders R. Post-surgery group therapy for gastric bypass patients. Obes Surg 2004 Sep; 14(8):112831

57. Cui $Y$, Elahi D, Andersen DK. Advances in the etiology and management of hyperinsulinemic hypoglycemia after Roux-en-Y Gastric Bypass. J Gastrointest Surg 2011 Oct;15(10):1879-88

58. Corsale I, Corsale C. Restoration of duodenal transit in the surgical treatment of postgastrectomy syndrome. The Soupault-Bucaille procedure. Minerva Chir. $2000 \mathrm{Jul}$-Aug; 55(7-8):523-7

59. Dapri G, Cadière GB, Himpens J. Laparoscopic reconversion of Roux-en-Y gastric bypass to original anatomy: technique and preliminary outcomes. Obes Surg 2011 Aug; 21(8):1289-95

60. Service GJ, Thompson GB, Service FJ, et al. Hyperinsulinemic hypoglycemia with nesidioblastosis after gastric-bypass surgery. N Engl J Med 2005 Jul 21; 353(3):249-54

61. Kim SH, Abbasi F, Lamendola C et al. Glucose-stimulated insulin secretion in gastric bypass patients with hypoglycemic syndrome: no evidence for inappropriate pancreatic beta-cell function. Obes Surg 2010 Aug;20(8):1110-6

62. Himpens J, Dapri G, Cadière GB. Laparoscopic conversion of the gastric bypass into a normal anatomy. Obes Surg 2006 Jul;16(7):908-12

63. McLaughlin T, Peck M, Holst J, et al. Reversible hyperinsulinemic hypoglycemia after gastric bypass: a consequence of altered nutrient delivery. J Clin Endocrinol Metab 2010 Apr; 95(4): 1851-5

64. Suter M, Donadini A, Romy S, et al. Laparoscopic Roux-en-Y gastric bypass: significant long-term weight loss, improvement of obesity-related comorbidities and quality of life. Ann Surg 2011 Aug; 254(2):267-73 
65. Harbottle L. Audit of nutritional and dietary outcomes of bariatric surgery patients. Obes Rev 2011 Mar; 12(3):198-204

66. Shai I, Henkin Y, Weitzman $S$ et al. Determinants of long-term satisfaction after vertical banded gastroplasty. Obes Surg 2003 Apr; 133(2):269-74

67. Sullivan M, Karlsson J, Sjöström L. et al. Swedish obese subjects (SOS) - an intervention study of obesity. Baseline evaluation of health and psychosocial functioning in the first 1743 subjects examinees. Int J Obes Relat Metab Disord1993 Sep; 17(9):503-12

68. Gentry K, Halverson JD, Heisler S. Psychologic assessment of morbidly obese patients undergoing gastric bypass: a comparison of preoperative and postoperative adjustment. Surgery 1984; 95:21520

\section{CHAPTER SIX AT A GLANCE}

\section{Long-term (9 years) outcomes of LRYGB}

-EBMIL:

$56.2 \%(88.0 \%$ at 2 years)

-Complications:

$9 \%$ internal hernia

28\% new-onset DMII

$8 \%$ hypoglycemia (neuroglycopenia)

-Conversions

$4 \%$ conversions (distalization, normal anatomy)

-Patient acceptance: satisfaction index $76.0 \%$

BAROS 2.0 


\section{Chapter 7.}

\section{Outcomes of Revisional Procedures for Insufficient Weight Loss or Weight Regain after Roux-en- $Y$ Gastric Bypass}

Jacques Himpens MD,Laia Coromina MD, Anneleen Verbrugghe MD, Guy-Bernard Cadière MD,PhD

Department of Gastrointestinal and Obesity Surgery, European School of Laparoscopic Surgery,Saint-Pierre University Hospital, Brussels, Belgium

Journal of Obesity Surgery, Volume 22, Number 11, November 2012 


\subsection{ABSTRACT}

Introduction: The Roux-en-Y gastric bypass (RYGB) performed laparoscopically (LRYGB) is the most frequently performed bariatric procedure in Belgium. However, late results in terms of weight loss or weight regain are inconsistent and may warrant a second procedure. This retrospective study analyzes the laparoscopic options for revisional surgery after LRYGB

Methods: Between January 1, 2001, and December 31, 2009, 70 patients underwent a new laparoscopic procedure for poor weight loss or weight regain after LRYGB. The revisional procedure was performed a median of 2.6 years (1-8) after the initial bypass operation. Fifty-eight patients were available for follow-up (82.9\%); 19 underwent distalization and 39 a new restrictive procedure.

Results: The mean body mass index (BMI) before the revisional procedure was $39.1+11.3 \mathrm{~kg} / \mathrm{m}^{2}$ (30.8-51.8), down from $42.7+19.7 \mathrm{~kg} / \mathrm{m}^{2}$ (33.0-56.6) initially, which corresponded to a percentage of excess weight loss (EWL) of $12.4+9.3 \%$ (1.0-29.1).

After the corrective procedure, with a follow-up of approximately 4 years, mean BMI was $29.6+12.4 \mathrm{~kg} / \mathrm{m}^{2}$ (18.0-45.5), for a significant additional \% EWL of $53.7+9.8 \%(2.0-65.8)$.

The overall severe complication rate was $20.7 \%$, and the reoperation rate was $10.4 \%$. The overall leak rate was $12.1 \%$. Patients suffering from leaks could consistently be treated conservatively or by stent placement. Two patients needed repeat reconversion after distal bypass.

The satisfaction index was good in just over $50 \%$ of the patients.

Conclusion: Revisional laparoscopic surgery after RYGB performed for weight issues provides good additional weight loss but carries significant morbidity. Leaks can usually be handled non-surgically. Patient satisfaction is only fair. 


\subsection{INTRODUCTION}

The laparoscopic Roux-en-Y gastric bypass (LRYGB) has become the most frequently performed bariatric procedure in Belgium, while for adjustable band gastroplasty (LAGB), the numbers are declining rapidly. Unfortunately, even the LRYGB is fraught with a significant number of failures in terms of weight loss. Despite the fact that many patients can be helped by counseling to correct their weight problems, a substantial number of patients need corrective procedures, often for weight issues. Some procedures aim at increasing restriction, whereas others aim at inducing malabsorption. Both endoscopic and surgical techniques are available.

\subsection{MATERIAL AND METHODS}

\subsubsection{Patients}

Nine hundred sixty-one patients were treated by LRYGB in our department of obesity surgery between January 1, 2000, and December 31, 2009. Among these patients, 623 underwent a gastric bypass as their first weight loss operation, but 338 (35.2\%) had undergone at least one bariatric procedure beforehand. In a sample of 77 patients followed over 9 years, we recently found that the final weight loss was not significantly different between the primary and the secondary LRYGB patients and averaged a loss of excess Body Mass Index (EBMIL) of some 56\% (data not shown, submitted for another publication in the Journal of Obesity Surgery)

Some of the LRYGB patients in our practice, however, did not experience satisfactory weight loss, or presented significant weight regain after an initial acceptable weight loss. According to Reinhold, weight loss is deemed insufficient when it does not reach $50 \%$ of the excess weight, or when the residual Body mass Index (BMI) remains higher than $35 \mathrm{~kg} / \mathrm{m}^{2} .^{1}$

The decision to reintervene, either laparoscopically or endoscopically, was made by a multidisciplinary team, consisting of a dietitian, a psychologist, a gastroenterologist, a radiologist, an endocrinologist and a bariatric surgeon. Whereas the psychologist evaluated the patients' psychological power to bear yet another operation, the dietitian merely analyzed the subjects' dietary adjustment mode to the bypass construction. In brief, 2 specific ways of adaptation to the reduced caloric intake were investigated: either an increase in the number of meals (grazing, polyphagia) or an augmentation of the size of meals (hyperphagia). ${ }^{2,3}$

The gastro-enterologist and the radiologist evaluated the size of the gastric pouch and of the gastro-enteral anastomosis (GE) and documented possible aberrations such as gastro-gastric fistula (GGF) or marginal ulcers. The endocrinologist investigated the need for additional measures to address the possible lack of response or the resurgence of comorbidities amenable to improve with additional 
weight loss. Finally, the surgeon decided on the type of corrective procedure compatible with the local anatomical conditions that could have been severely altered as after revisional LRYGB or in patients who had suffered from a leak after the LRYGB procedure.

\subsubsection{Procedures}

The following 6 corrective procedures were carried out (Table 2)

- endoscopic refashioning of the stomach pouch and of the GE.

- laparoscopic distalization of the bypass, in which the alimentary limb was sectioned flush with the anastomosis with the biliopancreatic limb and moved distally some $150 \mathrm{~cm}$ proximal to the ileocecal valve.

- laparoscopic placement of a non-adjustable, custom-made $6.5 \mathrm{~cm}$ long "Fobi" ring adjusted around the gastric pouch some $2 \mathrm{~cm}$ cephalad of the GE

- laparoscopic refashioning of the gastric pouch and the GE. The procedure consisted when indicated of resection of the "candy cane" (the blind end of the alimentary limb at the GE), and in all cases of refashioning of the GE, and of a sleeve resection of the greater curvature side of the gastric pouch, around an orogastric 34 French tube kept in close contact with the lesser curvature side. As a rule, at the same time the upper pole of the gastric remnant was resected.

- laparoscopic reconversion of the bypass into a normal anatomy and transformation into a sleeve gastrectomy (LSG) in one session

- laparoscopic plication of the pouch, the GE and the alimentary limb, around a 34 French orogastric tube.

The indications for each of the aforementioned procedures are:

- for the endoscopic procedure: patients with weight loss issues after revisional LRYGB, especially with evidence of loss of restriction at endoscopy and X-ray.

- for the laparoscopic procedures (table 2):

1. distalization procedure: patients after primary or revisional LRYGB, who did not experience sufficient weight loss OR who presented weight regain and increased caloric intake

2. placement of a "Fobi" ring: patients who maintained a rather normal aspect of the bypass but developed weight regain by a hyperphagia behavior after primary LRYGB

3. reconstruction of the bypass: patients who after primary or secondary bypass developed hyperphagia together with an objective anatomical flaw (gastro-gastric fistula, anastomotic ulcer, candy cane deformation of the alimentary loop concomitant with size increase of the gastric pouch)

4. LSG construction at reconversion into normal anatomy: patients who never lost acceptable weight after primary LRYGB 
5. Plication of the gastric pouch as well as the alimentary loop: patients who regained weight after secondary bypass or after bypass complicated by anastomotic leak

\subsubsection{Study design}

All patients operated on for insufficient weight loss or for weight regain after a LRYGB procedure performed at our institution were included in this retrospective study, that covered the period of time between January 1, 2000 and December 31, 2009.

The charts were reviewed and the data collected by 2 of the authors (AV, LC).

The primary outcome measurements were the weight loss parameters BMI and percentage of EWL (EWL\%) recorded in October 2011, as well as the postoperative complications. The secondary outcome analyzed was patient satisfaction, which was evaluated in accordance with the Bariatric Analysis and Reporting Outcome System (BAROS). ${ }^{3}$ In brief, with this evaluation tool, 3 psychomedical aspects are estimated: weight loss, changes in comorbidities and quality of life (QOL). Up to 3 points are allotted for each category, and points are deducted for complications and reoperations. $^{3}$

\subsection{STATISTICAL ANALYSIS}

Data were collected from a prospectively kept database. When normally distributed, the results were reported as mean + standard deviation and range. When the distribution was not normal, the results were expressed as median plus range. The t- test for paired variables was used for significance analysis of the evolution of the variables weight, BMI and \% EWL. Statistical significance was reached at $p<0.05$.

\subsection{RESULTS}

Between January 1, 2001, and December 31, 2009, 88 of the patients (9.2\%) who had undergone LRYGB in our department underwent revision for weight issues: either for insufficient weight loss or weight regain. The revisional procedure took place 3.0 years (range 1.5-8.0) after the LRYGB. Eighteen patients underwent endoscopic reshaping of the gastric pouch and anastomosis by use of the StomaphyX ${ }^{\circledR}$ device (Endogastric Solutions, Redmond, WA, USA). They were part of a feasibility study protocol and are not further discussed here.

Seventy patients were treated laparoscopically. Of the latter, complete data was available in 58 (82.9\%) and follow-up extended over a median of 48 months (18-122). 
Forty-eight patients (82.8\%) were women, and the patients' age averaged 50 +2.5 years old (18-78).

\subsubsection{Laparoscopic procedures (table1, table2)}

- Nineteen patients were treated by laparoscopic distalization of their bypass. Three patients in this group had undergone LAGB before the LRYGB procedure, followed by poor weight loss. One additional patient had had little benefit from her primary bypass in terms of weight loss and diabetes control. Fifteen additional patients had presented weight regain after primary LRYGB.

- In 10 patients, classified as hyperphagist after weight regain after primary bypass, a non-adjustable, custom-made $6.5 \mathrm{~cm}$ "Fobi" ring was placed laparoscopically around the gastric pouch, that had essentially remained unchanged (no dilation).

- In 12 patients, the gastric pouch and the GE were revised and refashioned laparoscopically. Three of the latter patients, all of whom had undergone bariatric procedures previously (LAGB in 1 and VBG in 2) suffered from poor weight loss and presented with medical therapy-resistant concomitant anastomotic ulcers. Five additional patients of this group, all of whom had undergone LAGB previously, suffered a gastro-gastric fistula (GGF). In 4 patients after primary LRYGB, the dietitian had diagnosed weight regain together with a hyperphagia behavior and gastroscopy and upper GI series had demonstrated a significant candy cane deformation of the alimentary loop.

- In 9 other patients who presented remarkably poor weight loss ( $E W L<10 \%)$ after primary LRYGB, the bypass was reversed and transformed into an LSG in one laparoscopic session, followed at a later stage by a laparoscopic duodenal switch (LDS) in 3.

- Eight patients underwent plication of the pouch, the GE and the alimentary limb for weight regain. Four of the patients had undergone LAGB before the bypass; three had had a vertical banded gastroplasty (VBG); the last patient had suffered an anastomotic leak at the time of the bypass carried out as a primary procedure. 
Table 1. Choice of corrective procedure depending on history of poor weight loss or weight regain. Poor weight loss was addressed vy a new philosophy: malabsorption (distalization) or pure restriction (LSG). LSG stands for Laparoscopic Sleeve Gastrectomy.

\begin{tabular}{l|c|c|c} 
Procedure & \multicolumn{2}{|l|}{$\begin{array}{l}\text { Number of Patients } \\
\text { Treated for }\end{array}$} & Total Number \\
Treated for & Weight Regain & \\
of Patients \\
\hline Distalization & 4 & 15 & 19 \\
Fobi Ring & 0 & 10 & 10 \\
Bypass Reconstruction & 3 & 9 & 12 \\
LSG & 9 & 0 & 9 \\
Plication & 0 & 8 & 8 \\
\hline TOTAL & 16 & 42 & 58
\end{tabular}

Table 2. Overview of the indication for revisional procedures for weight issues after primary and revisional laparoscopic Roux-en-Y gastric bypass. GGF stands for gastro-gastric fistula. LSG stands for laparoscopic sleeve gastrectomy.

\begin{tabular}{l|l} 
Normal anatomy & Anatomical abnormality \\
\hline No weight Loss $\rightarrow$ Distalization & Bypass Reconstruction \\
Weight Regain $\rightarrow$ Plication &
\end{tabular}

Laparoscopic Procedures for Weight Issues after Revisional or complicated LRYGB

\begin{tabular}{l|l} 
Normal anatomy & $\begin{array}{l}\text { Anatomical Flaw } \\
\text { (candy cane, pouch volume increase) }\end{array}$ \\
\hline No weight Loss $\rightarrow$ LSG & Bypass Reconstruction (hyperphagia) \\
Weight Regain $\rightarrow$ Distalization (polyphagia) & \\
$\rightarrow$ Fobi Ring (hyperphagia) &
\end{tabular}

Laparoscopic Procedures for Weight Issues after Primary LRYGB 


\subsubsection{Main outcomes}

The mean body mass index (BMI) before the revisional procedure was $39.1+11.3$ $\mathrm{kg} / \mathrm{m}^{2}(30.8-51.8)$, down from $42.7+19.7 \mathrm{~kg} / \mathrm{m}^{2}$ (33.0-56.6) initially, which corresponded to a pre-procedural percentage of excess weight loss (EWL) of $12.4+9.3 \%$ (-1.0-29.1).

The mean hospital stay for the revisional procedure was $5.9+10$ days $(1-78)$. There were no mortalities.

At the time of this study, after a median of $48(18-122)$ months after the revisional procedure, the overall BMI was $29.6+12.4 \mathrm{~kg} / \mathrm{m}^{2}(18.0-45.5)$. Compared to the initial BMI value, the difference was statistically significant $(p<0.001)$. Compared to the preprocedural value, this number reached statistical significance as well $(p<0.01)$. The additional percentage of EWL, with reference to preprocedural weight loss, was significant: $53.7+9.8 \%(2.0-65.8)(p<0.001)$.

The progression of BMI with time can be found in tables 3 (for the distalization procedure), 4 (for reconstruction of the bypass) and 5 (for all procedures combined).

Table 3. Progression of BMI with time after laparoscopic distalization.

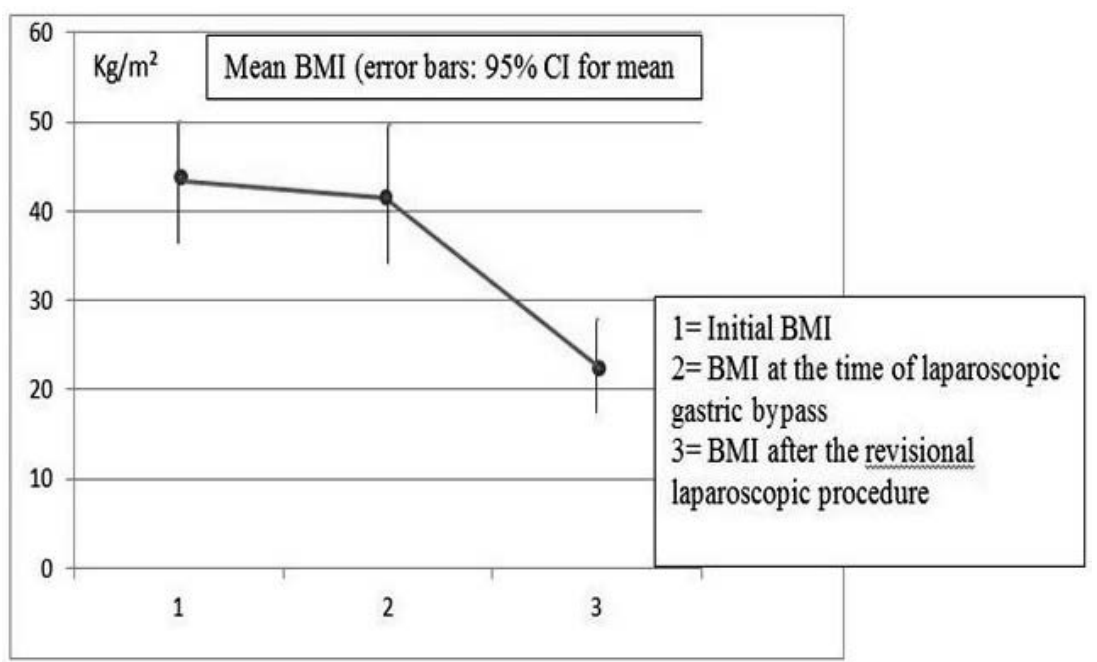


Table 4. Progression of BMI with time after laparoscopic reconstruction of the bypass.

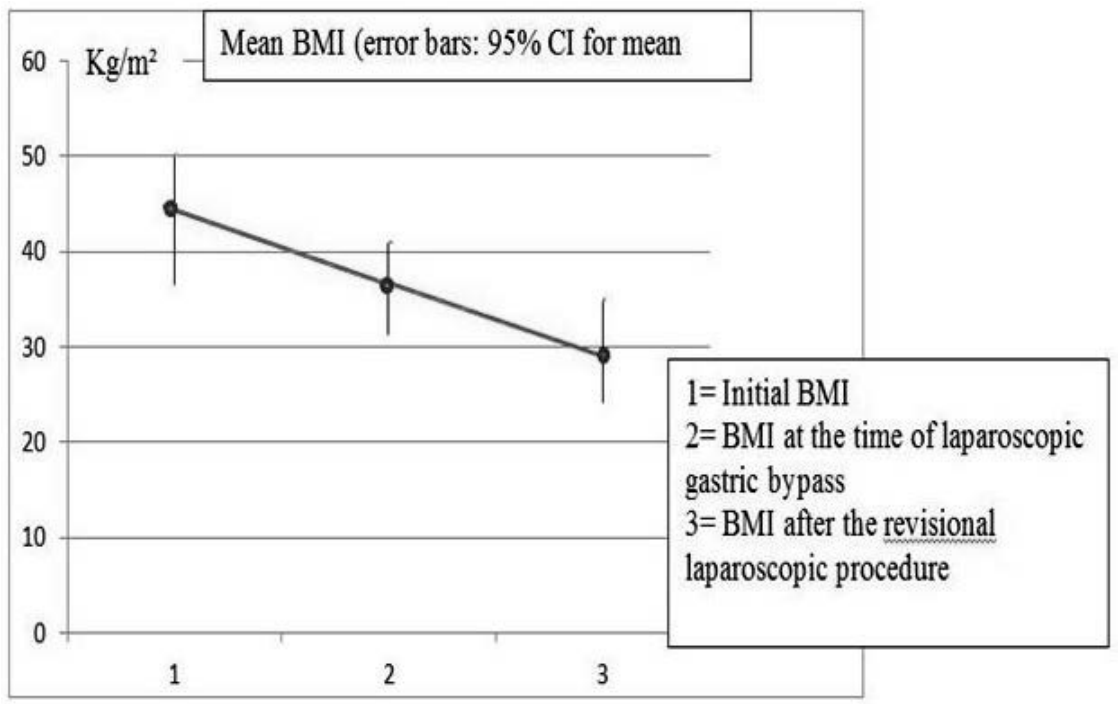

Table 5. Progression of BMI with time after laparoscopic revision for weight issues after laparoscopic RouxenY Gastric Bypass.

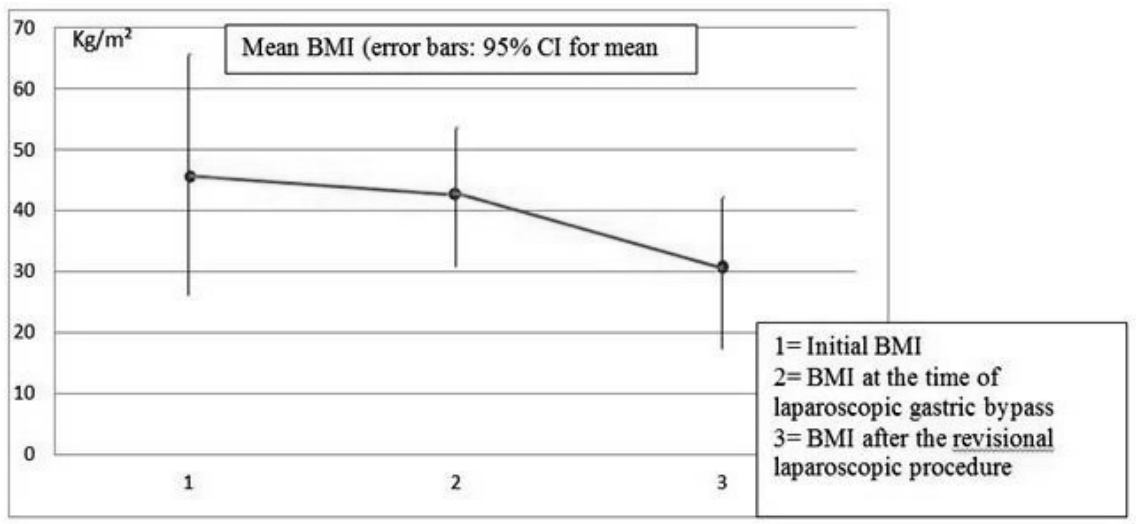

\subsubsection{Reoperations and complications (table 6)}

The overall reoperation rate was $10.4 \%$, and the overall severe complication rate was $20.7 \%$.

- In the distalization group only, the morbidity rate was $21.1 \%$. One of the patients in this latter group developed a Douglas abscess, probably on a hidden leak. She was treated conservatively and eventually healed but stayed in the hospital for two months. Two other distalization patients (10.5\%) needed reversal of the by- 
pass into its initial form because of cachexia and anorexia appearing some 2 years after the revisional procedure. A fourth patient required laparoscopic reoperation for an internal hernia.

- One (12.5\%) of the patients who underwent plication of the pouch, GE and alimentary limb, developed overwhelming sepsis from an infected intrauterine device 6 weeks after the procedure and underwent exploratory laparotomy that could exclude a leak at the operative site.

- There were 2 (20\%) postoperative intragastric erosions of Fobi rings. Both cases were reoperated on, and the bands were removed; they developed a leak and were successfully treated by stents.

- Three patients developed a leak after refashioning of the bypass construction. This group included 2(40\%) of the 5 GGF patients; they were managed successfully by stents. The third patient who had presented with an anastomotic ulcer was treated conservatively by proton pump inhibitors, antibiotics and parenteral nutrition.

- Two of the patients (28.6\%) who were submitted to reversal of the bypass together with LSG suffered leaks at the gastro-gastric anastomosis: one was treated successfully by a stent; the other suffered a short-lived fistula that healed with conservative measures.

Thus, the overall leak rate in the group of 58 patients was $12.1 \%(n=7)$. All the leaks encountered were successfully managed endoscopically or conservatively.

Table 6. Overview of complications after corrective operations for weight issues after laparoscopic RouxenY Gastric Bypass. LSG stands for Laparoscopic Sleeve Gastrectomy.

\begin{tabular}{l|c|c|c}
\hline Type of Procedure & Number of Patients & Number of \\
& Complications & Rumber of \\
& 19 & 4 & 3 \\
\hline Distalization & 10 & 2 & 2 \\
Fobi Ring & 12 & 2 & 1 \\
Bypass Reconstruction & 9 & 1 & 6 \\
LSG & 8 & 12 & \\
Plication & 58 & &
\end{tabular}




\subsubsection{Patient satisfaction}

After the corrective laparoscopic procedures, the BAROS score evaluation for quality of life was 3.02 (1-7.5), which is considered a "fair" outcome; ${ }^{1}$ of the 58 patients who could be evaluated, 30 (51.7\% of the patients) were satisfied, 7 (12.1\%) were neutral, and 21 (36.2\%) were dissatisfied.

\subsection{DISCUSSION}

Not all patients do well after a bariatric procedure, and the LRYGB is no exception. Some patients do not lose sufficient weight; others regain weight after an initial good weight loss; ${ }^{5}$ still others do well in terms of weight loss but suffer from side effects the procedure induced. Common invalidating side effects after LRYGB include: persisting gastro-esophageal reflux (GERD), ${ }^{6}$ exaggerated dumping ${ }^{7}$ and hypoglycemic syndrome. ${ }^{8}$ In this study we focused solely on the roughly $9 \%$ of patients who required reoperation after LRYGB because of weight issues.

The decision to revise a patient surgically for a bypass that failed in terms of weight loss is critical. ${ }^{9}$ If at all possible, conservative means should be preferred. ${ }^{10}$ Hence, a multidisciplinary team should be consulted for a unanimous decision before considering reoperation. ${ }^{11}$

The revisional procedures can be classified into two groups: endoscopic techniques $(n=18)$ and laparoscopic procedures $(n=70)$.

Because the incidence of complications after revisional surgery increases with the number of previous operations, ${ }^{12}$ the primary or secondary character of the initial bypass plays an important role in the decision-making. According to the literature, ${ }^{13}$ an endoscopic procedure should be the first choice to improve weight loss in previously operated cases, to limit morbidity.

Consequently, we usually elected for laparoscopic revisional surgery in relatively simple primary bypass patients. In addition, we chose for this approach in more complex cases where, according to the multidisciplinary consultation, the potential benefit from additional weight loss clearly outweighed the surgical risk. The choice as to the type of corrective procedure should be guided by the fear for complications. In patients in whom the bypass had been constructed in previously dissected tissues, or in whom tissues were altered by a postoperative fistula, we therefore tried to avoid stapling in that area and elected either non-resective techniques including plication of the gastric pouch and the alimentary loop, or distalization of the $\mathrm{Y}$ anastomosis.

Other factors influencing the choice of procedure, besides local anatomical conditions included: did the patient experience weight regain versus insufficient 
weight loss? (the latter inviting for a different philosophy, as a distal bypass or a sleeve gastrectomy); how did the comorbidities (especially DMII) evolve? (lack of response inviting for a more radical procedure, i.e. a distal bypass); how did the patient adjust his/her eating behavior? ${ }^{14}$ Patients who according to the dietitian's diagnosis had become grazers were preferably treated with a malabsorptive procedure, whereas volume eaters were treated by adding new restrictions (Figure 1).

\section{BARIATRIC ALGORITHM}

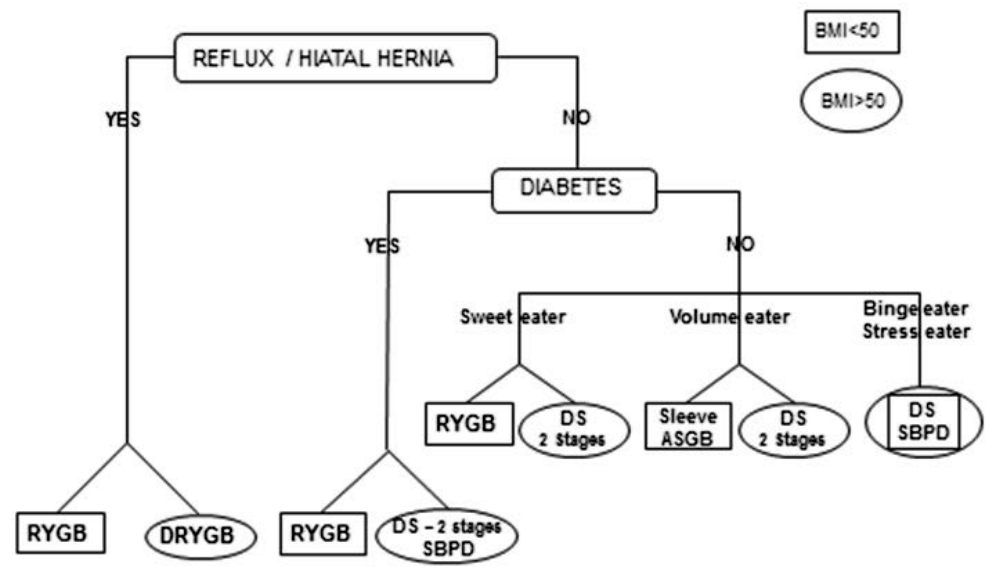

Figure 1. Algorithm for revisional surgery after failed Roux-enY Gastric bypass. DS= Duodenal Switch.

Despite the diversity of procedures and their indications, the surgical procedures overall provided significant additional weight loss (table 5).

The fact that the mechanism of action of the distal bypass, being malabsorptive, substantially differs from the classic RYGB makes it (theoretically) a logical choice in case of outright failure of the latter. However, while good weight loss indeed was obtained by distalizing the bypass ${ }^{14}$ (table 3 ), in the long term, protein malnutrition and cachexia developed in a number of patients. This latter evolution has been described extensively in the literature. ${ }^{15}$ The team around Sugerman ${ }^{16}$ demonstrated that converting a primary into a distal bypass could carry severe metabolic consequences, even resulting in mortality in some patients. Brolin ${ }^{17}$ found that only half of patients had clear benefits from distalization of the bypass. In a recent paper, Rawlins et al. ${ }^{9}$ described a series of 29 patients undergoing open distalization of a RYGB. In this construction, with a $100-\mathrm{cm}$-long common limb and a $250-\mathrm{cm}$ alimentary-common limb, 6 patients developed protein malnutrition, and one patient required reversal. We agree with these authors that, when distalization of the bypass is contemplated, it can only be performed in compliant follow-up patients. Despite these precautions, 2 (10.5\%) of our patients treated by this technique developed protein malnutrition. Fortunately, distal bypass construction proved to be 
just as reversible as conventional LRYGB, ${ }^{3}$ and protein malnutrition could be halted in the 2 patients who underwent reversal of their distalization. More gentle attempts at distalization (by lengthening the alimentary loop to $200 \mathrm{~cm}$, for example), however, have proved useless in the long term. ${ }^{18}$

Leading authors have stated that restriction corrected by restriction is fraught with poor results in terms of weight loss. ${ }^{19}$ Repeating a restrictive measure can be questioned, because weight loss failure after bypass, in fact, implies a failure to change old eating behaviors. ${ }^{20}$ Indeed, a bypass itself very seldom succeeds in changing a patient's eating habits. ${ }^{21}$ Conversely, it appears that volume increases after bypass surgery, as demonstrated by endoscopic or X-ray evidence, do not necessarily imply weight regain, therefore making new restrictive efforts theoretically all but futile. ${ }^{22}$ However, in very carefully selected cases, especially when patient compliance is questionable, additional restriction, rather than malabsorption, can be salutary. Additionally, the presence of a new restricting factor can be useful in patients who besides weight regain suffer from exaggerated dumping. ${ }^{23}$

- One option is the placement of a band, whether adjustable ${ }^{24}$ or not. $^{25}$ The banded bypass has been popularized by Fobi. ${ }^{26}$ Implanting an adjustable band reportedly carries better results, but this finding is not uniformly found. ${ }^{27} \mathrm{~A}$ significant drawback with the banding technique is the incidence of intragastric migration (erosion) as demonstrated in our series. ${ }^{28}$

- Another option for additional restriction is to laparoscopically reshape the bypass at the gastric pouch, the GE anastomosis and the proximal alimentary loop. This technique is technically demanding, and weight loss results are usually modest. ${ }^{29}$ It represents, however, a valuable option when the patient presents a clear anatomical flaw at endoscopy or barium swallow. These aberrations include a gastrogastric fistula (GGF), a candy cane deformation of the alimentary loop or an anastomotic ulcer, a condition that is very hard to treat by techniques other than surgery. ${ }^{5,12}$ The downside of the "bypass reshaping" procedure is the high incidence of postoperative leaks, especially when the procedure aimed at the correction of a GGF. To reduce complications, treatment of GGF has been attempted endoscopically, unfortunately with poor results. ${ }^{30}$

- Still another possibility is reversing the bypass ${ }^{32}$ and to complement this procedure with a sleeve gastrectomy. ${ }^{32}$ In our department, the conversion of a LRYGB into a LSG was carried out with the intention of eventually performing a DS, a clearly malabsorptive procedure, at a later stage. This technique was described earlier by our team. ${ }^{32}$ The numbers were too small and the follow-up too short to draw final conclusions about this technique, but the transformation into LSG could constitute a valuable option for patients who presented only modest weight loss after LRYGB and in whom a different "operative philosophy" was pursued. 
- An interesting last option is to address the pouch, the anastomosis and the alimentary limb all at once and to reduce their size. Parikh and Gagner have demonstrated that resecting the pouch and alimentary loop in a longitudinal fashion is feasible but not very effective. ${ }^{33}$ We believe that, in light of the risk of complications, especially because of significant tissue alteration as after redoLRYGB or in cases who suffered a postoperative leak, it is preferable to choose a procedure with limited risks. The plication we performed, while probably safer, mimicked the longitudinal resection carried out by Gagner but was inspired as well by the greater curvature plication techniques developed in similarity with LSG. $^{34}$ As in this latter procedure, we performed the plication with nonabsorbable material around a 34 French orogastric tutor tube. The results of these latter attempts appeared promising, but longer-term results must again be awaited.

Obviously, the beneficial results of revisional surgery should be weighed against the morbidity of this second procedure. Usually, secondary procedures are characterized by more severe side effects and complications. ${ }^{12}$ Our reoperation rate was comparable to the reoperation rate in open surgery. ${ }^{35}$ In our series, roughly one out of 5 patients developed a severe surgical complication. Whereas the mortality was zero, the severity of the complications translated into long hospital stays, approaching 6 days, versus the usual three days for a "normal" bypass. ${ }^{36}$ In our group, morbidity was quite high, especially when foreign material was involved. This result paralleled our finding with $L A G B$, in which approximately $30 \%$ of the patients developed intragastric migration of the band. ${ }^{37}$ As an analogy, it is not surprising to find high numbers of erosion when a band is placed around a staple line ${ }^{38}$ or in poorly vascularized tissues, ${ }^{39}$ as typically encountered in revisional surgery. We elected to remove the eroding "Fobi" rings laparoscopically, but a better option would have been to remove them endoscopically, ${ }^{40}$ as demonstrated by 2 patients developing leaks after laparoscopic ablation of the band.

Overall, the leaks that our patients encountered were successfully treated with conservative methods. As a rule, if at all possible, we preferred to treat leaks in bariatric patients by conservative means, as described by others ${ }^{41}$, or endoscopically by stents, if the leaks appeared too large or the tissues too atonic ${ }^{42}$. Selfexpanding, partly covered metallic stents were successfully used in patients who developed leaks after GGFs, after band erosion or after anastomotic revisions, as well as in one patient who leaked after transformation into LSG. The only patient we had to treat with a laparotomy was a patient in whom we had performed a plication of the gastric pouch and the alimentary loop and in whom we suspected a leak. Some 2 months postoperatively, she developed a fulminating sepsis that, with hindsight, appeared to be gynecological in origin. 
When we analyzed patient satisfaction, the results were only fair. Reperformed operations, as a rule, have poorer results than initial operations, ${ }^{43}$ and this rule goes for patient satisfaction as well. This finding most likely has to do with the complication rate, which is responsible for lower BAROS scores ${ }^{4}$ and/or with relatively poor patient acceptance, especially after new restrictive procedures. ${ }^{44}$ Patients should therefore be notified that despite anticipated, acceptable, additional weight loss, long-term satisfaction might become an issue after revisional surgery for failed gastric bypass.

\subsection{CONCLUSIONS}

With the increasing numbers of LRYGB, long term weight issues have become a problem for some patients. Several types of actions are possible, depending on the history (primary bypass or not) and on the type of weight problem (insufficient weight loss or weight regain). We focused here on laparoscopic revisions. Laparoscopic reoperations aimed at increasing malabsorption were effective, but at the cost of severe morbidity and symptoms of malnutrition, and they should therefore be performed only in very well selected cases. Adding a restrictive aspect can be performed by different means. The use of a constricting band, as well as reshaping the bypass construction, had a significant morbidity. Transforming the bypass into a sleeve, possibly as the first step of a DS, as well as plicating the pouch and the alimentary loop, deserves further consideration. Patient satisfaction was relatively disappointing, which may have had to do with the high morbidity figures.

\subsection{REFERENCES}

1. Reinhold RB. Critical analysis of long term weight loss following gastric bypass. Surg Gynecol Obstet 1982 Sep;155(3):385-94.

2. Kruseman $M$, Leimgruber $A, Z$ umbach $F$, et al. Dietary, weight, and psychological changes among patients with obesity, 8 years after gastric bypass. J Am Diet Assoc 2010 Apr;110(4):527-34.

3. Dapri G, Cadière GB, Himpens J. Laparoscopic reconversion of Roux-en-Y gastric bypass to original anatomy: technique and preliminary outcomes. Obes Surg 2011 Aug;21(8):1289-95.

4. Oria HE, Moorehead MK. Bariatric analysis and outcome reporting system (BAROS). Obes Surg. 1998;8:487-99.

5. Higa K, Ho T, Tercero F, et al. Laparoscopic Roux-en-Y gastric bypass: 10 year follow-up. Surg Obes Relat Dis 2011 Jul-Aug; 7(4):516-25.

6. Merrouche M, Sabaté JM, Jouet $P$, et al. Gastro-esophageal motility disorders in morbidly obese patients before and after bariatric surgery. Obes Surg 2007 Mar;17(7):894-900.

7. Tack J, Arts J, Caenepeel P, et al. Pathophysiology, diagnosis and management of postoperative dumping syndrome. Nat Rev Gastroenterol Hepatol 2009 Oct;6(10):583-90.

8. Cui Y, Elahi D, Andersen DK. Advances in the etiology and management of hyperinsulinemic hypoglycemia after Roux-en-Y gastric bypass. J Gastrointest Surg 2011 Oct;15(10):1879-88.

9. Rawlins ML, Teel D 2nd, Hedgcorth K, et al. Revision of Roux-en-Y gastric bypass to distal bypass for failed weight loss. Surg Obes Relat Dis.2011 Jan-Feb;7(1):45-9. 
10. Faria $\mathrm{SL}$, de Oliveira Kelly $\mathrm{E}$, Lins $\mathrm{RD}$, et al. Nutritional management of weight regain after bariatric surgery. Obes Surg 2010 Feb;20(2):135-9.

11. Runkel N, Colombo-Benkmann M, Huettl TP, et al. Evidence-based German guidelines for surgery for obesity. Int J Colorectal Dis 2011April;26(4):397-404.

12. Patel S, Szomstein S, Rosenthal RJ. Reasons and Outcomes of reoperative bariatric surgery for failed and complicated procedures (excluding adjustable gastric banding). Obes Surg $2010 \mathrm{Jul} 30$; 13.Ryou $\mathrm{M}$, Ryan MB, Thompson CC. Current status of endoluminal bariatric procedures for primary and revision indications. Gastrointest Endosc Clin N Am. 2011 Apr;21(2):315-33;

14. Dapri G, Cadière GB, Himpens J. Laparoscopic conversion of Roux-en-Y gastric bypass to distal gastric bypass for weight regain. Laparoendosc Adv Surg Tech A 2011 Jan-Feb;21(1):19-23;

15. Fobi MA, Lee $H$, Igwe $D$ Jr. et al. Revision of failed gastric bypass to distal Roux-en-Y gastric bypass: review of 65 cases. Obes Surg 2001 Apr;11(2):190-5;

16. Sugerman HJ, Kellum JM, DeMaria EJ. Conversion of proximal to distal gastric bypass for failed gastric bypass for superobesity. J Gastrointest Surg. 1997 Nov-Dec;1(6):517-24;

17. Brolin RE, Cody RP. Adding malabsorption for weight loss failure after gastric bypass; Surg Endosc 2007Nov;21(11):1924-6.

18. Christou NV, Look D, Maclean LD. Weight gain after short- and long-limb gastric bypass in patients followed for longer than 10 years. Ann Surg 2006 Nov;244(5):734-40.

19. Brolin RE, Cody RP. Weight loss outcome of revisional bariatric operations varies according to the primary procedure. Ann Surg 2008 Aug;248(2):227-32.

20. Cook CM, Edwards C. Success habits of long-term gastric bypass patients. Obes Surg 1999 Feb;9(1):80-2.

21. Guerdjikova Al, West-Smith L, Mc Elroy SL, et al. Emotional eating and emotional eating alternatives in subjects undergoing bariatric surgery. Obes Surg 2007 Aug;17(8):1091-6.

22. Roslin M. Comment on: Long-term follow-up in patients undergoing open gastric bypass as a revisional operation for previous failed restrictive procedures. Surg Obes Relat Dis $2011 \mathrm{Jul} 2$.

23. Z'graggen K, Guweidhi A, Steffen R, et al. Severe recurrent hypoglycemia after gastric bypass surgery. Obes Surg 2008 Aug;18(8):981-8.

24. Bessler M, Daud A, DiGiorgi MF, et al. Adjustable gastric banding as revisional bariatric procedure after failed gastric bypass-intermediate results. Surg Obes Relat Dis. 2010 Jan-Feb;6(1):31-5.

25. Dapri G, Cadière GB, Himpens J. Laparoscopic placement of non-adjustable silicone ring for weight regain after Roux-en-Y gastric bypass. Obes Surg 2009 May;19(5):650-4.

26. Fobi M. Banded gastric bypass: combining two principles.2004 ASBS Consensus Conference. Surg Obes Relat Dis. 2005 May-Jun;1(3):304-9.

27. Irani K, Youn HA, Ren-Fielding GA et al. Midterm results for gastric banding as salvage procedure for patients with weight loss failure after Roux-en-Y gastric bypass. Surg Obes Relat Dis 2011 MarApr;7(2):219-24).

28. Júnior WS, Pitanga CK, Borges $\mathrm{CN}$,et al. Treatment of gastrogastric fistula after Roux-en-Y gastric bypass: surgery combined with gastroscopy. Obes Surg. 2007 Jun;17(6):836-8.

29. Mueller MK, Wildi S, Schlz T et al. Laparoscopic pouch resizing and redo of gastro-jejunal anastomosis for pouch dilatation following gastric bypass. Obes Surg 2005 Sep;15(8):1089-95.

30. Fernandez-Esparrach G, Lautz DB, Thompson CC. Endoscopic repair of gastrogastric fistula after Roux-en-Y gastric bypass: a less-invasive approach. Surg Obes Relat Dis2010 May-June;6(3):282-8.

31. Himpens J, Dapri G, Cadière GB. Laparoscopic conversion of the gastric bypass into a normal anatomy. Obes Surg 2006 Jul;16(7):908-12.

32. Dapri G, Cadière GB, Himpens J. Laparoscopic conversion of Roux-en-Y gastric bypass to sleeve gastrectomy as first step of duodenal switch: technique and preliminary outcomes. Obes Surg 2011 Apr;21(4):517-23.

33. Parikh M, Heacock L, Gagner M. Laparoscopic "gastrojejunal sleeve reduction" as a revision procedure for weight loss failure after Roux-en-Y gastric bypass. Obes Surg 2011 May;21(5):650- 
34. Menchaca HJ, Harris JL, Thompson SE et al. Gastric plication: preclinical study of durability of serosato-serosa apposition. Surg Obes Relat Dis2011 Jan-Feb;7(1):8-14.

35. Hedberg J, Gustavsson S, Sundbom M. Long-term follow-up in patients undergoing open gastric bypass as a revisional operation for failed previous restrictive procedures. Surg Obes Relat Dis 2011 Jun 30.

36. Tiwari MM, Goede MR, Reynoso JF, et al; Differences in outcomes of laparoscopic gastric bypass. Surg Obes Relat Dis2011 May-June;7(3):277-82.

37. Himpens J, Cadière GB, Bazi M et al. Long-term outcomes of laparoscopic adjustable gastric banding. Arch Surg 2011 Jul;146(7):802-7.

38. Msika S. Surgery for morbid obesity: 2. Complications. Results of a technologic evaluation by the ANAES J Chir (Paris) $2003 \mathrm{Feb;140(1):4-21.}$

39. Kurian M, Sultan S, Garg K et al. Evaluating gastric erosion in band management: an algorithm for stratification of risk. Surg Obes Relat Dis2010 Jul-Aug;6(4):386-9.

40. Evans JA, Williams NN, Chan EP et al. Endoscopic removal of eroded bands in vertical banded gastroplasty: a novel use of endoscopic scissors (with video) Gastrointest Endosc 2006 Nov;64(5):801-4.

41. Casella G, Soricelli E, Rizzello M, et al. Nonsurgical treatment of staple line leaks after laparoscopic sleeve gastrectomy. Obes Surg 2009 Jul;19(7):821-6.

42. Eisendrath $\mathrm{P}, \mathrm{Cremer} \mathrm{M}$, Himpens J et al. Endotherapy including temporary stenting of fistulas of the upper gastrointestinal tract after laparoscopic bariatric surgery. Endoscopy 2007 Jul;39(7):625-30.

43. Cadière GB, Himpens J, Bazi M et al. Are laparoscopic gastric bypass after gastroplasty and primary laparoscopic gastric bypass similar in terms of results? Obes Surg 2011 June;21(6):692-8.

44. Al Harakeh AB, Larson CJ, Mathiason MA et al. BAROS results in 700 patients after laparoscopic Rouxen-Y gastric bypass with subset analysis of age, gender, and initial body mass index. Surg Obes Relat Dis2011 Jan-Feb;7(1):94-

\title{
CHAPTER SEVEN AT A GLANCE
}

\author{
Mid-term (4 years) outcome of revisional laparoscopic procedures after LRYGB \\ EWL \\ $53.7 \%$ \\ Complications \\ $21 \%($ severe) \\ $12 \%$ leaks (conservative $\mathrm{R} /$ ) \\ $10 \%$ reoperations ( $3 \%$ reconversion) \\ Patient acceptance \\ satisfaction index $51.7 \%$
}

BAROS 3.02 



Chapter 8.

\section{Summary \& final conclusions}




\subsection{SUMMARY}

The advent of laparoscopy has undoubtedly triggered a tremendous increase in the number of weight loss procedures. ${ }^{1}$ Nevertheless, the general public remains critical of such procedures. Many laypeople still consider obesity to be indicative of poor willpower and low self-esteem. ${ }^{2}$

The paradigm that every ounce of fat passes through the mouth is still very much present in today's society. ${ }^{3}$ Previously, extremely high morbidity and mortality rates may have justified the public's aversion to weight loss procedures. However, modern surgical approaches have a far better track record. ${ }^{4,5}$ Despite these improved results, detractors of bariatric surgery point to the significant numbers of failures, complications and reoperations that still occur after bariatric procedures. Unfortunately, most publications on the subject available today are fraught with bias and have short follow-up and incomplete data. Consequently, the conclusions drawn do not reach a high level of scientific proof.

Despite the definite drawback of being retrospective, our long-term studies are one of the first of this sort conducted. Most contemporary publications have reported on small numbers of patients and performed either short-term or crosssectional analyses. ${ }^{6,7,8}$

This study of the 3 procedures (LAGB, LSG and LRYGB) includes:

$1 /$ an analysis of the weight loss results

2/ an analysis of long-term follow-up data including patient acceptance

3 / an evaluation of corrective surgical measures after failing procedures

\subsubsection{Weight loss results (Table 1)}

According to Reinhold' ${ }^{9}$ a weight loss procedure is successful when it induces the loss of at least $50 \%$ of the excess weight (EWL\%) or when the final BMI is less than $35 \mathrm{~kg} / \mathrm{m}^{2}$. Other parameters mentioned in the literature for estimating the success of a bariatric procedure are based on the loss of excess BMI (\% EBMIL) or on the final BMI and take into account the initial BMI (Biron criteria). ${ }^{10}$

Contrasting with our experience, the meta-analysis of Buchwald ${ }^{11}$ focusing on all available bariatric procedures showed a marked discrepancy among the procedures, with a definite advantage to the malabsorptive over the hybrid procedures, and both aforementioned provided better results than the purely restrictive operations. That analysis, however, was based on both open and laparoscopic procedures and on relatively short-term studies. In our studies, the mean weight loss was distributed as follows: LAGB achieved an EWL of $48 \%$ after 12 years among patients who managed to keep their bands. LSG, as a sole procedure, achieved an EWL of $53.3 \%$ after 6+ years, and LRYGB had an EBMIL (which for relatively low BMIs is comparable to EWL provided the ideal BMI is defined at $25 \mathrm{~kg} / \mathrm{m}^{2}$ ) of $56.2 \%$ after 9 years. 
Based on the slope of the weight (BMI) curve (Table1), our patients are likely to experience comparable results after 12 years with any of the 3 procedures, each resulting in approximately 50\% EWL. These findings are similar to or inferior to the data in the literature. ${ }^{12,13,14}$

Table 1: Progression of mean BMI per year after laparoscopic adjustable gastric band (LAGB), sleeve gastrectomy (LSG) and Roux-en-Y gastric bypass (LRYGB). (Data from chapters 4, 5 and 6.) Notice the nadir value for $L S G$ and $L R Y G B$. For $L A G B$ the BMI remains relatively stable after the third year

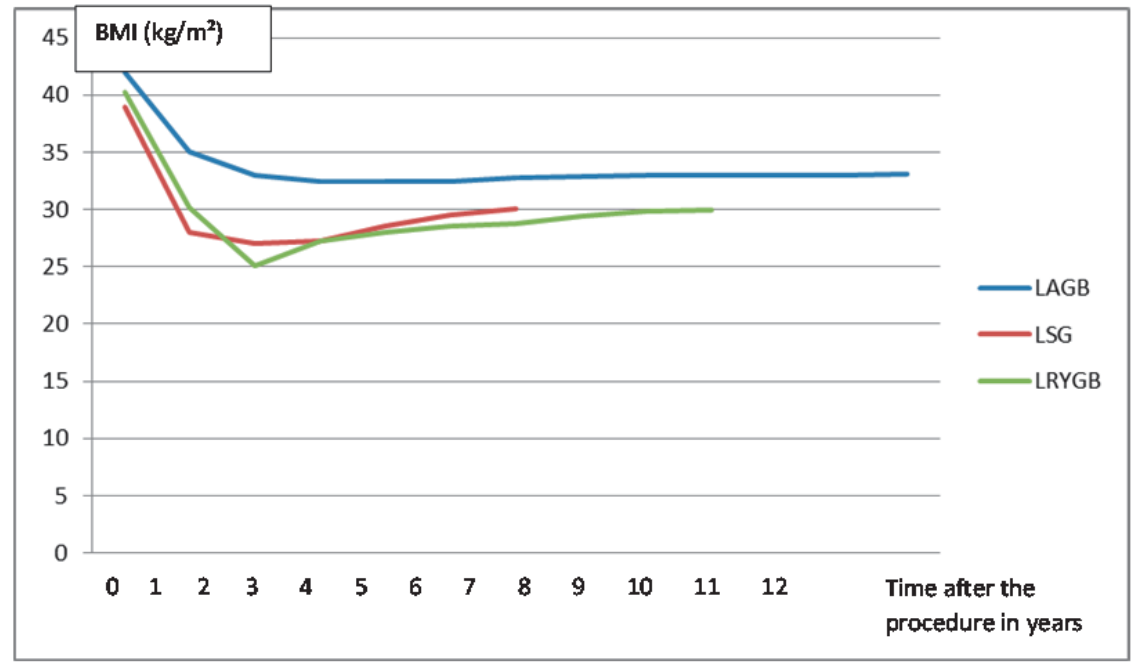

The phenomenon of weight regain was clearly observed for both LSG and LRYGB, wherein a definite weight nadir occurred followed by regain after 2 to 3 years, respectively, for LRYGB and LSG. With LAGB, the weight loss results, although slightly inferior, appear to be sustained over time, ${ }^{14}$ but this finding only includes the patients who retained their bands (Table 1). The relatively good outcomes of LAGB, considered the least invasive bariatric procedure has led some to conclude that this technique should be the first choice in all patients, whereas the RYGB and the BPD should be considered only as remedial operations. ${ }^{15}$

Conversely, Chevallier et al. ${ }^{16}$ defined precise patient characteristics that statistically correlate with a better outcome after LAGB. These characteristics were defined based on an extensive survey conducted in France. According to this work, patients under 40 years of age, with a $\mathrm{BMl}<50 \mathrm{~kg} / \mathrm{m}^{2}$ showed statistically significantly better results, provided they were willing to change their eating habits and to recover or increase their physical activity after surgery.

Nevertheless, it appears that, with time, only a certain number of patients continue to do well with any procedure, regardless of its type. Therefore, the main question regarding bariatric surgery may not be what type of surgery should be performed, but rather what type of patient should be chosen. One possible mecha- 
nism could be a genetic predisposition. ${ }^{17}$ These findings support the unconfirmed hypothesis that individual carriers of a melanocortin- 4 receptor gene defect suffer a higher complication rate after LAGB. ${ }^{18}$ According to this theory, it might be worthwhile in the future to genetically analyze obese patients to determine who may be a good candidate for weight loss surgery.

\subsection{Long-Term Follow-Up}

The importance of adequate follow-up after a weight loss operation cannot be overstated. One of the reasons why follow-up is so important is that the obese patient, in order to adhere to adequate dietary recommendations, needs outside assistance. This requirement may have to do with the typical personality structure of the obese individual. $^{19}$

In our practice, we, similar to others, ${ }^{20}$ had the tendency to be less diligent in following up with patients as the interval after surgery lengthened. Unfortunately, the assumption that patients will be conditioned to adhere to new behaviors and will be less impulsive after bariatric surgery, even years postoperatively, is not valid $^{21}$ Conversely, it has been difficult to detect changes in patients' dietary habits after bariatric surgery. Once counseling ends, formerly obese patients have the tendency to develop eating behaviors that are adjusted to the "new anatomical reality". Such patients learn to eat "around" their procedure ${ }^{23}$ by eating "easier food" (figure 2) or eating more frequently (polyphagia), ${ }^{24}$ all of which lead to higher caloric intake. These behaviors obviously can cause poor weight loss or even weight regain with the recurrence of obesity. The issue of follow-up can help to determine what type of procedure to choose for a particular patient. For example, LRYGB appears to be less follow-up-dependent than LAGB. ${ }^{25}$ Nevertheless, each of the 3 procedures has particular features that justify rigorous follow-up. In our studies, the follow-up rates were $54.3 \%$ for LAGB after 12 years, $78 \%$ for LSG after $6+$ years, and $61.1 \%$ for LRYGB after 9 years.

\section{Laparoscopic Adjustable Gastric Banding}

In the literature, there is marked inconsistency in LAGB results, ranging from extremely good ${ }^{26}$ to extremely poor. ${ }^{27}$

The most striking contrast is geographical. Uniformly, studies from Australia ${ }^{28}$ have far better outcomes than studies from other parts of the world, particularly Europe. $^{29}$

The Australian studies have demonstrated that for LAGB, weight loss results are markedly dependent on the number of postoperative office visits, ${ }^{25}$ and that better results are obtained with less aggressive band filling. ${ }^{30}$ Frequent visits are mandatory to evaluate the patient at different time points and to adjust band filling accordingly. ${ }^{31}$ There is an optimal fill volume, referred to as the "green zone" (figure 1). 
The green zone corresponds to the degree of intraluminal pressure that induces a sensation of satiety upon the ingestion of small but acceptably sized volumes of solid food and is not associated with dysphagia. ${ }^{32,32}$

Theoretically, gastric bands interfere only with the volume of intake and not with the type of food ingested. Hence, patients just "can eat less". This effect would imply that the need for patients to comply with dietary restrictions becomes less stringent. ${ }^{34}$ Proper adjustment of the band should allow for relative immunity against dietary changes. This characteristic constitutes a significant difference compared to the other two procedures, wherein poor alimentary choices inevitably lead to weight regain. According to some, this phenomenon has not been observed with LAGB, at least when the band is still in place. ${ }^{34}$

When the LAGB patient develops dysphagia secondary to an overinflated band (the so-called red zone), dilation of the pouch and/or the esophagus can occur. This dilation is pathognomonic for band overpressurization. High pressure in a spherical organ causes dilation according to Laplace's law. Briefly, Laplace's law states that the tension across the wall of the organ is proportional to its radius. An increase in radius (and therefore of volume) induced by overeating ${ }^{35}$ once dilation is initiated will thus result in higher tension, which creates more dilation. A frequent symptom of pouch dilation is heartburn. While this condition should raise suspicion of pouch dilation a de novo hiatal hernia $(\mathrm{HH})^{36,37}$ must be ruled out as well.

We found (chapter 3 ) that GERD was present after LAGB in less than $10 \%$ of the patients after 1 year. However, after 3 years more than 20\% displayed GERD, a pattern opposite to that of patients undergoing LSG. The initial treatment consists of simply emptying the band. ${ }^{38}$

An upper GI series performed after emptying the band differentiates GERD from band slippage or pouch dilation. ${ }^{39}$ Band slippage with painful dysphagia is a surgical emergency and should be treated either by replacing the band above the dilated part or by removing the band laparoscopically ${ }^{40}$ without delay. Conversely, in cases of simple dilation, after emptying, the band can be gradually reinflated over the course of about 6 weeks. ${ }^{41,42}$

Additionally, after LAGB, endoscopy should be performed frequently during routine follow-up to document possible band erosion. Varying rates of band erosion have been reported, ${ }^{43}$ ranging to as many as almost $30 \%$ of patients, ${ }^{44}$ as we found in our series (chapter 4). Band erosion can cause pain and port infection, but, frequently, the only symptom (if any) is weight regain. ${ }^{45}$ Despite the fact that the newer bands cause fewer erosions, ${ }^{46,47}$ we continue to think that most series underestimate the incidence of this complication, mostly because of the lack of symptoms. Many of our patients suffered from asymptomatic band erosion, and the diagnosis could only be made endoscopically.

Searching for hidden problems with frequent endoscopy and filling the band with the precise amount of fluid that provides restriction in the "green zone" will 
require a notably strenuous follow-up regimen. Many patients require monthly office visits for years. ${ }^{48}$

Obviously, such a regimen creates a considerable burden on the healthcare system. In Europe, the frequency of office visits is lower than in Australia. ${ }^{49}$ One of the most often-cited causes for the low number of office visits is a lack of adequate reimbursement for follow-up filling sessions. ${ }^{50}$

Practically speaking, even though the necessity of watching patients closely over the years is well accepted, such a painstaking regimen can be considered a major drawback of the LAGB technique within our health care system, especially given the exponential growth of the number of bariatric surgery patients. It is unknown if the Australian follow-up results can be replicated in other countries. The literature suggests that follow-up rates of greater than $50 \%$ are exceptional after $10+$ years in most Western countries. ${ }^{12,50}$

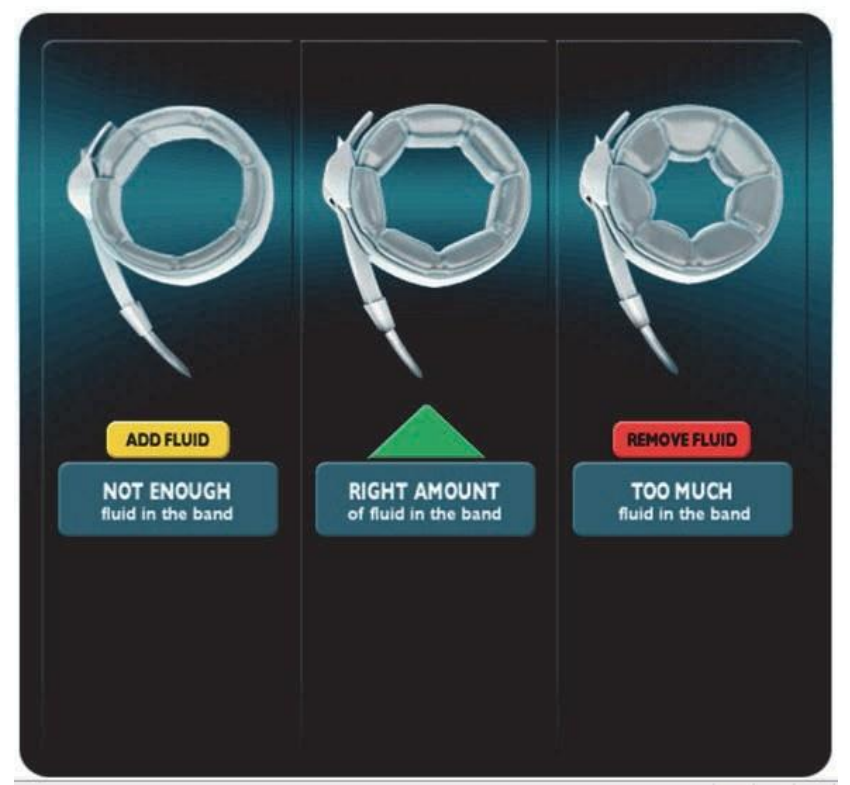

Figure 1. The yellow, green and red zones correspond to too little, adequate or too much restriction, respectively. Zones can be changed by varying the filling volume of the laparoscopic adjustable gastric band. (Source: internet shareware) 


\section{Laparoscopic Sleeve Gastrectomy}

As we mentioned in chapter 5, the lack of adequate follow-up in our studies may be linked to the weight regain we observed in LSG. With LSG, weight regain appears after the 3-year mark. This phenomenon is more frequent in patients who have not returned regularly for office visits after the 3 -year point. ${ }^{51}$ The number of patients with insufficient weight loss mirrors the number of patients reporting poor alimentary choices. (Figure 2)

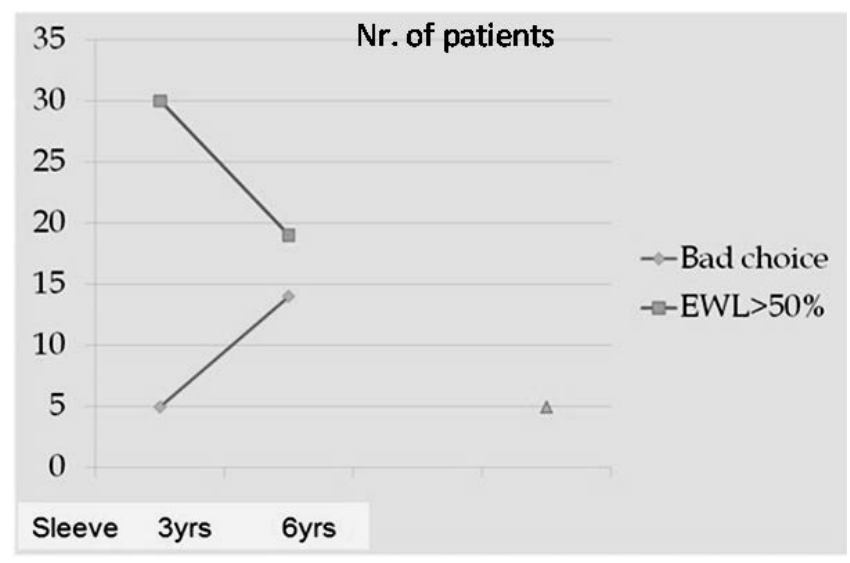

Figure 2. Negative correlation between the number of individuals with poor alimentary choices and \% excess weight loss after laparoscopic sleeve gastrectomy (total number of patients $=41$ ). (Data presented by the author at the second international consensus summit for sleeve gastrectomy, Miami, March 19-21, 2009)

Additionally, there is a striking correlation between the slope of weight regain and of new-onset GERD more than 3 years post-operation.(figure 3).We found that in most LSG patients, postoperative reflux symptoms disappeared after one year. In the longer term, however, a substantial number of patients developed new-onset GERD.

We mentioned in chapter 5 that one facilitating factor for GERD could be the regeneration of some of the fundus. This regeneration is facilitated by a relative downstream stenosis and induces a greater acid producing mucosal surface. Besides "fundus regeneration " the sleeved stomach, because of the resistance offered against a food bolus to go down, on the long term actually induces esophageal motility disturbancies and increases GERD. Frequently, peristaltic waves after sleeve are comparable to contraction recordings in achalasia (Perretta S, submitted data, figure 4). 


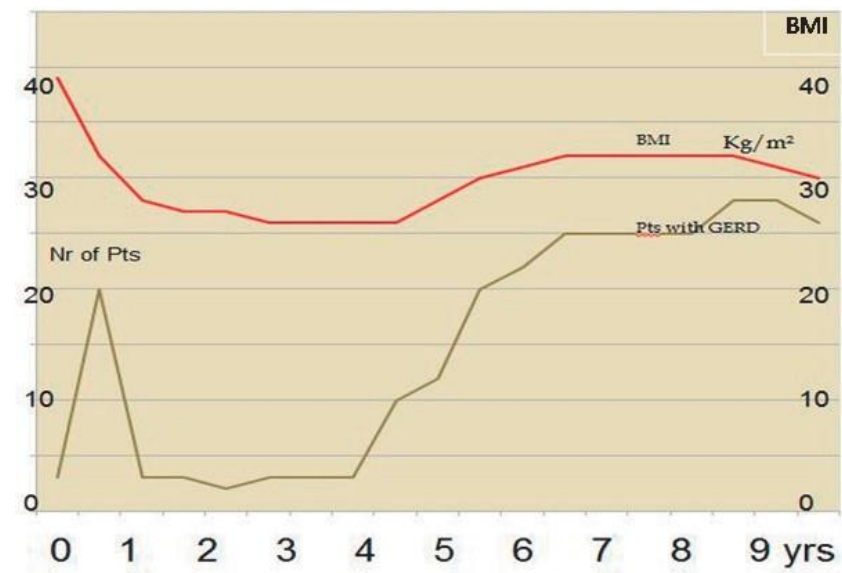

Figure 3. Progression with time of number of patients out of a total of 41 complaining of GERD and overall evolution of Body Mass Index. (Data presented by the author at the second international consensus summit for sleeve gastrectomy, Miami, March 19-21, 2009)

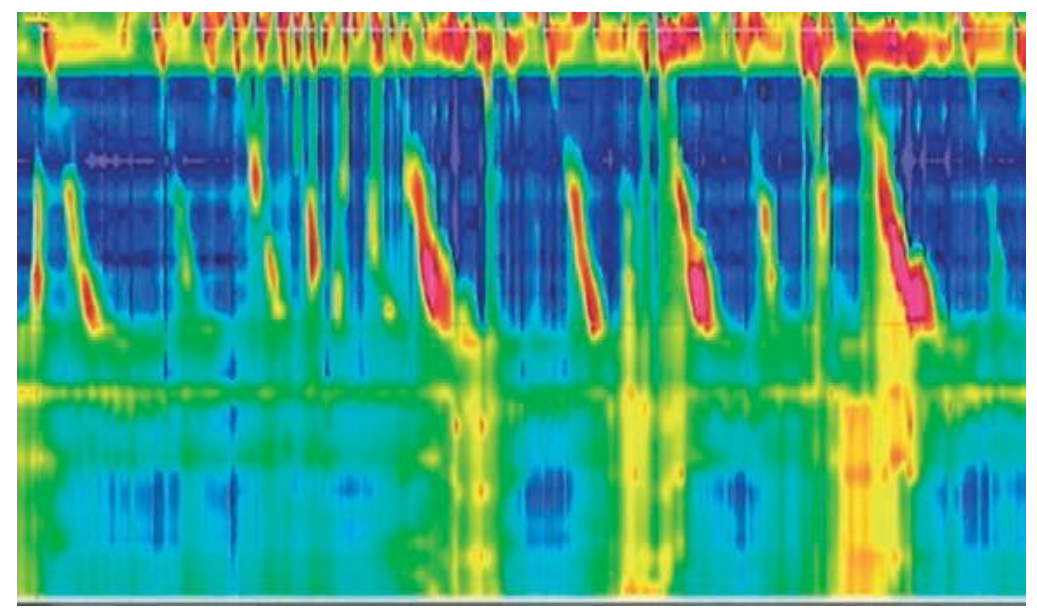

Figure 4. High Resolution Manometry in a LSG patient complaining of dysphagia and odynophagia 1 year postoperatively. Manometry recording shows irregular esophageal contractions and a migration of the Lower Esophageal Sphincter $4 \mathrm{~cm}$ inside the chest. (Courtesy Dr Perretta, Dr Dallemagne, Dr Marescaux, IRCAD, Strasbourg, France)

Another explanation is that, with time, certain patients start systematically to eat more than the volume capacity of the sleeved stomach. This phenomenon has been witnessed previously after VBG. ${ }^{52}$ The sensation of esophageal overfill is commonly attributed to reflux. Unlike acid-induced GERD, however, these symptoms typically do not occur at night, except early in the night after an oversized meal. This stasis phenomenon is also encountered with LAGB. ${ }^{53}$ Typically, some relief is obtained with proton pump inhibitors, but this result does not disprove the theory of nonacid reflux. ${ }^{54}$ After LSG, patients demonstrating weight regain occurring with reflux 
symptoms should alarm the surgeon. These patients should be referred to aggressive alimentary counseling. Additionally, a complaint of reflux should encourage the surgeon to perform an endoscopy or upper GI series to document the reflux and to rule out apical gastric dilatation or "fundus reformation". This is an important finding, because a repeat resection can be considered in such cases ${ }^{55}$ only (figure 5).
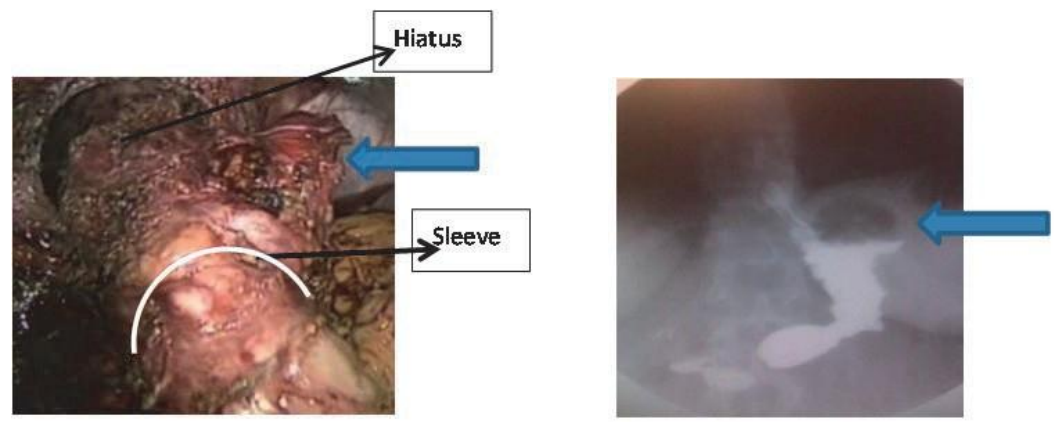

Figure 5. Apical gastric dilatation or «fundus reformation» (arrow) years after sleeve gastrectomy.

Obviously, GERD-like symptoms can only be detected when patients adhere to their follow-up routine. However, passed the 3 years mark, yearly office visits should suffice to detect GERD complaints and to act accordingly, as shown by studies of an endoscopic surveillance regimen for Barrett's esophagus. ${ }^{56}$ We therefore recommend a "humane" follow-up regimen beyond 3 years after LSG that consists of yearly office visits with annual endoscopy.

For the "restrictive procedures" LAGB and LSG the appearance of heartburn, generally indicative for GERD, should be considered an alarming symptom suggestive for weight regain mechanisms and thus be addressed by swift diagnostic and therapeutic action

\section{Laparoscopic Roux-en-Y Gastric Bypass}

The aforementioned restrictive component of the gastric bypass is significant for LRYGB, but other clinical factors significantly intervene. Bypassing the duodenum creates a situation in which the ingested food reaches the jejunum via a secretionfree alimentary limb without being mixed with the gastric, biliary, pancreatic and duodenal secretions. This bypassing causes a sharp increase in gastrointestinal hormones, especially GLP1, PYY and glucagon, which is followed by an "exaggerated insulin response". 57

These hormones cause a variety of symptoms. The well known"dumping syndrome" (a form of postcibal syndrome) occurs early in the postprandial phase but we found that this condition largely disappears with time (chapter 6). Conversely, 
we found that a syndrome of repeated postprandial hypoglycemia with neurological symptoms (neuroglycopenia) can occur several years after the procedure. Because these symptoms are mainly triggered by the ingestion of carbohydrates, ${ }^{58}$ they can usually be eliminated by good dietary counseling and drastic reduction of alimentary carbohydrates. Symptoms of hypoglycemia should raise the suspicion that the patient is abusing carbohydrates, particularly sugars, which is a behavior that invariably also leads to weight (re)gain. ${ }^{58}$ Sweets can cause weight gain because repeated hypoglycemic spells trigger a craving for more sweets, thereby stimulating the development of snacking/grazing behavior.

Therefore, follow-up after LRYGB is important to intercept dietary flaws that can cause weight gain and metabolic disturbances. Moreover, after LRYGB, office visits with blood work are needed to detect vitamin and mineral deficits that commonly occur several years after surgery..$^{59,60}$

For the "hybrid procedure" LRYGB the long-term appearance of symptoms of extreme fatigue, dizziness and tremor, compatible with hypoglycemia caused by dietary flaws inducing weight (re)gain, should be addressed by swift dietary and behavioral counseling.

\subsubsection{Correction of poor weight loss after LAGB, LSG and LRYGB}

When individuals state that they eat larger volumes (hyperphagia), the anatomical integrity of the restrictive construction may be suspect, and a surgical revision might be helpful to correct the "technical failure". These patients have been shown to benefit from replacing or repositioning of the band ${ }^{61}$ (figure 6), repeat sleeve procedures, ${ }^{55}$ reshaping of the pouch after bypass, ${ }^{62}$ revision of the $\mathrm{GE}^{63}$ or combinations thereof. $^{64}$ 


\section{TECHNICAL FAILURE}

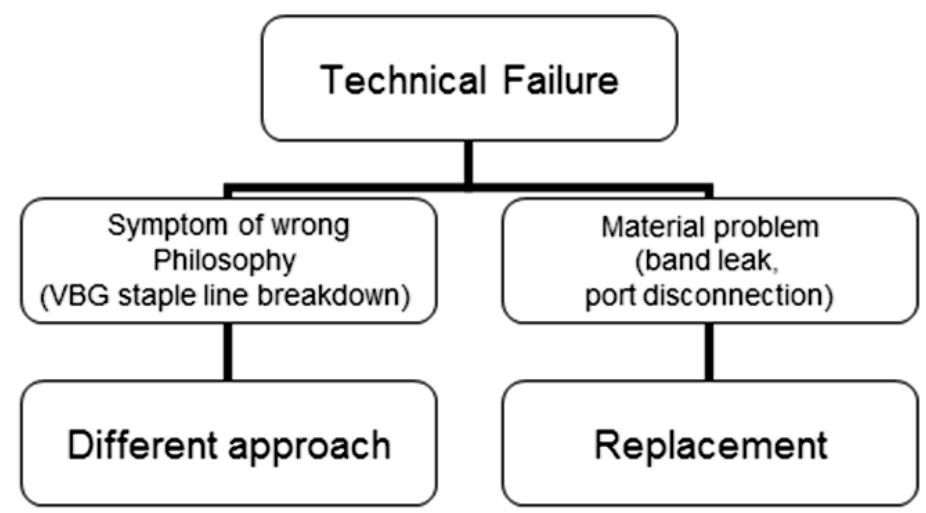

Figure 6. Example of procedural algorithm for failed bariatric procedure because of technical issues.

However, volume increase does not necessarily constitute a cause for weight regain. For instance, no definite link has been found between an increase in the volume of the alimentary limb compartment after LRYGB and weight regain. ${ }^{65,66}$ Also, no link has been found between expansion of the sleeved stomach after LSG and progress of the weight curve. ${ }^{67}$

Therefore, except for patients who fail to lose weight because of obvious technical flaws [e.g., the band is too low, the fundus was left behind in an LSG (figure 5)], there is no reason to believe that a new restriction would help where the first one has failed, despite adequate execution.

Rather than reducing caloric intake by mechanical means, a better option is to achieve restriction by "central" means. Drug therapy for this goal is lacking to date, and psychotherapy remains the only other means of centrally controlling caloric intake. However, as mentioned earlier, the results of counseling are highly dependent on the adequacy of follow-up. ${ }^{68}$ Moreover, attempts to change eating habits have a high failure rate. It is doubtful that dietary advice would be followed more closely after an operation when it was not followed previously. ${ }^{69}$ Obese patients typically are not compliant ${ }^{70}$ with dietary measures.

Nevertheless, because revision surgeries typically are associated with higher morbidity rates than primary procedures, repeat surgery should be performed only when counseling fails. It is beyond the scope of this work to analyze the endoscopic options for weight loss after surgery has failed. Instead, we will analyze the outcomes of the revision surgeries performed in our practice, and we will try to draw conclusions regarding an "ideal" strategy (figure 7,8). 


\section{REDO ALGORITHM}

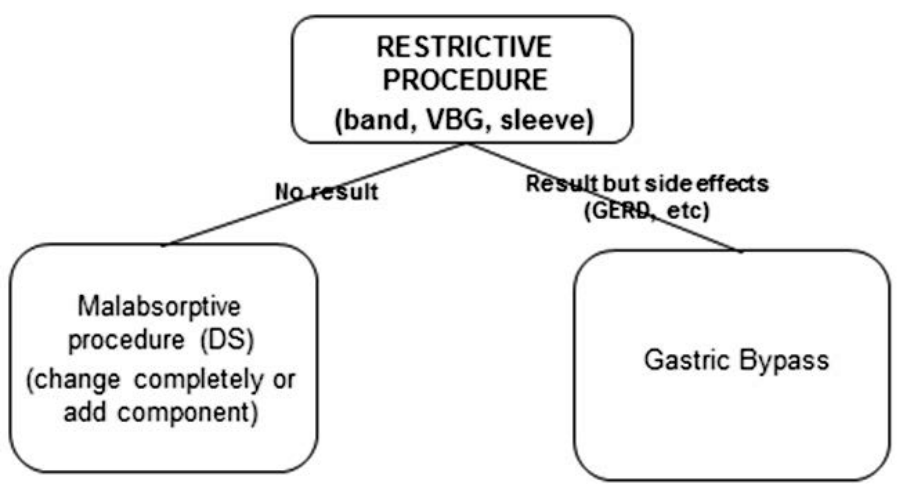

Figure 7. Procedural algorithm for failed bariatric restrictive procedure.

\section{Laparoscopic Adjustable Gastric Banding}

Failure of LAGB manifests most often by the loss of the band. In our long-term study (chapter 4), approximately $50 \%$ of the patients had lost their band by 12 years. We have shown that after band removal, patients usually experience a sharp increase in weight if no additional measures are taken. The most commonly performed salvage procedure after $L A G B$ is $L R Y G B .^{71,72,73}$

Patients converted to LRYGB after LAGB do better in terms of weight loss. In our experience, weight loss in patients submitted to LRYGB after failed LAGB remained identical to primary gastric bypass (PGB) patients, ${ }^{74}$ but the incidence of complications, including leaks, was significantly higher. This finding has not been observed in all series. ${ }^{75}$ Another important condition is treatment-resistant stenosis. We mentioned this in chapter 4 and demonstrated elsewhere ${ }^{74}$ that our stenosis rate for one-stage LRYGB after LAGB was as high as $26.3 \%$. We most often performed band ablation and LRYGB in one stage, a strategy that, according to some, could be the cause of GE stenosis. ${ }^{76}$ However, peroperatively the band constitutes a good landmark and provides a means of traction that is helpful in dissection. In our experience, among patients often coming from elsewhere whose bands had been lost prior to our intervention, we experienced significantly more perioperative difficulties caused by the development of a pseudo-capsule and by the usually still present gastrogastric bridge stitches, which obscure the anatomy. We feel that these factors constitute a good argument for performing the LRYGB and the band ablation in a single stage. Regardless, performing an anastomosis in previously dissected tissue takes more time and typically has higher morbidity rates, ${ }^{77}$ even when a 2 -stage strategy is elected. 
For LRYGB after LAGB, the anastomosis usually will necessarily be made in the vicinity of the scar tissue created by the band to avoid having to deal with either an undersized or an oversized gastric pouch. Ill-sized gastric pouches have been implicated in poor weight loss results after RYGB. ${ }^{78}$ Consequently, when LRYGB is chosen as a substitute procedure after LAGB, a surgical dilemma exists. Either a virtual gastric pouch (with poorly restrictive eso-enteral anastomosis) or, conversely, a large pouch must be created, at a distance from the scar tissue, which will probably result in poor weight loss. Alternatively, the anastomosis must be constructed in previously dissected territory, exposing the patient to more short- and long-term complications, including anastomotic leaks and stenosis.

Consequently, yet other options have been investigated. They include performing a BPD and leaving a large pouch after transection in healthy tissue ${ }^{79}$ or avoiding an anastomosis altogether and performing an SG.

We have shown ${ }^{80}$ that LSG after LAGB is feasible, and that the complication rate is acceptable. The additional weight loss, however, was modest, providing a total weight loss relative to the pre-band weight in the low $40 \%$ range. Consequently, our policy at the time became to perform a one-stage DS in selected patients after LAGB failure $^{80}$. Unfortunately, despite good overall outcomes and a surprisingly low complication rate, we experienced one fatality in a group of 31 patients. Since then we have only performed DS as a 3-stage procedure with a degree of lag time after LSG performed after LAGB.

For patients who do well after LAGB but display poor weight loss, another theoretical possibility is to keep the band and to construct an intestinal bypass as in DS without performing an SG. This strategy has been described by Favretti in 24 patients. ${ }^{81}$ However, in our limited and unpublished experience, this procedure caused intractable diarrhea. Abundant liquid stool after a combined LAGB and intestinal switch can be explained by a wash-out phenomenon. Scopinaro ${ }^{82}$ predicted that as large amounts of food gather in the normal-volume stomach beyond the obstacle of the band and reach the shortened small bowel, these amounts of food significantly override the absorption capacity of the alimentary and common limbs. Because of the combination of deceptive weight loss and intractable diarrhea we found in our patients, intestinal bypass in connection with LAGB has no place in our armamentarium of revisional bariatric procedures.

\section{Laparoscopic Sleeve Gastrectomy}

LSG has a better track record than LAGB over a 3-year span, as we have demonstrated (chapter 3). However, after more than 6 years, our positive results declined (chapter 5 ). Because approximately $60 \%$ of the patients did not meet the Reinhold criteria at the mid-term evaluation, a new procedure was contemplated in a substantial number of patients. Three possible approaches are possible in cases of failing LSG. 
1. The first option is to repeat the gastrectomy as first described by Baltasar ${ }^{55}$. We mentioned above that this possibility is only worth evaluating when there are clear anatomical reasons to do so. In the majority of cases, however, a new strategy should be contemplated.

2. In the literature, the most often cited revision operation is LRYGB. Schauer et al. demonstrated that in a group of 126 extremely obese patients, a majority did well with LRYGB after LSG. ${ }^{83}$ Rosenthal and co-workers ${ }^{84}$ showed that in patients complaining of GERD after LSG (which is a common finding often linked to weight regain), RYGB is a good option. RYGB is considered to be the preferred treatment for GERD after a previous restrictive bariatric procedure. ${ }^{85}$ However, the weight loss figures for RYGB after LSG, are poorer compared with RYGB after LAGB. $^{86}$ In addition, in our experience, patients often complain of bloating after a revisional RYGB after LSG. Bloating is a common symptom after stomach surgery. In this particular case, the limited volume of the bypassed stomach can constitute a smaller than usual expansion bellows, creating uncomfortable sensations when pressure increases in the system. ${ }^{87}$ Therefore, in patients with GERD and weight loss issues after LSG, we prefer to explore the hiatus to cure a possible hernia and to perform DS rather than LRYGB. Exploring the hiatus is however mandatory, since GERD does not evolve well after simple DS (chapter5)

3. SG was first described as part of the DS procedure and DS can obviously be considered the logical corrective procedure for failing LSG. DS and BPD are recognized as the most effective procedures for weight loss. ${ }^{10}$ In addition, a 2-stage strategy eliminates the most dangerous consequence of one-stage DS, i.e., poor patient compliance, which can cause a life-threatening situation. The staged approach helps to exclude patients who cannot comply with dietary requirements and follow-up commitments. An additional benefit is that the remaining stomach, once fully healed after the SG, allows for sufficient volumes to be taken in, thereby eliminating the risk of protein malnutrition, which is one of the most dreaded complications after BPD. ${ }^{88}$

\section{Laparoscopic Roux-en-Y Gastric Bypass}

For LRYGB our long-term results (chapter 6) demonstrated a few flaws that have not been highlighted previously, such as a significant number of weight loss failures. Attempts to correct this by accentuating the restrictive aspect seemed to confirm the fact that re-restriction is not the best option for poor weight loss after LRYGB. Placement of an unadjustable ring was characterized by a high erosion rate, and laparoscopic refashioning of both the pouch and the anastomosis did not provide durable results. Plication of the pouch, anastomosis and alimentary limb looked promising, but similar attempts at resection rather than plication were not conclusively effective in the experience of Gagner et al. ${ }^{89}$ Our attempts at increasing malabsorption provided good weight loss results be it at a high cost. In a group of 19 
patients who underwent distalization of the bypass, we had to reconvert 2 patients for nutritional issues. This finding confirmed the data of Sugerman et al. ${ }^{90}$ We concluded that despite good results in terms of weight loss, the distalization of a Rouxen-Y reconstruction should only be considered as a last resort (chapter 7).

Unlike in patients undergoing the other 2 procedures, revisions after LRYGB often were required for metabolic reasons. Despite the positive influence on existing type 2 Diabetes Mellitus (DM II), new onset DM II and neuroglycopenia were recorded at an alarming frequency after LRYGB. Dietary measures obviously are the first treatment option to resolve this issue, but as we mentioned above, changes in dietary habits are extremely difficult to achieve. Consequently, we had to undo the bypass in a number of patients and revert them to a normal anatomy. Restoration of normal anatomy appeared to resolve the neuroglycopenia and is certainly a more logical and less aggressive treatment than pancreatectomy ${ }^{91}$ for the treatment of this syndrome. Converting the bypass back to normal anatomy had a low morbidity rate. The long-term results were however characterized by a notably high frequency (3/8) of GERD. ${ }^{93}$ Therefore, during the reversal procedure, special attention must be paid to the hiatal area. We recently started to perform a complete dissection of the crura and to approximate the crura by a posterior figure- 8 stitch $^{92}$ to correct this possible complication.

Because reversal to a normal anatomy results in weight regain in a majority of cases $^{93}$ we decided to submit our patients to single-stage sleeve gastrectomy during the conversion. This procedure could subsequently be complemented by a biliopancreatic diversion ${ }^{94}$ in cases of insufficient weight loss. Even though we experienced one case of leakage at the staple line, there were no reoperations, as all complications could be treated conservatively. The conversion of LRYGB to normal anatomy or to LSG in one or two stages signifies a paradigm shift that opens up a variety of options (figure 8). 


\section{REDO ALGORITHM}

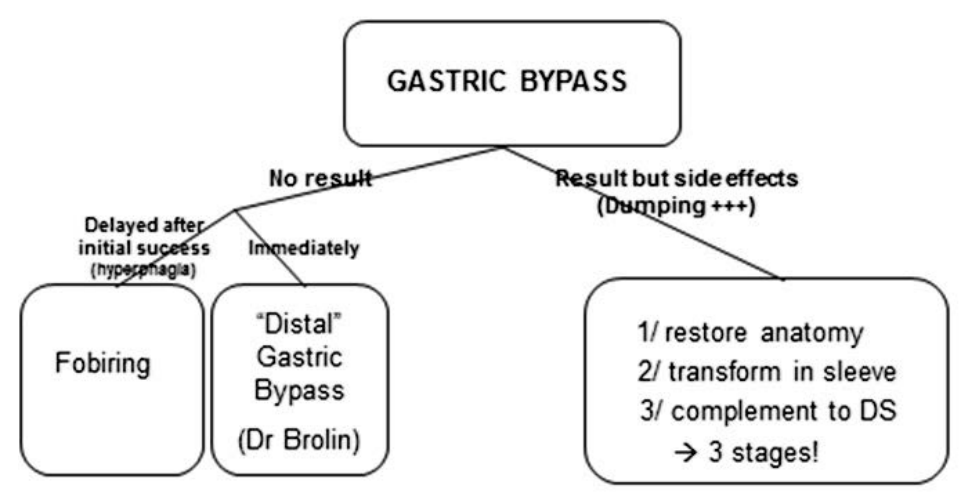

Figure 8. Procedural algorithm for failed Roux-en-Y gastric bypass

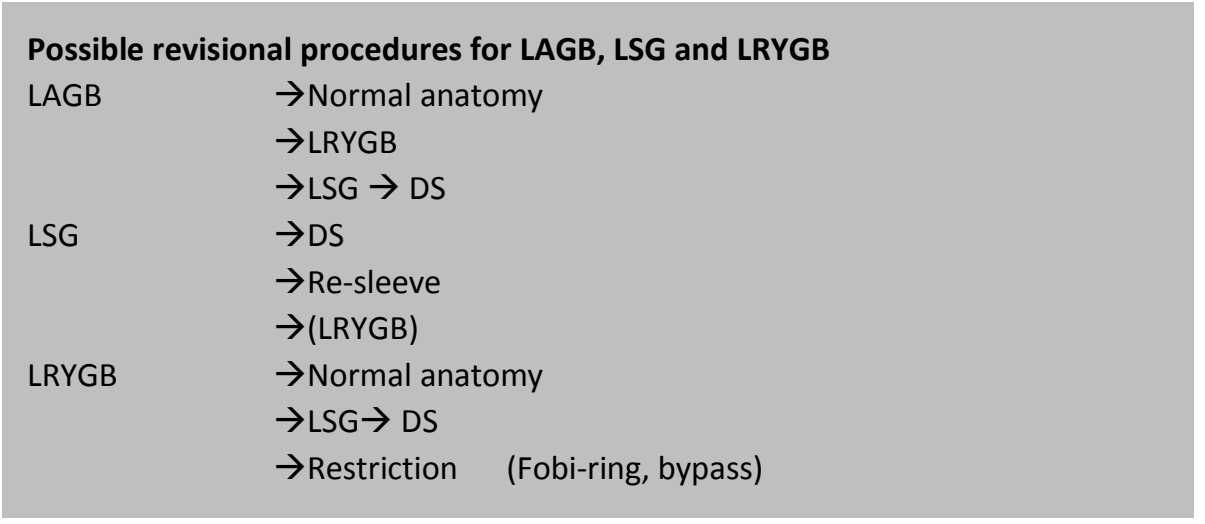

\subsubsection{Patient Satisfaction after LAGB, LSG and LRYGB}

A remarkable finding in our study is that patient acceptance remains high, even in cases with modest weight loss. Patient satisfaction can be expressed in different ways. The most commonly used method is the BAROS (BariatricAnalysis and Reporting Outcome System). ${ }^{95}$ When one analyzes patient satisfaction after open bariatric surgery, there appears to be an obvious relationship with the extent of weight loss. However, after laparoscopy, this relationship does not seem to be as marked. For example, only $40 \%$ of patients experienced good weight loss results after LAGB, yet close to $80 \%$ were happy (chapter 4). With LSG (chapter 5) and LRYGB (chapter 6), 
we have found similar results. The discrepancy between laparoscopy and open surgery can be explained by several factors.

- First, open surgery is characterized by a significant number of long-term complications that are directly caused by the laparotomy. Up to $40 \%$ of the patients develop an incisional hernia, a number that is notably higher than with laparoscopy, where the incidence of incisional hernia is approximately ten times lower. $^{96}$

- Second, hospital stays are considerably shorter after laparoscopic weight loss operations. ${ }^{97,98}$ Consequently, patients remember the laparoscopic procedure as being easier than an open operation. There is evidence that length of hospital stay is a critical factor in the patient's subjective evaluation of the severity of an operation. $^{99}$ This factor may intervene in the lower degree of acceptance we recorded after repeat operations for failing LRYGB

- Third, with the prevalence of "social media", the feeling of belonging to a group is significantly more important than during the open surgery era. In prospective randomized studies, no significant advantage could be found for laparoscopic compared with open procedures, but laparoscopic procedures are subjectively evaluated as more modern. ${ }^{100}$

Regardless of the reason, better patient acceptance is an important issue because it may indicate a lower threshold for patients to accept undergoing a second corrective procedure, if needed. Therefore, it appears that the laparoscopic approach provides psychological conditions that facilitate subsequent surgical treatment. It is noteworthy however, that patient acceptance declines rapidly in case of mishaps with the corrective procedure (chapter 7 ).

Patient satisfaction after laparoscopic bariatric surgery is not necessarily indicative for good clinical results. Thus, considering the link between poor weight loss and the persistence of comorbidities, corrective action may be warranted even in satisfied patients.

\subsection{FINAL CONCLUSIONS}

After having performed the world's first laparoscopic bariatric procedure some 20 years ago, we have by now accumulated a substantial experience with the long term outcomes of the most popular weight loss operations.

Adjustable band gastroplasty (LAGB) creates a stable weight loss of $48 \%$ at 12 years postoperatively in patients who managed to keep their band. Sleeve gastrectomy (LSG) and Roux-en-Y gastric bypass (LRYGB), are characterized by some weight re- 
gain occurring after respectively 3 and 2 years postoperatively. For LSG, EWL is 53.3 $\%$ after 6 years and for LRYGB, EBMIL is $56.2 \%$ after 9 years.

Failure of LAGB translates most often in removal of the band, because of erosion into the stomach or because of pouch dilation. The most frequent long-term unwanted side-effect of LSG is GERD. For LRYGB, internal hernias and late issues of glucose metabolism consisting of new-onset type 2 diabetes and neuroglycopenia are the most frequent complications.

Despite inconsistent results in terms of weight loss and despite a number of late complications, patient satisfaction remains acceptable for the 3 procedures $(60.3 \%$ for LAGB, $56.6 \%$ for LSG and $76.0 \%$ for LRYGB), most likely because in case of failure, surgical laparoscopic revision is a realistic alternative.

For LAGB, besides removal of the band, LRYGB is the most frequently chosen option in case of severe complications or unsatisfactory results. For LSG, except in cases of obvious anatomical flaws, the construction can be complemented by a DS to improve weight loss. For LRYGB, a corrective option consists of distalization, or reversal into normal anatomy, and from there, into LSG, which probably constitutes the safer option.

Our work was not able to identify one bariatric procedure of choice. However, in case of failure, traditional laparoscopic bariatric procedures can be salvaged by laparoscopic conversion

\subsection{REFERENCES}

1. Hydock CM. A brief overview of bariatric surgical procedures currently being used to treat the obese patient. Crit Care Nurs Q. 2005 Jul-Sep;28(3):217-26.

2. McClure AC, Tanski SE, Kingsbury J, et al. Characteristics associated with low self-esteem among US adolescents. Acad Pediatr. 2010 Jul-Aug;10(4):238-44.e2.

3. Berkel LA, Poston WS, Reeves RS, et al. Behavioral interventions for obesity. J Am Diet Assoc. 2005 May;105(5 Suppl 1):S35-43. Review.

4. Buchwald $\mathrm{H}$, Estok R, Fahrbach $\mathrm{K}$, et al. Trends in mortality in bariatric surgery: a systematic review and meta-analysis. Surgery. 2007 Oct;142(4):621-32; discussion 632-5. Review.

5. Flum DR, Belle SH, King WC et al. Perioperative safety in the longitudinal assessment of bariatric surgery.Longitudinal Assessment of Bariatric Surgery (LABS) Consortium. N Engl J Med. $2009 \mathrm{Jul}$ 30;361(5):445-54.

6. Niville E, Dams A, Reremoser S, et al. Mid-term Experience with the Cousin Bioring-Adjustable Gastric Band. Obes Surg. 2012 Jan;22(1):152-7..

7. Strain GW, Saif T, Gagner M, et al. Cross-sectional review of effects of laparoscopic sleeve gastrectomy at 1,3 and 5 years. SurgObes Relat Dis 2011 Nov-Dec;7(6):714-9. 
8. Suter M, Donadoni A, Romy S, et al. Laparoscopic Roux-en-Y gastric bypass: significant long-term weight loss, improvement of obesity-related comorbidities and quality of life. Ann Surg 2011 Aug; 254(2):267-73.

9. Reinhold RB. Critical analysis of long term weight loss following gastric bypass. Surg Gynecol Obstet. 1982 Sep;155(3):385-94.

10. Biron S, Hould FS, Lebel S, et al. Twenty years of biliopancreatic diversion: what is the goal of the surgery? Obes Surg 2004;14:160-4.

11. Buchwald $H$, Avidor $Y$, Brauwald $E$, et al. Bariatric surgery: a systematic review and meta-analysis. JAMA 2004 Oct13;292(14):1727-34.

12. Sarela Al, Dexter SP, O'Kane M, et al. Long-term results after laparoscopic sleeve gastrectomy: 8-9 years results. Surg Obes Relat Dis $2011 \mathrm{Jul} 20$.

13. Higa K, Ho T, Tercero F et al. Laparoscopic Roux-en-Y gastric byass: 10 year follow-up. Surg Obes Relat Dis 2011 Jul-Aug;7(4):516-25.

14. Weichman $\mathrm{K}$, Ren $\mathrm{C}$, Kurian $\mathrm{M}$, et al. The effectiveness of adjustable gastric banding: a retrospective 6-year U.S. follow-up study. Surg Endosc 2011 Feb;25(2):397-403.

15. de Luis DA, Aller R, Sagrado MG, et al. Influence of lys656asn polymorphism of leptin receptor gene on surgical results of biliopancreatic diversion. J Gastrointest Surg 2010 May;14(5):899-903.

16. Chevallier JM, Paita M, Rodde-Dunet $\mathrm{MH}$, et al.; Predictive factors of outcome after gastric banding: a nationwide survey on the role of center activity and patients' behavior. Ann Surg. 2007 Dec;246(6):1034-9

17. Kellogg TA Revisional bariatric surgery Surg Clin North Am 2011 Dec;91(6):1353-71

18. Peterli $R$, Peters $T$, von Flüe $M$, et al. Melanocortin-4 receptor gene and complications after gastric banding. Obes Surg 2006 Feb;16(2):189-95

19. Amann B, Merqi R, Torrent $C$, et al. Abnormal temperament in patients with morbid obesity seeking surgical treatment. J Affect Disord. 2009 Nov;118(1-3):155-60.

20. Peacock JC, Zizzi SJ. An assessment of patient behavioral requirements pre-and post-surgery at accreditated weight loss centers. Obes Surg 2011 Dec;21(12):1950-7.

21. Ryden A, Sullivan M, Torgerson JS, et al. A comparative controlled study of personality in severe obesity: a 2-y follow-up after intervention. Int J Obes Relat Metab Disord. 2004 Nov;28(11):1485-93.

22. Guerdjikova Al, West-Smith L, McElroy SL, et al. Emotional eating and emotional eating alternatives in subjects undergoing bariatric surgery. Obes Surg 2007 Aug;17(8):1091-6.

23. Taylor VH, Sharma AM. A patient with personal control of the adjustable gastric band and bulimia: a psychiatric complication. Obes Surg 2006 Oct; 16(10):1386-7.

24. Dapri G, Cadière GB, Himpens J. Laparoscopic placement of non-adjustable silicone ring for weight regain after Roux-en-Y gastric bypass. Obes Surg 2009 May;19(5):650-4.

25. El Chaar M, McDeavitt K, Richardson S Does patient compliance with preoperative bariatric office visits affect postoperative excess weight loss? Surg Obes Relat Dis. 2011 Nov-Dec;7(6):743-8.

26. Steffen R. The history and role of gastric banding. Surg Obes Relat Dis. 2008 MayJun; 4(3 Suppl):S713.

27. Demaria EJ, Sugerman HJ, Meador JG, et al. High failure rate after laparoscopic adjustable silicone gastric banding for treatment of morbid obesity. Ann Surg 2001 jun;233(6):809-18.

28. O'Brien PE, Dixon JB. Lap-band: outcomes and results. J Laparoendosc Adv Surg tech A. 2003 Aug;13(4):265-70.

29. Suter M, Calmes JM, Paros A et al. A 10-year experience with laparoscopic gastric banding for morbid obesity: high long-term complication and failure rates. Obes Surg $2006 \mathrm{Jul} ; 16(7): 829-35$.

30. Busetto L, Segato G, De Marchi F, et al;. Postoperative management of laparoscopic gastric banding. Obes Surg 2003; 13(1):121-27.

31. Brown W, Korin A, Burton P, et al. Laparoscopic adjustable gastric banding. Aust Fam Physician 2009 dec;38(12):972-6.

32. Burton PR, Brown WA, Laurie $C$, et al. Effects of gastric band adjustments on intraluminal pressure. Obes Surg 2009 Nov;19(11):1508-14. 
33. Fried $M$. The current science of gastric banding: an overview of pressure-volume theory in band adjustments. Surg Obes Relat Dis; 2008 May-Jun;4(3 Suppl):S14-21.

34. Ren CJ, Fielding GA. Laparoscopic adjustable gastric banding [Lap-Band]. Curr Surg 2003 Jan-Feb 60(1):30-3.

35. Poole N, Al Atar A, Bidlake L, et al. Pouch dilatation following laparoscopic adjustablegastric banding: psychobehavioral factors (can psychiatrists predict pouch dilatation?). Obes Surg. 2004;14(6):798801.

36. Azagury DE, Varban O, Tavakkolizadeh A, et al. Does laparoscopic gastric banding create hiatal hernias? Surg Obes Relat Dis. 2011 Aug 6 Epub ahead of print

37. Brown WA, Burton PR, Anderson M et al. Symmetrical pouch dilatation after laparoscopic adjustable gastric banding: incidence and management. Obes Surg. 2008 Sep;18(9):1104-8.

38. Hamdan K, Somers S, Chand M. Management of late postoperative complications of bariatric surgery. BrJ Surg. 2011 Oct;98(10):1345-55.

39. Boru C, Silecchia G. Bariatric emergencies: what the general surgeon should know. Chirurgia (Bucur). 2010 Jul-Aug;105(4):455-64.

40. Manganiello $M$, Sarker S, Tempel M, et al. Management of slipped adjustable gastric bands. Surg Obes Relat Dis. 2008 Jul-Aug;4(4):534-8; discussion 538.

41. Dargent J. Esophageal dilatation after laparoscopic adjustable gastric banding: definition and strategy. Obes Surg. 2005 Jun-Jul;15(6):843-8.

42. Iyad Eid, Daniel W. Birch, Arya M. Sharma, et al Complications associated with adjustable gastric banding for morbid obesity: a surgeon's guide Can J Surg. 2011 February; 54(1): 61-66.

43. Tolonen $P$, Victorzon $M$, Mäkelä J. 11-year experience with laparoscopic adjustable gastric banding for morbid obesity: what happened to the first 123 patients? Obes Surg. 2008 Mar;18(3):251-255.

44. Martikainen $T$, Pirinen $E$, Alhava $E$, et al. Long-term results, late complications and quality of life in a series of adjustable gastric banding. Obes Surg. 2004;14(5):648-654.

45. Kohn GP, Hansen CA, Gilhome RW. Laparoscopic management of gastric band erosions: a 10-year series of 49 cases. Surg Endosc. 2011 Oct 13.

46. Matlach J, Adolf D, Benedix F, et al. Small-diameter bands lead to high complication rates in patients after laparoscopic adjustable gastric banding. Obes Surg. 2011 Apr;21(4):448-56.

47. Carelli AM, Youn HA, Kurian MS, et al. Safety of the laparoscopic adjustable gastric band: 7-year data from a U.S. center of excellence. Surg Endosc. 2010; 24(8):1819-1823.

48. Dallal RM, Bailey L. Outcomes with the adjustable gastric band. Surgery. 2008 Mar;143(3):329-33.

49. Michalik M, Lech P, Bobowicz M, et al. A 5-year Experience with Laparoscopic Adjustable Gastric Banding-Focus on Outcomes, Complications, and Their Management. Obes Surg. 2011 Nov;21(11):1682-6.

50. TCoyle D, Buxton MJ, O'Brien BJ. Stratified cost-effectiveness analysis: a framework for establishing efficient limited use criteria. Health Econ. 2003 May;12(5):421-7.

51. Himpens J, Dobbeleir J, Peeters G. Long-term results of laparoscopic sleeve gastrectomy for obesity. Ann Surg. 2010 Aug;252(2):319-24.

52. Iannelli $A$, Addeo $P$, Dahman $M$, et al Laparoscopic conversion of vertical banded gastroplasty with an antireflux wrap into Roux-en-Y gastric bypass. Obes Surg. $2007 \mathrm{Jul} ; 17(7): 901-4$.

53. Naef $M$, Mouton WG, Naef $U$, et al. Esophageal dysmotility disorders after laparoscopic gastric banding--an underestimated complication. Ann Surg. $2011 \mathrm{Feb}$;253(2):285-90.

54. Fujiwara Y, Takahashi S, Arakawa T, et al. A 2008 questionnaire-based survey of gastroesophageal reflux disease and related diseases by physicians in East-Asian countries. Digestion 2009;80:119-28.

55. Baltasar A, Serra C, Pérez N, et al. Re-sleeve gastrectomy. Obes Surg 2006;16:1535-8.

56. Bright T, Schloithe A, Bull JA et al. Outcome of endoscopy surveillance for Barrett's oesophagus. ANZ J Surg. 2009 Nov;79(11):812-6.

57. Dirksen C, Hansen DL, Madsbad S, et al. Postprandial diabetic glucose tolerance is normalized by gastric bypass feeding as opposed to gastric feeding and is associated with exaggerated GLP-1 secretion: a case report. Diabetes Care. 2010 Feb;33(2):375-7. 
58. Faria $\mathrm{SL}$, de Oliveira Kelly $\mathrm{E}$, Lins $\mathrm{RD}$, et al. Nutritional management of weight regain after bariatric surgery. Obes Surg. 2010 Feb;20(2):135-9.

59. Dalcanale L, Oliveira CP, Faintuch J, et al. Long-term nutritional outcome after gastric bypass. Obes Surg. 2010 Feb;20(2):181-7.

60. Ernst B, Thurnheer M, Schultes B. Copper deficiency after gastric bypass surgery. Obesity (Silver Spring). 2009 Nov;17(11):1980-1.

61. Bueter M, Thalheimer A, Wierlemann A, et al. Reoperations after gastric banding: replacement or alternative procedures? Surg Endosc 2009 Feb;23(2):334-40

62. Thompson C, Jacobsen G, Schroder G, et al. Stoma size critical to 12-month outcomes in endoscopic suturing for gastric bypass repair Surg Obes Relat Dis 2011, April 19 Epub ahead of print.

63. Ryou M, Ryan MB, Thompson CC. Current status of endoluminal bariatric procedures for primary and revision indications. Gastrointest Endosc Clin N Am. 2011 Apr;21(2):315-33.

64. Gagner M. Laparoscopic Jejunal Sleeve: A Simple and Ideal New Technique for Revision of Roux-en-Y Gastric Bypass After Weight Regains Technical Aspects. Surg Technol Int. 2010;20:147-52.

65. Topart P, Becouarn G, Ritz P Pouch size after gastric bypass does not correlate with weight loss outcome. Obes Surg. 2011 Sep;21(9):1350-4.

66. Roslin M. Comment on: long-term follow-up in patients undergoing open gastric bypass as a revisional operation for previous failed restrictive procedures; . Surg Obes Relat Dis $2011 \mathrm{Jul} 20$.

67. Pomerri F, Foletto M, Allegro G, et al. Laparoscopic sleeve gastrectomy--radiological assessment of fundus size and sleeve voiding. Obes Surg. 2011 Jul;21(7):858-63.

68. Peacock JC, Zizzi SJ. An Assessment of Patient Behavioral Requirements Pre- and Post-Surgery at Accredited Weight Loss Surgical Centers. Obes Surg. 2011 Dec;21(12):1950-7.

69. Kruseman $M$, Leimgruber A, Zumbach F,et al. Dietary, weight, and psychological changes among patients with obesity, 8 years after gastric bypass. J Am Diet Assoc 2010 Apr; 110(4):527-34.

70. Kulick D, Hark L, Deen D. The bariatric surgery patient: a growing role for registered dietitians. J Am Diet Assoc. 2010 Apr;110(4):593-9.

71. Ardestani A, Lautz DB, Tavakkolizadeh A. Band revision versus Roux-en-Y gastric bypass conversion as salvage operation after laparoscopic adjustable gastric banding. Surg Obes Relat Dis. 2011 JanFeb;7(1):33-7.

72. Rogers AM. Improvement of esophageal dysmotility after conversion from gastric banding to gastric bypass. Surg Obes Relat Dis. 2010 Nov-Dec;6(6):681-3

73. Hamza N, Darwish A, Ammori MB et al. Revision laparoscopic gastric bypass: an effective approach following failure of primary bariatric procedures. Obes Surg. 2010 May;20(5):541-8

74. Cadière GB, Himpens J, Bazi M, et al; Are laparoscopic gastric bypass after gastroplasty and primary laparoscopic gastric bypass similar in terms of results, Obes Surg 2011 Jun;21(6):692-8

75. te Riele WW, Sze YK, Wiezer MJ, et al. Conversion of failed laparoscopic gastric banding to gastric bypass as safe and effective as primary gastric bypass in morbidly obese patients. SurgObes Relat Dis 2008;4:735-9.

76. Van Nieuwenhove $\mathrm{Y}$, Ceelen W, Van Renterghem K, et al Conversion from band to bypass in two steps reduces the risk for anastomotic strictures. Obes Surg. 2011 Apr;21(4):501-5.

77. Hallowell PT, Stellato TA, Yao DA, et al Should bariatric revisional surgery be avoided secondary to increased morbidity and mortality? Am J Surg. 2009 Mar;197(3):391-6.

78. Campos GM, Rabl C, Mulligan K. Factors associated with weight loss after gastric bypass. Arch Surg. 2008 Sep;143(9):877-883; discussion 884. 79.Dolan K, Fielding G. Bilio pancreatic diversion following failure of laparoscopic adjustable gastric banding Surg Endosc 2004 Jan;18(1):60-3.

80. Dapri G, Cadière GB, Himpens J. Laparoscopic conversion of adjustable gastric banding and vertical banded gastroplasty to duodenal switch Surg Obes Relat Dis. 2009 Nov-Dec;5(6):678-83.

81. Favretti F, Segato G, Ashton D. Laparoscopic adjustable gastric banding in 1,791 consecutive obese patients: 12-year results. Obes Surg. 2007 Feb;17(2):168-75.

82. Scopinaro N. Thirty-five years of Biliopancreatic Diversion-an attempt to complete the published information useful for a better clinical use of the operation. Obes Surg. 2012 Mar;22(3):427-32 
83. Cottam D, Qureshi FG, Mattar SG, et al. Laparoscopic sleeve gastrectomy as an initial weight-loss procedure for high-risk patients with morbid obesity.. Surg Endosc. 2006 Jun;20(6):859-63.

84. Abdemur A, Fendrich I, Rosenthal R. Laparoscopic conversion of laparoscopic sleeve gastrectomy to gastric bypass for intractable gastroesophageal reflux disease. Surg Obes Relat Dis. 2011 Jun 1.

85. Tutuian R. Obesity and GERD: pathophysiology and effect of bariatric surgery. Curr Gastroenterol Rep. 2011 Jun;13(3):205-12.

86. Weiner RA, Theodoridou S, Weiner S. Failure of laparoscopic sleeve gastrectomy - further procedure? Obes Facts. 2011;4 Suppl 1:42-6.

87. Salet GA, Samsom M, Roelofs JM, Responses to gastric distension in functional dyspepsia. Gut.1998 Jun;42(6):823-9.

88. Scopinaro N, Marinari G.M., Gianetta E., et al The respective importance of the alimentary limb (AL) and the common limb (CL) in Protein absorption (PA) after BPD. Obes Surg 1997; 7:108 (abstract).

89. Parikh M, Heacock L, Gagner M. Laparoscopic "gastrojejunal sleeve reduction" as a revision procedure for weight loss failure after Roux-en-Y gastric bypass. Obes Surg. 2011 May;21(5):650-4.

90. Sugerman HJ, Kellum JM, DeMaria EJ. Conversion of proximal to distal gastric bypass for failed gastric bypass for superobesity. J Gastrointest Surg. 1997 Nov-Dec;1(6):517-24; discussion 524-6

91. Service GJ, Thompson GB, Service FJ et al. Hyperinsulinemic hypoglycemia with nesidioblastosis after gastric-bypass surgery. N Engl J Med 2005 Jul 21;353(3):249-54.

92. Fingerhut A, Etienne JC, Millat B. Laparoscopic antireflux surgery--technique and results Ther Umsch. 1997Sep;54(9):492-9.

93. Dapri G, Cadière GB, Himpens J. Laparoscopic Reconversion of Roux-en-Y Gastric Bypass to Original Anatomy: Technique and Preliminary Outcomes. Obes Surg 2011 Aug;21(8):1289-95.

94. Dapri G, Cadière GB, Himpens J. Laparoscopic Conversion of Roux-en-Y Gastric Bypass to Sleeve Gastrectomy As First Step of Duodenal Switch: Technique and Preliminary Outcomes. Obes Surg2011 Apr;21(4):517-23.

95. Oria HE, Moorehead MK. Bariatric Analysis and Reporting Outcome System Obes Surg. 1998;8(5):487-499.S.

96. Hawn MT, Snyder CW, Graham L, et al. Long-term follow-up of technical outcomes for incisional hernia repair J Am Coll Surg. 2010 May;210(5):648-55, 655-7.

97. Masoomi H, Mills S, Dolich MO Comparison of Outcomes of Laparoscopic Versus Open Appendectomy in Adults: Data from the Nationwide Inpatient Sample (NIS), 2006-2008. J Gastrointest Surg. 2011 Dec;15(12):2226-31.

98. Kim KH, Jung DH, Park KM. Comparison of open and laparoscopic live donor left lateral sectionectomy. Br J Surg. 2011 Sep;98(9):1302-8. doi: 10.1002/bjs.7601.

99. Sørlie T, Sexton $H$, Sørlie. To what degree can patient satisfaction be explained? An analysis of a retrospective study. Tidsskr Nor Laegeforen. 1997 Aug 10;117(18):2637-40.

100.Ryan KA, Sanders AN, Wang DD et al. Tracking the rise of stem cell tourism. Regen Med. 2010 Jan;5(1):27-33. 
